Florida International University FIU Digital Commons

$11-13-2014$

\title{
Evidence of Climate Variability and Tropical Cyclone Activity from Diatom Assemblage Dynamics in Coastal Southwest Florida
}

Emily R. Nodine

Florida International University, enodi001@fiu.edu

DOI: $10.25148 /$ etd.FI14110752

Follow this and additional works at: https://digitalcommons.fiu.edu/etd

Part of the Paleobiology Commons, and the Terrestrial and Aquatic Ecology Commons

\section{Recommended Citation}

Nodine, Emily R., "Evidence of Climate Variability and Tropical Cyclone Activity from Diatom Assemblage Dynamics in Coastal Southwest Florida" (2014). FIU Electronic Theses and Dissertations. 1657.

https://digitalcommons.fiu.edu/etd/1657 


\title{
FLORIDA INTERNATIONAL UNIVERSITY \\ Miami, Florida
}

\section{EVIDENCE OF CLIMATE VARIABILITY AND TROPICAL CYCLONE ACTIVITY FROM DIATOM ASSEMBLAGE DYNAMICS IN COASTAL SOUTHWEST FLORIDA}

\author{
A dissertation submitted in partial fulfillment of \\ the requirements for the degree of \\ DOCTOR OF PHILOSOPHY \\ in \\ BIOLOGY
}

by

Emily Rodeheffer Nodine 
To: $\quad$ Interim Dean Michael R. Heithaus

College of Arts and Sciences

This dissertation, written by Emily Rodeheffer Nodine, and entitled Evidence of Climate Variability and Tropical Cyclone Activity from Diatom Assemblage Dynamics in Coastal Southwest Florida, having been approved in respect to style and intellectual content, is referred to you for judgment.

We have read this dissertation and recommend that it be approved.

Jennifer Richards

Hugh Willoughby

James Heffernan

Colin Saunders

Evelyn Gaiser, Major Professor

Date of Defense: November 13, 2014

The dissertation of Emily Rodeheffer Nodine is approved.

Interim Dean Michael R. Heithaus College of Arts and Sciences

Dean Lakshmi N. Reddi University Graduate School

Florida International University, 2014 


\section{DEDICATION}

I dedicate this dissertation to my husband, Paul Nodine, and to my parents,

Jonathan and Jane Rodeheffer. I could not have completed this work without their loving support and encouragement. 


\section{ACKNOWLEDGMENTS}

I would like to thank my major professor, Dr. Evelyn Gaiser, for her guidance and encouragement throughout this process, as well as invaluable advice about the direction of the research and analysis. I would like to thank Dr. Gaiser, and family and friends Paul Nodine, Patricia Henshaw-Frankenberger, Mara Woosley, and Timothy Loyd for volunteering their time and efforts to help with the extensive field sampling that was involved in Chapters 2 and 3. Chapters 4 and 5 were made possible by a collaboration with the palaeoecology group at Utrecht University in the Netherlands. I would like to thank Drs. Friederike Wagner-Cremer, Timme Donders, Emmy Lammertsma, Gert-Jan Reichart, and especially Holger Cremer, for providing sediment core materials and invaluable advice and assistance throughout the project. Additionally, I would like to thank Drs. Jennifer Richards and Sherri Cooper for providing insightful comments that helped to improve early chapter drafts. Finally, I would like to thank all of the members of the periphyton lab during my tenure as a graduate student, especially Franco Tobias, Dr. Josette La Hee, and Dr. Sylvia Lee, who provided patient help and support during times of stress and sometimes tedious laboratory work, and made this whole experience an enjoyable process.

I thank Florida International University for supporting me financially through research and teaching assistantships that gave me valuable experience, and for the Dissertation Year Fellowship that supported the final work. I also appreciate financial support for the research conducted for Chapter 2 that was provided by the Cristina Menendez Fellowship administered by the Southeast Environmental Research Center at Florida International University in conjunction with the Miccosukee Tribe. 


\begin{abstract}
OF THE DISSERTATION
EVIDENCE OF CLIMATE VARIABILITY AND TROPICAL CYCLONE ACTIVITY FROM DIATOM ASSEMBLAGE DYNAMICS IN COASTAL SOUTHWEST
\end{abstract} FLORIDA

by

\author{
Emily Rodeheffer Nodine \\ Florida International University, 2014 \\ Miami, Florida \\ Professor Evelyn Gaiser, Major Professor
}

Estuaries are dynamic on many spatial and temporal scales. Distinguishing effects of unpredictable events from cyclical patterns can be challenging but important to predict the influence of press and pulse drivers in the face of climate change. Diatom assemblages respond rapidly to changing environmental conditions and characterize change on multiple time scales. The goals of this research were to 1) characterize diatom assemblages in the Charlotte Harbor watershed, their relationships with water quality parameters, and how they change in response to climate; and 2) use assemblages in sediment cores to interpret past climate changes and tropical cyclone activity.

Diatom assemblages had strong relationships with salinity and nutrient concentrations, and a quantitative tool was developed to reconstruct past values of these parameters. Assemblages were stable between the wet and dry seasons, and were more similar to each other than to assemblages found following a tropical cyclone. Diatom assemblages following the storm showed a decrease in dispersion among sites, a pattern 
that was consistent on different spatial scales but may depend on hydrological management regimes.

Analysis of sediment cores from two southwest Florida estuaries showed that locally-developed diatom inference models can be applied with caution on regional scales. Large-scale climate changes were suggested by environmental reconstructions in both estuaries, but with slightly different temporal pacing. Estimates of salinity and nutrient concentrations suggested that major hydrological patterns changed at approximately 5.5 and 3 kyrs BP. A highly temporally-resolved sediment core from Charlotte Harbor provided evidence for past changes that correspond with known climate records. Diatom assemblages had significant relationships with the three-year average index values of the Atlantic Multidecadal Oscillation and the El Niño Southern Oscillation. Assemblages that predicted low salinity and high total phosphorus also had the lowest dispersion and corresponded with some major storms in the known record, which together may provide a proxy for evidence of severe storms in the paleoecological record. 


\section{TABLE OF CONTENTS}

CHAPTER

PAGE

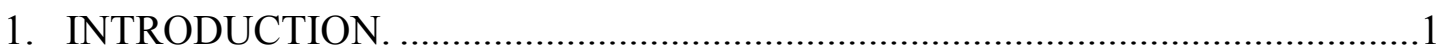

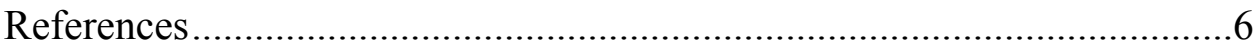

2. DISTRIBUTION OF DIATOMS ALONG ENVIRONMENTAL GRADIENTS IN THE CHARLOTTE HARBOR, FLORIDA (USA), ESTUARY AND ITS WATERSHED: IMPLICATIONS FOR BIOASSESSMENT OF SALINITY

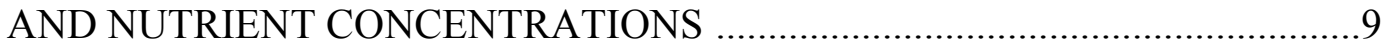

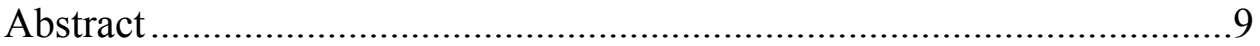

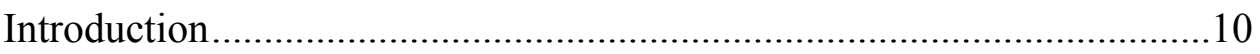

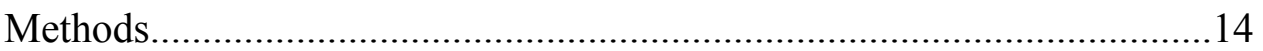

Study landscape context.................................................... 14

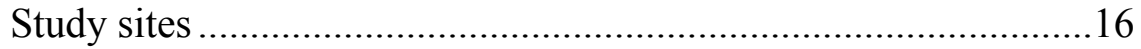

Sample collection, preparation, and laboratory analysis ............17

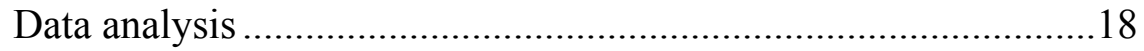

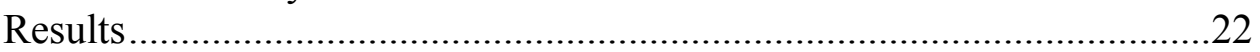

Diatom assemblage composition ..........................................22

Environmental conditions and relationships to assemblage

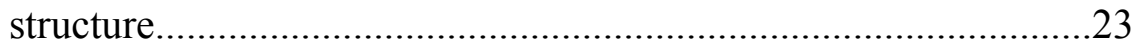

Environmental preferences and predictions..............................26

Discussion

Diatom distribution and relationships to environmental

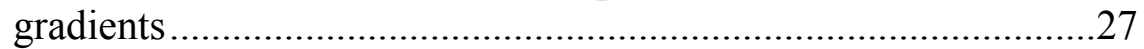

Weighted averaging inference models ......................................33

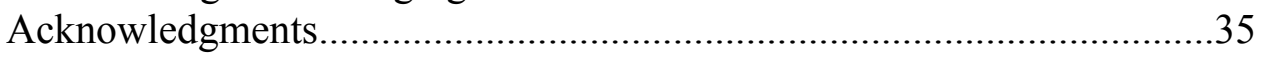

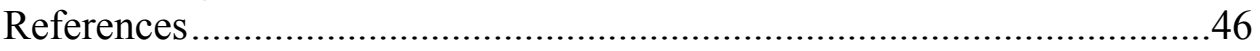

3. SEASONAL DIFFERENCES AND RESPONSE TO A TROPICAL STORM REFLECTED IN DIATOM ASSEMBLAGE CHANGES IN A SOUTHWEST

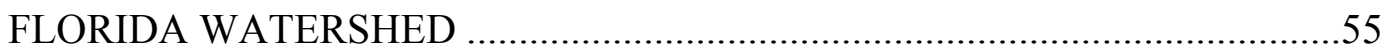

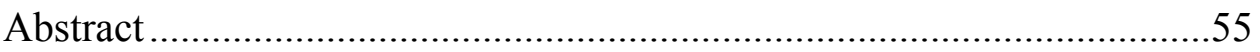

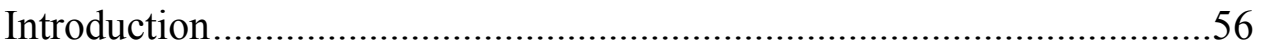

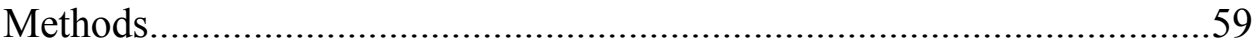

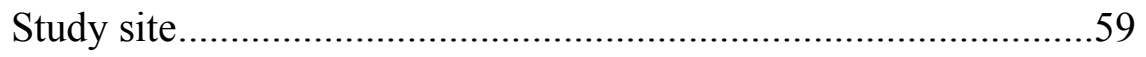

Sample collection, preparation, and laboratory analysis .............61

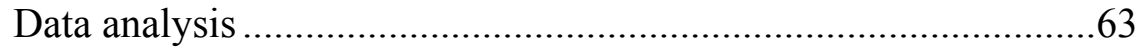

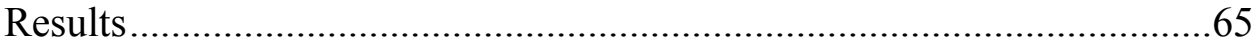

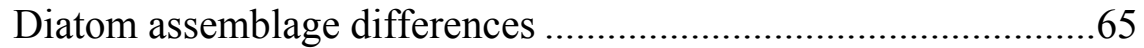

Relationships with environment ..........................................67

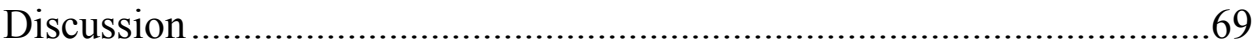

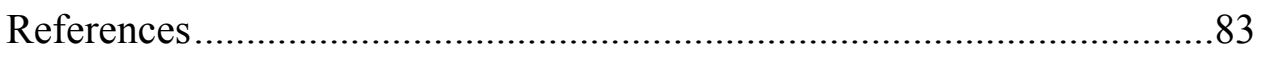


4. MID- TO LATE-HOLOCENE CHANGES IN LARGE-SCALE HYDROLOGICAL PATTERNS AND GEOGRAPHICAL VARIABILITY INFERRED FROM DIATOM ASSEMBLAGES IN TWO GULF COAST

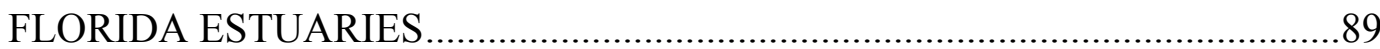

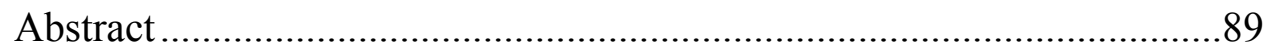

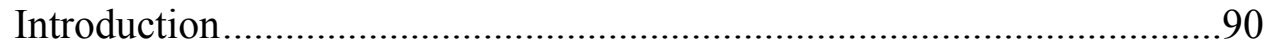

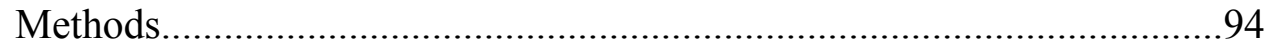

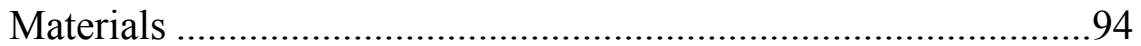

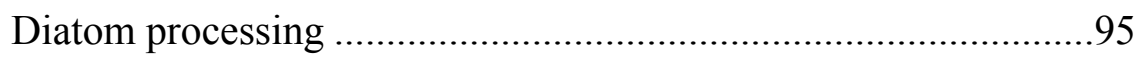

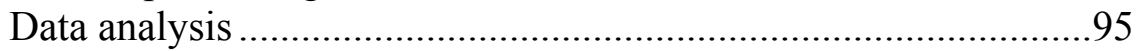

Diatom optima and tolerances ……………………....................97

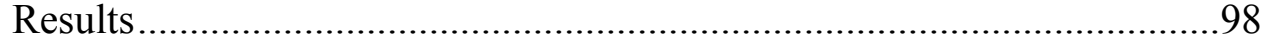

Diatom assemblage transitions ………………………..................

Estimates of past hydrology changes ..........................................100

Discussion 101

Diatom assemblage transitions ..................................................101

Past salinity and nutrient estimates/ inferred hydrological

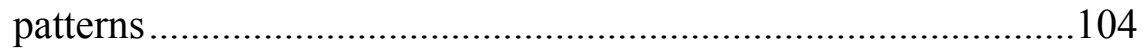

Tampa Bay .................................................................104

Charlotte Harbor ……………………………………......105

Regional differences ………………………………................107

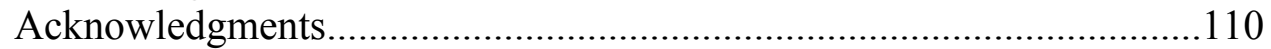

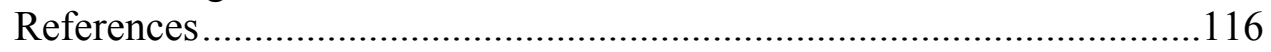

5. DIATOM ASSEMBLAGE CHANGES REFLECT LARGE-SCALE CLIMATE CYCLES, TROPICAL CYCLONE ACTIVITY, AND ANTHROPOGENIC CHANGES DURING THE LAST 130 YEARS IN

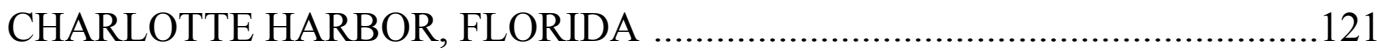

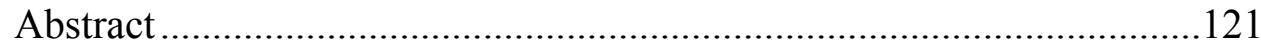

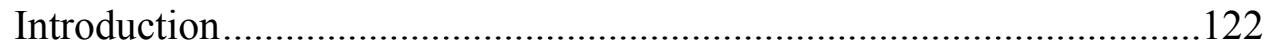

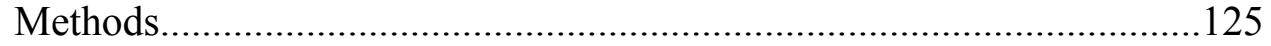

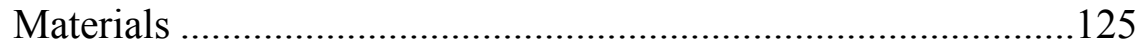

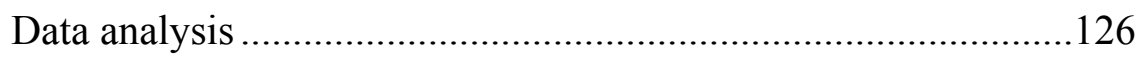

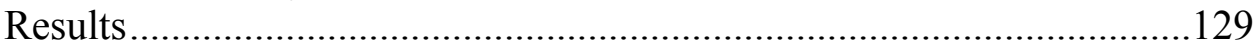

Diatom assemblage transitions ...............................................129

Relationships with drivers.......................................................131

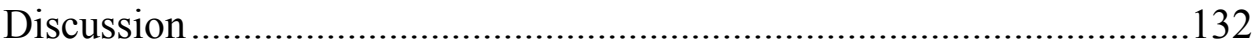

Diatom assemblage transitions ………………………..............132

Evidence of past storm events.................................................136

Conclusions and future directions.......................................................138

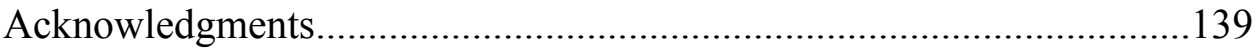

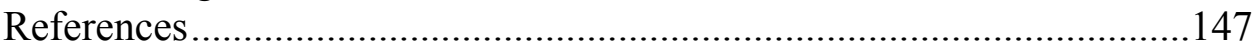

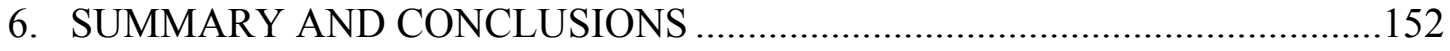

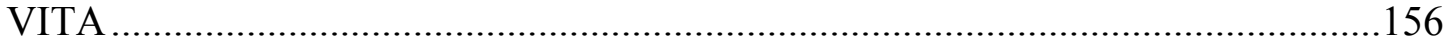




\section{LIST OF TABLES}

TABLE

PAGE

Table 1. Analysis of similarity (ANOSIM) comparing regions by a) diatom assemblage composition, and $\mathrm{b}$ ) environmental measurements. **Significantly different at $\mathrm{p}<0.001 ;{ }^{*}$ significantly different at $\mathrm{p}<0.05$.

Table 2. Analysis of similarity (ANOSIM) comparing diatom assemblages in a) upstream river reaches, b) downstream river reaches, and environmental characteristics in c) upstream river reaches, and d) downstream river reaches. **Significantly different at $\mathrm{p}<0.001 ;{ }^{*}$ significantly different at $\mathrm{p}<0.05$.

Table 3. Mean relative abundance of the most abundant taxa in site assemblages grouped by region. Taxa that comprise at least 5\% mean relative abundance in a region are shown.

Table 4. Optima (Opt.) and tolerances (Tol.) for salinity (Sal.), total phosphorus (TP), total nitrogen (TN), and distance (Dist.) for abundant and indicator diatom species. Significant regional indicator species are designated by region $(\mathrm{C}$ Caloosahatchee, M Myakka River, P Peace River, H Harbor sites). All are significant at $\mathrm{p}<0.05 ; *$ designates $\mathrm{p}<0.01 ; * *$ designates $\mathrm{p}<0.001$.

Table 5. Mean, standard deviation (in parentheses below), and range (in italics below) of environmental variables for each region and for all sites: conductivity (Cond.), salinity (Sal.), total phosphorus (TP), total nitrogen (TN), total carbon (TC), and distance (Dist.) from site in harbor center where sediment cores were collected.

Table 6. Pearson's correlation coefficients of the environmental variables across the Charlotte Harbor watershed: conductivity (Cond.), salinity (Sal.), total phosphorus (TP), total nitrogen (TN), total carbon (TC), and distance (Dist.) from site in harbor center where sediment cores were collected. *Significant correlations at $\alpha<0.05$.

Table 7. Pearson's correlation coefficients for each environmental variable with the species ordination. $*$ designates statistical significance at $p<0.05 ; * *$ denotes statistical significance at $\mathrm{p}<0.001$.

Table 8. Three strongest correlations of combinations of variables with species dissimilarity matrices when a) all environmental variables are included, and b) with salinity, distance, and conductivity excluded: Salinity (S), distance (D), conductivity (C), total phosphorus (TP), total nitrogen (TN), total carbon (TC). $*$ designates statistically significant correlation at $\mathrm{p}<0.05 ; * *$ denotes statistically significant correlation at $\mathrm{p}<0.01$. 
Table 9. ANOSIM of diatom assemblage composition (a) and environmental variables (b) between the dry season (March), the days following TS Debby (June), two weeks following TS Debby (July), and the wet season (November).

* indicates statistically significant at $\mathrm{p}<0.05$. .76

Table 10. Indicator species for dry season, wet season, and period following storm that are significant in all sites taken together and at least one sub-basin.

Table 11. Pearson's correlation coefficients for each hypothesized driver with the diatom assemblage ordination. ${ }^{*}$ designates statistical significance at $p<0.05$. 


\section{LIST OF FIGURES}

FIGURE

PAGE

Fig. 1. Map showing location of study sites in Charlotte Harbor, Florida, and three major river inflows.

Fig. 2. Nonmetric multidimensional scaling ordination diagrams based on BrayCurtis similarity in diatom composition of a) the whole Charlotte Harbor watershed dataset, b) Caloosahatchee River sites, c) Myakka River sites, d) Peace River sites, and e) Harbor sites. Overlaid trajectories show the magnitude and direction of the correlation of the species ordination with environmental variables: salinity (SAL), conductivity (COND), distance from the Harbor center (DIST), total phosphorus (TP), total nitrogen (TN), total carbon (TC), and pH. Each diagram is oriented with salinity aligned on the horizontal axis.

Fig. 3. Plots of observed vs. diatom predicted a) salinity, b) distance, c) total nitrogen, and d) total phosphorus using weighted averaging partial least squares regression with cross validation on the dataset of all Charlotte Harbor watershed sites.

Fig. 4. Map showing location of sampling sites across the Charlotte Harbor watershed.

Fig. 5. NMDS ordination biplots showing differences in diatom assemblage composition ( $a$ and $b$ ) and environmental variables ( $c$ and d) for all sites (plotted points) over time. The same ordination is shown in $a$ and $b$ with two overlays: $a$ ) solid line surrounding samples from wet and dry seasons and dotted line surrounding samples from the two post-storm sampling events, and b) vectors showing the magnitude and direction of correlations of environmental variables with diatom assemblage dissimilarity. The ordination of environmental variables is shown with the same two overlays: c) solid line surrounding wet and dry season sampling events and dotted line surrounding the two post-storm sampling events, and d) correlations of environmental variables with the sample dissimilarity among sites.

Fig. 6. Bar graph showing the index of multivariate dispersion (IMD) for diatom assemblages in all sites and each sub-basin during the seasons not affected by the storm (light gray) and the sampling period following the storm (dark gray).

Fig. 7. Bar graphs of the IMD value (number above each bar) for each region at each sampling time: Mar (dry season), Jun (within 4 days after TS Debby), Jul (2 weeks following TS Debby), and Nov (wet season).

Fig. 8. Plots of environmental changes at each sampling time by region. 
Fig. 9. Kendall's tau correlations of diatom assemblage composition with environmental variables through the seasons. Greater distance from the zero line

(no correlation) represents a stronger correlation.

Fig. 10. Kendall's tau correlations of diatom assemblage composition with environmental variables through the seasons in each sub-basin: Harbor sites (a), Caloosahatchee River (b), Myakka River (c), and Peace River (d). Greater distance from the zero line (no correlation) represents a stronger correlation.

Fig. 11. Map showing location of two sediment cores taken from Tampa Bay and Charlotte Harbor.

Fig. 12. Stratigraphy plots showing percent relative abundance of abundant diatom Taxa with depth in core for Tampa Bay (top) and Charlotte Harbor (bottom). Gray and white bands illustrate zones defined by constrained cluster analysis.

Fig. 13. Nonmetric multidimensional scaling ordination diagrams based on BrayCurtis similarity of diatom assemblages in sediment cores from Tampa Bay (left) and Charlotte Harbor (right). Solid line represents the trajectory of time from the surface sample to the oldest; approximate dates are labeled along the trajectory. Dotted circles delineate zones defined by constrained cluster analysis.

Fig. 14. Graph of diatom valves per gram of sample found in Tampa Bay (top) and Charlotte Harbor (bottom), where additional samples were analyzed to examine this period in greater detail.

Fig. 15. Estimated values of variables inferred from the diatom assemblages in each core. Horizontal lines represent standard error; gray and white bands illustrate the zones defined by constrained cluster analysis in each core. Dotted lines connect levels in each core that represent the same time period.

Fig. 16. Means of reconstructed salinity and nutrient concentration estimates by zone for each core. Letters indicate significant difference between pairs within each core.

Fig. 17. Map showing location of the sediment core taken from Charlotte Harbor.

Fig. 18. Constrained cluster analysis dendrogram showing sample division into zones at first two branches (dotted lines).

Fig. 19. Stratigraphy plots showing percent relative abundance of abundant diatom taxa with depth in core. Gray and white bands illustrate zones defined by constrained cluster analysis (number on right). 
Fig. 20. Nonmetric multidimensional scaling ordination diagrams based on BrayCurtis similarity of diatom assemblages in sediment core. Solid line represents the trajectory of time from the surface sample to the oldest; approximate dates are labeled along the trajectory. Dotted circles delineate zones defined by constrained cluster analysis.

Fig. 21. Nonmetric multidimensional scaling ordination diagrams based on BrayCurtis similarity of diatom assemblages from the period of known records in the sediment core and correlations with hypothesized drivers overlaid. Drivers include the AMO index and 3-year average, the ENSO index and 3-year average, the population of the surrounding watershed (Pop), and the year represented. All ordinations are rotated to align the year with the $\mathrm{x}$-axis: a) all dated samples, from $\sim 1893$ to 2009; b) Zone 1 representing $\sim 1996$ to 2009; Zone 2 representing $\sim 1980$ to 1996; and the later portion of Zone 3 that includes ENSO values representing $\sim 1950$ to 1980 .

Fig. 22. Bar graphs of the IMD value (number above each bar) for each sample group: those with diatom-inferred estimates higher than $(\mathrm{H})$, within $(\mathrm{M})$, and lower than $(\mathrm{L})$ one standard deviation from the mean parameter estimate. 


\section{INTRODUCTION}

The present study provides evidence of complex interactions that drive diatom assemblage changes on different time scales. Understanding the nature of environmental changes on different spatial and temporal scales will be increasingly important to interpret local changes as climate change and sea level rise continue to accelerate. As changes in freshwater flow and nutrient influx result from climate change and/or anthropogenic effects, it is important to understand how ecosystem response regimes are affected by management so that we can make informed decisions that may help to mitigate negative impacts on the ecosystem. Findings from this study can be used to improve predictions of future changes, providing insight as water management decisions are updated with the goals of improving ecosystem integrity and resilience while protecting human interests.

Estuaries are highly dynamic on many spatial and temporal scales, changing in response to tides, seasonal hydrological and biological patterns, multidecadal climate and land use patterns, as well as erratic events such as storms and anthropogenically generated effluence. Because they are influenced by both terrestrial and marine ecosystems, and more recently, anthropogenic effects, estuarine ecosystems are particularly sensitive to the pace and quality of freshwater inflow, sea level fluctuations, and stochastic disturbances such as storm events and anthropogenic alteration (e.g., Nixon 1995; Wiseman et al. 1999; Anderson et al. 2002). With accelerating climate change and increasing coastal human populations, it is important to understand how 
ecosystems and societies may be affected by changing dynamics and protected from negative impacts.

South Florida, with its low topographic relief, porous karst aquifer, and intensely developed coastline, is particularly vulnerable to sea level rise (e.g. Ross et al. 2009; Saha et al. 2011; summarized in Noss 2011), and is struck by hurricanes and tropical storms (tropical cyclones) more frequently than anywhere else in the United States (Gentry 1974). Over the millennial time scale, the coastline of South Florida formed in response to changing rates of gradually rising sea level coupled with small changes in the hydrologic cycle that influence precipitation and runoff. On a much shorter time scale, tropical cyclones can alter tidal water flow patterns, change water chemistry through pollution and contamination, stimulate eutrophication effects such as algae blooms, and cause catastrophic damage to human communities (e.g. Son et al. 2007, Briceño and Boyer 2010, Tomasko et al. 2006).

The frequency, intensity, and spatial landfall patterns of tropical cyclones tend to vary with global climate cycles that operate on various time scales (Landsea et al. 1999; Kerr 2000; Goldenberg et al. 2001) and are expected to change with increasing levels of greenhouse gases in the atmosphere (Landsea et al. 1999; Bender et al. 2010). Understanding long-term trends will become increasingly difficult because of unprecedented climate change (Schiermeier 2011), as changing conditions may disguise or accentuate poorly understood natural cycles (Enfield and Cid-Serrano 2010).

Predicting how storm and hydrological dynamics will be affected by accelerating climate change requires an understanding of the underlying ecosystem processes that drive changes, both today and prior to modern anthropogenic effects. Paleoecological proxy 
methods, calibrated with known ecosystem changes, can provide evidence of these processes further in the past than are available from recorded measurements.

Diatom assemblages preserved in sediments provide evidence of past environmental changes on the basis of the relative abundance of taxa present at different times (i.e., depths in a sediment core), because different taxa have measurable preferences and tolerances for different environmental parameters (Battarbee 1986; Cooper 1999). Their short generation times allow them to respond to changes in environmental conditions over time scales that integrate short term fluctuations in driving variables, but also provide an early signal of directional change (Battarbee 1986; Stevenson et al. 2010). Documenting changes in diatom assemblages related to changing environmental parameters driven by seasonal cycles and extreme events today will provide a tool for interpretation of ecosystem change on broad temporal scales recorded in sediments.

Charlotte Harbor, on southwest Florida's Gulf Coast, is an estuary with a large and heterogeneous watershed, providing an opportunity to compare hydrologically altered and relatively pristine sub-basins in a connected system. Charlotte Harbor has three major freshwater inflows that represent distinct regions within the watershed and differ in the extent and nature of their surrounding land use and history of human alteration. The river watersheds contain a complex matrix of agricultural areas, phosphorus mines, urban areas, and relatively pristine conservation lands that provide contrasting environmental gradients for examining controls on diatom assemblage structure. Diatom assemblages have been used successfully to reveal changes in salinity and nutrient concentration gradients in other parts of Florida (Gaiser et al. 2006; Huvane 
2002; Frankovich et al. 2006; Wachnicka et al. 2010; Wachnicka and Gaiser 2011), and some studies have shown that taxon responses are consistent across watersheds, while others have shown that they are different on sub-basin scales (Armitage et al. 2006; Telford et al. 2006; Wachnicka et al. 2010).

The major goals of the present study were to understand how diatom assemblages are distributed across environmental gradients in a heterogeneous watershed today; understand how they change in response to seasonal freshwater fluctuations and a severe storm; evaluate long time-scale hydrological changes in Charlotte Harbor determined by diatom-inference models and investigate model applicability in another southwest Florida estuary; and evaluate evidence for a diatom signal of past tropical cyclones and climate cycles in comparison with the known record. Chapter 2 is focused on the first goal of understanding how diatom assemblages are aligned with environmental parameters. The main objectives were to 1) characterize diatom assemblage distribution across the Charlotte Harbor estuary and its inflows at a time of low freshwater flow to detect underlying spatial patterns; 2) investigate the relative influence of water quality variables on diatom assemblage composition within and among regions of the watershed; and 3) determine how accurately local environmental conditions can be predicted using extant diatom assemblage structure.

Chapter 3 focuses on the goal of understanding how diatom assemblages change in response to changing freshwater flow and a severe storm across the same environmental gradients. The approach in Chapter 3 was to answer three key questions: 1) are there differences among diatom assemblages between the wet and dry seasons in a coastal, hydrologically-dynamic watershed?; 2) do tropical cyclones alter community 
composition, and if so, on what time scale?; and 3) what are the key environmental drivers of these changes?

In Chapters 4 and 5, I applied relationships between contemporary diatom assemblages and their environment to longer time scales using sediment core analysis. Chapter 4 examines large-scale hydrological changes in southwest Florida throughout the Holocene based on diatom-inference models developed in Chapter 1, and investigates the applicability of Charlotte Harbor-derived models to nearby Tampa Bay. Its key objectives were to 1) characterize the diatom assemblages in sediment cores from two Gulf Coast estuaries and identify times of compositional shifts; 2) use transfer functions to quantify past environmental changes; 3 ) interpret long-term hydrological changes from diatom-inferred estimates of past salinity and nutrient concentrations; and 4) evaluate the regional applicability of locally-derived diatom inference models.

The focus of Chapter 5 is to identify patterns of diatom assemblage fluctuations related to environmental changes in the watershed and evaluate evidence for signals of tropical cyclone occurrence and larger climate cycles. The specific goals in this chapter were to 1) characterize the diatom assemblages in a highly temporally-resolved sediment core from a southwest Florida estuary and identify times of compositional shifts; 2) identify patterns in the timing of diatom assemblage changes that may be related to large scale climate cycles, severe storms, and anthropogenic pressures; and 3) evaluate evidence of past storm events provided from diatom-based environmental inferences. Chapter 6 provides a general summary and conclusions from this study. 


\section{References}

Anderson, D., P. Glibert, and J. Burkholder. 2002. Harmful algal blooms and eutrophication: Nutrient sources, composition, and consequences. Estuaries 25: 704-726.

Armitage, A.R., T.A. Frankovich, J.W. Fourqurean. 2006. Variable responses within epiphytic and benthic microalgal communities to nutrient enrichment. Hydrobiologia 569: 423-435

Battarbee, R.W. 1986. Diatom analysis. In B.E. Berglund (Editor), Handbook of Holocene palaeoecology and palaeohydrology. Caldwell: Blackburn, 527-570.

Bender, M. A., T. R. Knutson, R. E. Tuleya, J. J. Sirutis, G. A. Vecchi, S. T. Garner and I. M. Held. 2010. Modeled Impact of Anthropogenic Warming on the Frequency of Intense Atlantic Hurricanes. Science 327: 454-458.

Briceño, H., and J. Boyer. 2010. Climatic Controls on Phytoplankton Biomass in a Subtropical Estuary, Florida Bay, USA. Estuaries and Coasts 33: 541-553.

Cooper, S.R. 1999. Estuarine paleoenvironmental reconstructions using diatoms. In E.F. Stoermer and J.P. Smol (Editors), The Diatoms: Applications for the Environmental and Earth Sciences, $1^{\text {st }}$ edition ed., pp. 352-373.

Enfield, D. B., and L. Cid-Serrano. 2010. Secular and multidecadal warmings in the North Atlantic and their relationships with major hurricane activity. International Journal of Climatology 30: 174-184.

Frankovich, T.A., E. Gaiser, J.C. Zieman, and A.H. Wachnicka. 2006. Spatial and temporal distributions of epiphytic diatoms growing on Thalassia testudinum Banks ex König: Relationships to water quality. Hydrobiologia 569: 259-271.

Gaiser. E.E., J.H. Richards, J.C. Trexler, R.D. Jones, and D.L. Childers. 2006. Periphyton responses to eutrophication in the Florida Everglades: Cross-system patterns of structural and compositional change. Limnology and Oceanography 51: 617-630.

Gentry, R. C. 1974. Hurricanes in South Florida. In P.J. Gleason (Editor), Environments of South Florida: Present and Past. Miami: Miami Geologic Society.

Goldenberg, S. B., C. W. Landsea, A. M. Mestas-Nuã Ez, and W. M. Gray. 2001. The Recent Increase in Atlantic Hurricane Activity: Causes and Implications. Science 293: 474-479.

Huvane, J.K. 2002. Modern diatom distributions in Florida Bay: A preliminary analysis. In J.W. Porter and K.G. Porter (Editors), The Everglades, Florida Bay, and coral reefs of the Florida Keys: An ecosystem sourcebook. Boca Raton: CRC, pp. 479-493. 
Kerr, R. A. 2000. A North Atlantic Climate Pacemaker for the Centuries. Science 288: 1984-1985.

Landsea, C. W., R. A. Pielke, A. M. Mestas-Nuñez, and J. A. Knaff. 1999. Atlantic Basin Hurricanes: Indices of Climatic Changes. Climatic Change 42: 89-129.

Nixon, S.W. 1995. Coastal marine eutrophication: A definition, social causes, and future concerns. Ophelia 41: 199-219.

Noss, R.F. 2011. Between the devil and the deep blue sea: Florida's unenviable position with respect to sea level rise. Climatic Change 107: 1-16.

Ross, M.S., J.J. O'Brien, G. Ford, K. Zhang, and A. Morkill. 2009. Disturbance and the rising tide: the challenge of biodiversity management on low-island ecosystems. Frontiers in Ecology and the Environment 7: 471-478.

Saha, A.K., S. Saha, J. Sadle, J. Jiang, M.S. Ross, R.M. Price, L.S.L. Sternberg, and K.S. Wendelberger. 2011. Sea level rise and South Florida coastal forests. Climatic Change 107: 81-108.

Schiermeier, Q. 2011. Can violent hurricanes, floods and droughts be pinned on climate change? Scientists are beginning to say yes. Nature 477: 148-149.

Son, S., T. Platt, C. Fuentes-Yaco, H. Bouman, E. Devred, Y. Wu and S. Sathyendranath. 2007. Possible biogeochemical response to the passage of Hurricane Fabian observed by satellites. Journal of Plankton Research 29: 10.

Stevenson, R.J., Y. Pan, and H. Van Dam. 2010. Assessing environmental conditions in rivers and streams with diatoms. In E.F. Stoermer and J.P. Smol (Editors), The Diatoms: Applications for the Environmental and Earth Sciences, $2^{\text {nd }}$ edition. Cambridge: Cambridge University Press, pp. 57-85.

Telford, R.J., V. Vandvik, and H.J.B. Birks. 2006. Dispersal limitations matter for microbial morphospecies. Science 19: 1015.

Tomasko, D., C. Anastasiou, and C. Kovach. 2006. Dissolved oxygen dynamics in Charlotte Harbor and its contributing watershed, in response to hurricanes Charley, Frances, and Jeanne-Impacts and recovery. Estuaries and Coasts 29: 932-938.

Wachnicka, A., E.E. Gaiser, L. Collins, T.A. Frankovich, J. Boyer. 2010. Distribution of diatoms and development of diatom-based models for inferring salinity and nutrient concentrations in Florida Bay and adjacent coastal wetlands of South Florida (USA). Estuaries and Coasts 33: 1080-1098. 
Wachnicka, A., and E.E. Gaiser. 2011. Ecology and distribution of diatoms in Biscayne Bay, Florida (USA): Implications for bioassessment and paleoenvironmental studies. Ecological Indicators 11: 622-632.

Wiseman, W.J. Jr., N.N. Rabalais, M.J. Dagg, and T.E. Whitledge. 1999. Nutrient Enhanced Coastal Ocean Productivity in the Northern Gulf of Mexico -- Understanding the Effects of Nutrients on a Coastal Ecosystem. Decision Analysis Series No. 14. Silver Spring: NOAA Coastal Ocean Program. 


\title{
2. DISTRIBUTION OF DIATOMS ALONG ENVIRONMENTAL GRADIENTS IN THE CHARLOTTE HARBOR, FLORIDA (USA), ESTUARY AND ITS WATERSHED: IMPLICATIONS FOR BIOASSESSMENT OF SALINITY AND NUTRIENT CONCENTRATIONS
}

(Published under the same title as: Nodine, E.R. and E.E. Gaiser. 2014. Estuaries and Coasts 37: 864-879. Copyright released.)

\begin{abstract}
The relative abundance of diatom species in different habitats can be used as a tool to infer prior environmental conditions and evaluate management decisions that influence habitat quality. Diatom distribution patterns were examined to characterize relationships between assemblage composition and environmental gradients in a subtropical estuarine watershed. I identified environmental correlates of diatom distribution patterns across the Charlotte Harbor, Florida, watershed; evaluated differences among three major river drainages; and determined how accurately local environmental conditions can be predicted using inference models based on diatom assemblages. Sampling locations ranged from freshwater to marine $(0.1-37.2 \mathrm{ppt}$ salinity) and spanned broad nutrient concentration gradients. Salinity was the predominant driver of differences among diatom assemblages across the watershed, but other environmental variables had stronger correlations with assemblages within the subregions of the three rivers and harbor. Eighteen indicator taxa were significantly
\end{abstract}


affiliated with sub-regions. Relationships between diatom taxon distributions and salinity, distance from the harbor, total phosphorus (TP), and total nitrogen (TN) were evaluated to determine the utility of diatom assemblages for predicting environmental values using a weighted averaging-regression approach. Diatom-based inferences of these variables were strong (salinity $\mathrm{R}^{2}=0.96$; distance $\mathrm{R}^{2}=0.93$; $\mathrm{TN} \mathrm{R}^{2}=0.83$; $\mathrm{TP}$ $\mathrm{R}^{2}=0.83$ ). Diatom assemblages provide reliable estimates of environmental parameters on different spatial scales across the watershed. Because many coastal diatom taxa are ubiquitous, the diatom training sets provided here should enable diatom-based environmental reconstructions in subtropical estuaries that are being rapidly altered by land and water use changes and sea level rise.

\section{Introduction}

Estuaries and their associated coastal ecosystems are among the most productive habitats in the world, because they receive nutrients from both terrestrial and marine sources, and more recently, anthropogenic inputs (e.g. Nixon 1995; Wiseman et al. 1999; Anderson et al. 2002). Geologically, they are relatively transient environments that formed as sea level rose following the last ice age and they exist in a balance between the present day sea level, freshwater inflow, and sediment deposition and transport (Day et al. 1989; Perillo 1995; Guccione 1995). Changes in the relative influence of sea level and freshwater flow affect the salinity and nutrient concentrations across coastal watersheds, which in turn control the composition and distribution of algal communities (Therriault and Levasseur 1986; Mallin et al. 1993). Enhanced freshwater flow can 
reconfigure estuarine environmental gradients and change algal communities in different ways: increases in precipitation reduce salinity and increase atmospheric nutrient deposition (e.g. Fisher and Oppenheimer 1991; Mallin et al. 1993; Paerl 1995; Nixon 1995), and runoff from the watershed increases inputs of terrestrial nutrients (e.g. Glibert et al. 2006; Zhang et al. 2009), which can lead to eutrophication and hypoxia (e.g. Paerl 2006; Stevens et al. 2006; Rabalais et al. 2010). Estuarine ecosystems are therefore particularly sensitive to human alteration of runoff, terrestrial nutrient inputs, and sea level fluctuations.

Estuarine ecosystems exhibit temporal and spatial variation in environmental conditions that are influenced by surface and groundwater exchange from freshwater inflows and the sea. Characterizing the spatial dynamics of biological assemblage structure in order to evaluate and predict changes in the ecosystem on different time scales is an important goal for understanding estuary dynamics and community ecology (Soininen et al. 2004; Cottenie 2005). A spatial perspective of ecological communities can also help define how and where anthropogenic activities affect ecosystems and help evaluate management plans and monitoring strategies (Craig and Bosman 2013).

Diatom assemblages are good indicators of environmental transitions across estuaries because of their widespread occurrence and measurable preferences and tolerances for different environmental conditions (Battarbee 1986; Cooper 1999). Their short generation times allow them to respond to changes in environmental conditions over time scales that integrate high variation in physicochemical features but that also provide an early signal of directional change (Battarbee 1986; Stevenson et al. 2010). Diatom diversity and composition can vary significantly over small spatial and temporal 
scales (Parsons et al. 1999; Smol and Cumming 2000; Reid and Ogden 2009), enabling interpretation of environmental characteristics in transitional areas where taxa might tolerate local conditions but do not thrive in them through subtle differences in their relative abundances across gradients (Gaiser et al. 1998; Frankovich et al. 2006). Where diatoms have strong relationships with environmental conditions, ecological response functions or transfer functions can be developed to quantitatively infer environmental variables from diatom assemblage composition (Fritz et al. 1991 and 2010; Birks 1995 and 1998; Juggins 2013). Because they preserve well in sediment, diatom assemblages can thus provide inferences about environmental conditions occurring in estuaries prior to human alteration and over long time scales using sediment core analysis (Cooper et al. 2010).

For this study, I investigated the spatial distribution of diatoms relative to environmental gradients in the Charlotte Harbor watershed, on southwest Florida's Gulf Coast. South Florida, with its shallow topographic relief, porous karst aquifer, and intensely developed coastline, is particularly vulnerable to sea level rise (e.g. Ross et al. 2009; Saha et al. 2011; summarized in Noss 2011) and has an extraordinary history of hydrological alteration due to early efforts to drain Everglades wetlands for agricultural and urban development (summarized in Grunwald 2006; McVoy et al. 2011). The Charlotte Harbor watershed encompasses a large area and includes three major rivers that provide most of the freshwater inflow to the estuary. The three rivers represent distinct regions within the Charlotte Harbor watershed that differ in the extent and nature of their surrounding land use and history of human alteration. The river watersheds contain a complex matrix of agricultural areas, phosphorus mines, urban areas, and relatively 
pristine conservation lands that provide contrasting environmental gradients for examining controls on diatom assemblage structure.

During periods of high freshwater inflow such as after a tropical storm, episodic hypoxia occurs in Charlotte Harbor in response to nutrient loading and stratification (Tomasko et al. 2006; Stevens et al. 2006; Kim et al. 2010), and in late summer the hypoxic zone can approach $90 \mathrm{~km}^{2}$ (Camp, Dresser, and McKee, Inc. 1998). The spatial and temporal characteristics of nutrient loading across the watershed are complex, but previous research has linked nitrogen inputs to phytoplankton productivity that may cause expansion of the hypoxic zone (McPherson and Miller 1990; McPherson et al. 1990; Montgomery et al. 1991; Turner et al. 2006). Algal productivity related to these hypoxia events responds differently to nutrient additions along a salinity gradient in the Charlotte Harbor estuary (Montgomery et al. 1991; Morrison et al. 1998). Specifically, nutrient limitation shifts from nitrogen-limited in most of this watershed to phosphoruslimited farther south (Heil et al. 2007). Further characterization of environmental gradients and their control on biological communities is important for understanding the spatial structure of environmental change, as well as for guiding appropriate water quality management.

Diatom assemblages may provide insight into changes along these gradients in the Charlotte Harbor estuary, since they have been used successfully to reveal changes in salinity and nutrients gradients in other parts of Florida (Gaiser et al. 2006; Huvane 2002; Frankovich et al. 2006; Wachnicka et al. 2010; Wachnicka and Gaiser 2011). Some studies have shown that taxon responses are consistent across watersheds, while others 
have shown that they are different on sub-basin scales (Armitage et al. 2006; Telford et al. 2006; Wachnicka et al. 2010).

For this study, extensive spatial sampling across the Charlotte Harbor estuary and its watershed was conducted to characterize the relationships between taxa and environmental gradients and enable inference about past conditions. Specifically, my goals in this study were to 1) characterize diatom assemblage distribution across the Charlotte Harbor estuary and its inflows at a time of low freshwater flow that maximizes capacity for detecting underlying spatial patterns; 2) investigate the relative influence of water quality variables on diatom assemblage composition within and among regions of the watershed; and 3) determine how accurately local environmental conditions can be predicted using extant diatom assemblage structure. Where prediction models are identifiable and strong, resulting diatom-based environmental transfer functions can be used to determine environmental histories from sediment records to provide restoration targets, as well as to track contemporary ecological response to management decisions. These biological interpretations could prove particularly valuable as water management decisions are continually updated with the goals of improving ecosystem integrity and resilience while maintaining function for flood control and navigation (SFWMD 2008). 


\section{Methods}

Study landscape context

Charlotte Harbor has a large watershed, spanning 12,653 $\mathrm{km}^{2}$ of central and south Florida, and an estuary surface area of approximately $700 \mathrm{~km}^{2}$ (Hammett 1988). It receives freshwater from three major rivers, the Myakka, Peace, and Caloosahatchee, as well as numerous small creeks and streams. Total freshwater inputs to the estuary including the three rivers, remaining watershed (coastal area and creeks and streams), and precipitation, averages over 3,500 millions of gallons per day (Hammett 1988). Charlotte Harbor is particularly appropriate for examining environmental influences on diatom assemblage structure because of its spatial variability in hydrological histories associated with different land uses.

In the late $19^{\text {th }}$ century, the Caloosahatchee River was channelized and connected to Lake Okeechobee as part of an effort to drain the Everglades, significantly affecting the hydrology of the river. The historically shallow, meandering flow way was deepened and straightened to facilitate flood control and navigation (Lane 1990). Freshwater flow through the Caloosahatchee River is now highly managed, as the economic interests of flood control and navigation require maintenance of the artificial flow way; however, recognizing that management decisions can have negative impacts on water quality, legislation also requires that management plans restore and protect the ecological integrity of Charlotte Harbor surface waters (SFWMD 2008). The flow of the Caloosahatchee River is now managed by the U.S. Army Corps of Engineers and South 
Florida Water Management District via three lock and dam structures: the Moore Haven locks at the junction with Lake Okeechobee, the Ortona locks, and the W.P. Franklin locks, which are farthest downstream and now provide a barrier to tidal action and marine water influence upstream (Lane 1990; Chamberlain and Doering 1997). Much of the drainage area of the Caloosahatchee is in agriculture; the Peace River watershed also includes extensive agriculture as well as phosphate mining (Pierce et al. 2004). For approximately twenty years in the late $19^{\text {th }}$ and early $20^{\text {th }}$ centuries, the bottom of the Peace River was dredged for phosphate extraction until operations moved inland, though the impacts of mining continue to affect the watershed (Martin and Kim 1977; O'Donnell 1990). In contrast, the Myakka River watershed is relatively pristine, as it is largely undeveloped with much of its watershed in permanent conservation lands (Dorsey and Barry 1990). Its drainage basin has more freshwater wetland area than the rest of the Charlotte Harbor watershed and also has expansive tidal wetlands. Streamflow analysis of the three rivers spanning 50 years showed a statistically significant declining trend in the Peace River flow volume, which might be explained by decreasing pressure due to groundwater withdrawals from the Floridan aquifer, but no significant trend elsewhere in the watershed (Hammett 1988; Pierce et al. 2004). The three rivers also differ widely in their drainage area; the Caloosahatchee is approximately $120 \mathrm{~km}$ long with a watershed of 3,570 $\mathrm{km}^{2}$, the Myakka River is nearly the same length $(110 \mathrm{~km})$ but with a watershed of only $610 \mathrm{~km}^{2}$, and the Peace River is $170 \mathrm{~km}$ long with a watershed of $3,540 \mathrm{~km}^{2}$ (Lane 1990; O’Donnell 1990; Dorsey and Berry 1990). 
Study sites

Fifty sites were selected for sampling in Charlotte Harbor, the Peace River, the Caloosahatchee River, and the Myakka River (Fig. 1). Sites were selected to capture salinity and nutrient gradients in the watershed and included open marine and brackish areas, and freshwater reaches of each river $(<0.5$ ppt salinity). Sites located beyond the point where the mouth of each river exceeded $1 \mathrm{~km}$ without further narrowing and those adjacent to two barrier islands that separate the estuary from the Gulf of Mexico were designated as Harbor sites. One sample, collected in the center of the harbor in a depositional environment from which sediment cores were taken for paleoecological study (described in Van Soelen et al. 2012), was selected to represent the central harbor and distance from that point was measured for all other samples. The upstream-most sites (furthest from the harbor center) in each river were $149 \mathrm{~km}$ (Peace River), $119 \mathrm{~km}$ (Caloosahatchee River), and 48 km (Myakka River). Caloosahatchee River samples were taken from either side of the W.P. Franklin locks (the farthest locks downstream), and the most upstream site was immediately downstream of the Ortona locks.

Sample collection, preparation, and laboratory analysis

Samples were collected in March 2012, which is during the dry season for southwest Florida and near the middle of the period of minimal freshwater flow that generally occurs between November and May (Hammett 1988). Sediments were collected by hand, by scraping the uppermost estimated $1 \mathrm{~cm}$ layer from the surface to 
capture the material deposited during approximately the last year; accretion rates during the past 100 years have increased to approximately $0.74 \mathrm{~cm}$ per year (Van Soelen et al. 2012). This upper sediment layer contains diatoms from a variety of habitats and is expected to include a mix of benthic, epiphytic, and planktonic taxa (Cooper 1999). Where deep water prohibited collection by hand, an Ekman dredge was used to retrieve undisturbed surface sediments and the upper $1 \mathrm{~cm}$ was scraped from the surface. Samples were transported to the laboratory on ice and then frozen. At the time of sample collection, salinity, conductivity, temperature, and $\mathrm{pH}$ were measured at mid-depth in the water column using a YSI multiparameter Sonde.

In the laboratory, samples were thawed and homogenized by hand. Approximately $10 \mathrm{ml}$ of sediment was reserved for diatom analysis and the remainder was dried and ground for analysis of total phosphorus (TP) with a UV-2101PC Scanning Spectrophotometer, total nitrogen (TN) with an ANTEK 7000 N Nitrogen Analyzer, and total carbon (TC) with a Perkin Elmer Series II CHNS/O (2400) Analyzer by the Southeast Environmental Research Center Nutrient Analysis Laboratory at Florida International University. Diatom samples were cleaned using a series of acid baths following the oxidation technique described by Battarbee (1986) and then diluted until a neutral $\mathrm{pH}$ was achieved. A measured aliquot of 0.006 to $0.1 \mathrm{ml}$ (depending on diatom concentration) of the resulting mixture was removed by calibrated pipette, placed on a coverslip and dried. Coverslips were then permanently mounted onto glass slides using Naphrax ${ }^{\circledR}$. A minimum of 500 diatom valves were identified from each sample along measured, random transects using a Nikon E4000 light microscope at 1000x magnification. Identification of diatoms was based on regional and standard diatom 
taxonomic literature (e.g. Peragallo and Peragallo 1897-1908; Foged 1984; Hendey 1964;

Hein et al. 2008; Witkowski et al. 2000).

Data analysis

The abundance of all taxa in each sample was calculated relative to total abundance of diatom valves counted. Taxa occurring in at least three samples with a relative abundance of at least $0.5 \%$ in at least one sample were included for statistical analyses, because inclusion of rare taxa increases noise in the dataset (McCune and Grace 2002). Relative abundance data were fourth-root transformed to more closely approximate a normal distribution and to downscale the relative importance of very abundant taxa. Indicator species analysis (ISA) was used to identify taxa that were strongly associated with a particular region. Indicator values are based on affinity for a group from taxon persistence in the group (in most samples from that group) and exclusivity to that group (not found in most other groups) (McCune and Grace 2002).

Environmental data were transformed using the method that best reduced the skewness for each variable. Conductivity and salinity values were arcsine transformed, nutrient data (TP, TN, and TC) were log-10 transformed, $\mathrm{pH}$ was inverse transformed, and distance from the Harbor center was square-root transformed. All environmental data were then normalized (mean subtracted and divided by standard deviation) to equalize values to a common scale (Clarke and Warwick 2001). Pearson's correlation coefficients were calculated to evaluate the strength of associations among environmental variables. 
Similarity matrices were created using Bray-Curtis similarity to evaluate diatom assemblage patterns and Euclidean distance for the environmental data (Clarke and Warwick 2001). Analysis of similarity (ANOSIM) was used to determine the similarity of diatom assemblages and environmental values among the four regions and among downstream and upstream river sites (Clarke and Gorley 2006). R values reported represent the difference of mean ranks of taxa by relative abundance and range from 0 to 1 with increasing dissimilarity; comparisons having a $\mathrm{p}<0.05$ were considered significantly different (Clarke and Warwick 2001). Nonmetric multi-dimensional scaling (NMDS) ordination (Kruskal and Wish 1978) was used to visualize assemblage patterns within and among regions. After evaluating the stress of ordinations with up to five axes, two-dimensional NMDS was selected to ease interpretability of results, given that stress values did not decrease greatly with additional axes. Stress is a measure of the departure from fit of the sample dissimilarity to distance in the ordination; it tends to decrease with additional axes, as more of the sample variance is represented, but additional dimensions make interpretation increasingly difficult (McCune et al. 2002). Environmental vectors representing the direction and strength of each variable's correlation with assemblage differences were overlaid on the assemblage ordinations.

Pearson's and Kendall correlation coefficients were calculated representing the linear and rank relationship, respectively, between each variable and the NMDS ordination of diatom assemblage (McCune and Grace 2002). Bio-env stepwise analysis (BEST) was also used to evaluate the dissimilarity matrices. This analysis conducts a Mantel test on the dissimilarities among taxa and environmental data to determine which subsets of environmental variables have the strongest correlation with assemblage 
dissimilarity (Clarke and Gorley 2006). This analysis was conducted for the full dataset and for each of the four regions separately to evaluate how relationships differ among spatial scales and locations. The analyses were conducted using the software Primer version 6 (Clarke and Gorley 2006) and PC-ORD version 5 (McCune and Mefford 1999).

The optimum of each taxon for the environmental variable of interest was determined by averaging the values of each variable at sites where the taxon occurred and weighting it by its relative abundance at each site. This method enabled calculation of a quantitative model of each variable for each site, based on the optima and abundance of the taxa present. This weighted-averaging regression-calibration approach assumes that species with optima closest to the observed value of a parameter will be most abundant at that site (Birks 1995). The breadth of tolerance of each taxon along each gradient was calculated as the abundance-weighted standard deviation of each variable (Birks 1995). Weighted averaging partial least squares (WA-PLS) regression with cross-validation was used to develop predictions of salinity, geographic distance from the central harbor point, TN and TP. This method incorporates the residual correlations in the assemblage data (Ter Braak et al. 1993) and improves model performance in datasets where taxa have broad tolerances (Battarbee et al. 1999). The accuracy of diatom-based prediction models for these variables was evaluated by examining the relationship between observed environmental measurements at each site and values predicted by the optima, tolerances, and relative abundances of taxa in the assemblage at that site (the diatom-inferred value), and through evaluation of the root mean square error of prediction (RMSEP). Observed values of all variables were plotted against the residuals from these prediction models to evaluate relationships that might explain bias. Taxon optima calculated within each 
region were also plotted against optima estimated by the whole dataset to investigate regional bias, or skewness in applying a regionally-based model for the whole dataset. These analyses were conducted using C2 version 1.7.2 software (Juggins 2011).

\section{Results}

Diatom assemblage composition

A total of 296 diatom taxa were identified from samples across the Charlotte Harbor watershed. The most abundant taxa in the watershed were Catenula adhaerens Mereschkowsky, Planothidium delicatulum (Kützing) Round and Bukhtiyarova, Staurosirella martyi (Héribaud) Morales and Manoylov, Amphicocconeis disculoides (Hustedt) De Stefano and Marino, and Achnanthes lanceolata (Brébisson ex Kützing) Grunow, all with a mean relative abundance of greater than four percent across all sites. Species richness across sites ranged from 18 to 65 , and was not correlated with any environmental variable, including distance. Average species richness was lowest in the Caloosahatchee River sites (37) and highest in the Myakka River (48). Peace River and Harbor sites had an average of 45 and 44 taxa per site, respectively. Diatom assemblages in each region were significantly different from assemblages in every other region $(\mathrm{p}<$ 0.03), and the two rivers with the broader sampling area, the Peace and Caloosahatchee, were especially different from the Harbor sites (Table 1). The assemblages in the furthest downstream river sites where tidal mixing occurs were significantly different between the Caloosahatchee and Myakka Rivers and the Peace and Caloosahatchee Rivers, but there 
was no significant difference between assemblages in the downstream Peace and Myakka Rivers (Table 2). In the upstream reaches of the rivers, there were significant differences between the Peace and Caloosahatchee River assemblages and the Peace and Myakka River assemblages, but no significant difference between assemblages in the upstream Caloosahatchee and Myakka Rivers.

The most abundant taxa (five percent and greater average relative abundance) in each region included two or more taxa that were common throughout the watershed, as well as some that were abundant only in that region (Table 3). Indicator species analysis revealed statistically significant indicators for each region (Table 4). Gomphonema brasiliense Grunow was the best indicator for the Caloosahatchee River $(p=0.003), F$. sopotensis was the best indicator for the Peace River $(\mathrm{p}<0.001)$, Nitzschia coarctata Grunow was the best indicator for the Myakka River $(\mathrm{p}<0.001)$, and Fallacia nyella (Hustedt ex Simonsen) Mann was the best indicator for the Harbor region $(\mathrm{p}=0.006)$.

Environmental conditions and relationships to assemblage structure

Gradients of salinity, conductivity, $\mathrm{pH}, \mathrm{TP}, \mathrm{TN}$, and TC were apparent but varied in length and degree of overlap among the four regions (Table 5). A strong salinity gradient was present in each river with values ranging from almost completely fresh $(<$ $0.5 \mathrm{ppt})$ to brackish (>19 ppt). Nutrient gradients were also evident and varied in length among regions. The highest value for $\mathrm{TN}$ in the Caloosahatchee River $(1.6 \mathrm{mg} / \mathrm{g})$ was equal to the mean value in the Peace River, which had a much longer gradient (mean 3.0 $\mathrm{mg} / \mathrm{g}$ ); the Harbor sites had the highest mean TN and longest gradient of all the regions. 
The mean TP concentration in the Peace River $(4670 \mu \mathrm{g} / \mathrm{g})$ was almost four times the mean for the Caloosahatchee River $(1255 \mu \mathrm{g} / \mathrm{g})$, which had the next longest TP gradient and next highest concentrations. The Myakka River had the shortest TP gradient of the three rivers, which fell entirely within the range found in the Caloosahatchee River, and the Harbor had an even smaller range and the lowest mean concentration for TP.

Pearson's correlation coefficients indicated strong spatial patterns, with distance correlated with all variables except for TN and TC (Table 6). Nutrient concentrations generally had weak correlations with other variables and one another. ANOSIM revealed significant environmental differences among some but not all of the sub-regions (Table 1). Water quality of the Myakka River was not significantly different from either the Harbor or the Peace River but was different from the Caloosahatchee River $(\mathrm{p}<0.001)$. The Caloosahatchee River water quality was also significantly different from the Peace River and the Harbor ( $\mathrm{p}<0.006$ and $\mathrm{p}<0.001$, respectively), and the Peace River and Harbor also differed in water quality $(\mathrm{p}<0.001)$. When separated into downstream reaches (where tidal mixing occurs) and upstream reaches (no tidal mixing), the three rivers were all significantly different from each other in the downstream reaches and only the Peace River and Caloosahatchee River were not significantly different in the upstream reaches (Table 2).

Different environmental variables correlated with assemblage patterns at different spatial scales (Fig. 2a, b, c, d, e), as shown in two-dimensional NMDS ordinations (2D stress $=0.18 ; 3 \mathrm{D}$ stress $=0.12$ for all sites). Salinity had the strongest correlation with the assemblage patterns across the whole watershed $(\mathrm{R}=0.89 ; \mathrm{p}<0.001)$, but not within individual regions (Table 7). Distance was also strongly correlated with assemblage 
patterns, and had the strongest correlation with the Peace River assemblages $(\mathrm{R}=0.89 ; \mathrm{p}$ $<0.001$ ). Conductivity had the strongest relationship with Myakka River assemblages ( $\mathrm{R}$ $=0.97 ; \mathrm{p}<0.001)$, but salinity and distance were nearly as strong $(\mathrm{R}=0.96 ; \mathrm{p}<0.001$ and $\mathrm{R}=0.95 ; \mathrm{p}<0.01$, respectively). In the Caloosahatchee River and Harbor sites, TC has the strongest relationship with the assemblages $(R=0.67$ and 0.61 , respectively; $p<$ 0.05), and TC was the only statistically significant relationship for the Harbor sites.

The Mantel test (BEST) revealed which combinations of variables had the strongest correlation with assemblage dissimilarity in each region and across the whole watershed (Table 8). Salinity, distance, and conductivity were most strongly correlated with differences in assemblage composition and were significantly correlated with one another. For the whole watershed, the strongest association between assemblage dissimilarity and environmental dissimilarity was with salinity alone, followed by salinity with distance.

When the overriding covarying environmental variables, salinity, distance, and conductivity, were excluded from consideration, the correlation between environmental dissimilarity explained by the remaining variables remained strong. The strongest combination with the exclusion of these variables was $\mathrm{pH}, \mathrm{TC}$, and $\mathrm{TN}(\mathrm{R}=0.31 ; \mathrm{p}<$ 0.01). In the Caloosahatchee River sites, the strongest correlation with assemblage dissimilarity was also salinity, followed by salinity with distance. Excluding salinity, distance, and conductivity, TC had the highest correlation with assemblage dissimilarity but was not statistically significant.

In the Myakka River, conductivity alone had the highest correlation with assemblage dissimilarity, followed by the combination of salinity, distance, and 
conductivity. Excluding these three, $\mathrm{TP}$ and $\mathrm{pH}$ both had significant correlations with assemblage dissimilarity. In the Peace River, salinity and distance had the highest correlation with assemblage dissimilarity, followed by distance alone. TP, $\mathrm{pH}$, and TC were also correlated with assemblage dissimilarity. In the Harbor sites, $\mathrm{pH}$ had the highest correlation with assemblage dissimilarity, but no relationships were statistically significant. Upstream assemblages did not have any statistically significant relationships with environmental variables, but downstream assemblages were correlated with $\mathrm{pH}, \mathrm{TP}$, and distance. With distance, salinity, and conductivity excluded, TP had the strongest correlation with downstream assemblages.

Environmental preferences and predictions

Across the entire watershed and within each region, diatom taxa reliably predicted salinity, distance, TN and TP using the weighted-averaging regression-calibration approach (Table 4); however, optima calculated within a given region often differed from those calculated from the whole dataset, causing regional models to over- or underpredict values for the whole dataset. Therefore the strongest inference models were those developed using the watershed as a whole (Fig. 3). Prediction models for salinity and distance were very strong $\left(\mathrm{R}^{2}=0.96\right.$ and 0.93 , respectively). Nutrient prediction models were also strong $\left(\mathrm{R}^{2}=0.82\right.$ and 0.83 for $\mathrm{TN}$ and $\mathrm{TP}$, respectively). There were no significant correlations found between residuals and any other environmental variable. 


\section{Discussion}

Diatom distribution and relationships to environmental gradients

The significant environmental variation across the Charlotte Harbor watershed provided an excellent opportunity to characterize spatial controls on algal assemblages and their relationships to regional characteristics and water quality patterns. These relationships should be applicable across the Gulf Coast, since diatom assemblages in Charlotte Harbor included many taxa reported in other Gulf Coast estuaries. Three of the most abundant taxa in the Harbor sites, O. pacifica, A. disculoides, and D. minor, were reported by Cremer et al. (2007) in Rookery Bay, Florida, south of Charlotte Harbor; Opephora species and A. disculoides were also reported by Van Soelen et al. (2010) in Tampa Bay, Florida, north of Charlotte Harbor, as well as other taxa that were common in the Harbor sites such as P. delicatulum (5\% mean relative abundance), Cyclotella litoralis Lange and Syvertsen, and Paralia sulcata (Ehrenberg) Cleve (each 1\% mean relative abundance). In contrast, diatom assemblages found in the Myakka, Peace, and Caloosahatchee Rivers are poorly documented. Morales (2002 and 2005) noted the importance of small, fragilarioid diatoms in the brackish waters of the Peace and Caloosahatchee Rivers and resolved some taxonomic discrepancies. Some of the genera that were the focus of these studies were common in the Peace and Caloosahatchee River sites, including Staurosirella, Fragilaria, and Opephora. No previous documentation of the diatom flora of the Myakka River was found, except it was noted as a location where a recently-described species, Staurosira stevensonii Manoylov, Morales and Stoermer, 
which was not identified in this study, was found (Manoylov et al. 2003); the Peace and Caloosahatchee Rivers, as well as many other Florida streams, were also identified locations for this species. Several of the most common taxa in the river regions, including A. lanceolata, C. adhaerens, and Staurosira construens var. venter (Ehrenberg) Hamilton, have been reported in eastern United States estuaries such as the Chesapeake Bay and the Pamlico and Neuse estuaries of North Carolina (Cooper 1995 and 2000); however, they have rarely been reported elsewhere along the Gulf Coast, suggesting that additional characterization and taxonomic evaluation of the diatom flora is needed along river to sea gradients in this region.

Several diatom taxa exhibited strong affinities for a particular region, as evidenced by the relatively high number (18, or six percent of all identified taxa) of significant indicator species. Region-specific taxa optima differed from optima based on the whole watershed, which may be related to the smaller environmental gradient represented in each region compared to the whole watershed, but suggests that assemblage composition may be controlled by different environmental factors on different spatial scales. The diatom assemblages differed among regions suggesting variable environmental controls among sub-basins. Differing correlations of environmental variables to assemblage dissimilarity among sites within each region also suggests variable environmental control on different spatial scales and is consistent with the findings of previous research on diatom community spatial structure in freshwater streams (e.g. Pan et al. 2000; Soininen et al. 2004).

The best indicator species for the Harbor and Myakka River sites, F. nyella and N. coarctata, have previously been reported in other coastal areas including Brazilian 
beaches (Garcia 2003) and intertidal mudflats in Europe (e.g. Haubois et al. 2005).

Indicator species for the Peace River were generally those having the highest optima for total phosphorus, but G. brasiliense, an indicator for the Caloosahatchee River, had the second highest total phosphorus optimum of all abundant or indicator species and was not found in the Peace River sites. Its overall low occurrence (average 1\% relative abundance in the Caloosahatchee River assemblages and not found anywhere else) might explain its limited distribution (six sites, all in the upper Caloosahatchee); the only site where $G$. brasiliense constituted more than ten percent relative abundance was the site with the highest total phosphorus concentrations found outside of the Peace River, which was immediately upstream from the Franklin locks that separate the upstream flow way from marine influence. The optimum value for distance from the Harbor for G. brasiliense was comparable to the optima for Peace River indicator species, which may be a stronger indication of its habitat affinity, given its overall low occurrence in the watershed, although its salinity optimum was lower than most Peace River indicators. Interestingly, good indicators for the Harbor sites typically had lower salinity optima than indicators for the Myakka River, but this could suggest that different environmental variables are more important drivers for the distribution of these taxa. Additional sampling of the Myakka River in farther upstream reaches may help to clarify environmental drivers that are not related to salinity. Additional quantification of the autecology of diatom taxa in this watershed will provide improved ability to interpret these findings and evaluate impacts of water management decisions. For example, because G. brasiliense was found only at sites upstream of the lock separating the Caloosahatchee from marine waters, it may be a reliable indicator of this unique habitat. This species has not previously been reported in 
studies of Lake Okeechobee diatom flora (e.g. Stoermer et al. 1992), but may be associated with water chemistry changes that occur in response to freshwater releases from the lake.

Significant water quality differences among regions and sub-regions provided insight into how environmental variables affect biological patterns on different spatial scales. Water quality differences were evident among most regions, and some differences were stronger on the sub-regional scale. When considering only the downstream river sites that are subject to tidal mixing, each river was significantly different from the others, and the difference between the Peace and Caloosahatchee Rivers was stronger among downstream sites than upstream, which suggests that tidal mixing is not the dominant environmental control in at least one of these areas. Upstream sites were significantly different (both with distance included and excluded as a variable) except for the Peace and Caloosahatchee Rivers, which had the longest spatial reaches and may suggest moderation of environmental gradients at reaches farther inland. The salinity gradient, for example, is much gentler in the upstream reaches of these two rivers, with a much smaller range over a larger distance. Although differences among mean salinity values for each river were apparent (e.g. the mean salinity in the Myakka River was nearly four times the mean salinity in the Peace River), these differences were not surprising given the geographical characteristics of each river and the number of samples taken from each; the lower salinity means in the Peace and Caloosahatchee Rivers were likely because they are longer rivers and the sample size in inland reaches was higher, as reflected in their higher mean values for geographic distance. Salinity was clearly expected to covary with distance from the harbor, but the relationship is not 
strictly linear. Where salinity was below $1 \mathrm{ppt}$, which it was in $36 \%$ of all sites, there is not a significant relationship between salinity and distance, suggesting that the expected covariation derived from the salinity gradient is greatly diminished in these inland reaches.

Salinity, which has been shown to be an important factor controlling diatom distribution within estuarine ecosystems (Snoejis 1994; Underwood et al. 1998; Frankovich et al. 2006; Wachnicka et al. 2010), was the variable most strongly related to assemblage composition across the watershed. Within each catchment inflow, however, environmental variables differed in the strength of their correlation with assemblage dissimilarity and tended to differ in the order of dominant controls. The covariation of salinity with other variables makes it difficult to evaluate the relative influence of each variable on assemblages independently (Thornton et al. 2002); by sampling across a large spatial gradient that encompassed the freshwater reaches in each river where covariation is diminished, some of these relationships can begin to be teased apart. Nitrogen, which is the limiting nutrient in this watershed, particularly during the dry season (Montgomery et al. 1991; Morrison et al. 1998; Heil et al. 2007), did not significantly correlate with assemblage differences in any region of the watershed, which could be due to relatively low extant concentrations throughout the watershed. TP concentrations were significantly related to compositional dissimilarity in the Myakka River region and the watershed as a whole, and TP in conjunction with $\mathrm{pH}$ and $\mathrm{TC}$ had a lesser but still significant relationship with community structure in the Peace River. It is not surprising that TP was related to assemblage structure in the Peace River because it had elevated TP concentrations compared to the other regions. It is somewhat surprising however, that TP 
had an even stronger correlation with assemblage composition in the Myakka River, where concentrations were lower. The stronger correlation suggests that TP has a stronger relative control on diatom assemblages in the Myakka River than it does in the Peace River, where taxa may be regionally adapted to higher concentrations. All measured variables in the Peace River were significantly correlated with assemblage dissimilarity except for TN, while in the Myakka River only TP, salinity, conductivity, and distance were correlated with assemblage dissimilarity; relationships between Myakka River assemblages and TN, TC, and $\mathrm{pH}$ were not significant.

Estuarine diatom assemblages have complex spatial dynamics. Previous studies have demonstrated that different diatom assemblages can be found in similar environmental conditions across estuarine and salt marsh habitats (e.g. Sullivan 1978 and 1982; Navarro and Torres 1987), which is consistent with my findings in the Charlotte Harbor watershed. The notion that micro-organisms should be cosmopolitan across tolerable conditions (Baas-Becking 1934) has been challenged by evidence of endemism and spatial limitation in diatoms (Kociolek and Spaulding 2000; Telford et al. 2006; Vanormelingen et al. 2008). Kociolek and Spaulding (2000) suggested that historical landscape factors have a greater effect on modern-day diatom assemblage patterns than does dispersal capacity. My results appear to support this idea, in that the upstream reaches of the Peace and Caloosahatchee Rivers did not differ significantly in environmental characteristics among sites but the diatom assemblages were significantly different $(\mathrm{R}=0.83, \mathrm{p}<0.001$; Table 2$)$. In a contiguous watershed where dispersal should not be limited, similar assemblages should occur where environmental differences are not substantial. 
While difficult to quantify, the difference in the hydrological history of these two upstream areas may explain the dissimilar diatom assemblages, or it may contribute additional environmental controls not measured; for example, sediment grain size was not evaluated in this study but can influence diatom distribution and can be altered through anthropogenic activity such as the mining that occurred in the Peace River (Cahoon et al. 1999). Similarly, Sullivan (1978 and 1982) found elevation, which was poorly correlated with other variables, explained most of the variability in diatom assemblage similarity across Gulf Coast salt marshes (most likely due to dessication regimes, which were not a factor for my study sites). Although it seems unlikely that factors like hydrodynamic energy play a significant role in driving assemblage composition in these upstream reaches during the dry season, as flow drops to nearly zero (Hammett 1988), it is possible that they are important during other seasons and could be important at other sites.

Weighted averaging inference models

The WA-PLS models based on the diatom optima predictions were strong for the variables of interest, particularly salinity $\left(\mathrm{R}^{2}=0.96\right)$. This diatom-based inference value for salinity was slightly higher, but comparable to others generated previously for other regions, including the southeastern coast of Florida $\left(\mathrm{R}^{2}=0.91\right.$; Gaiser et al. 2005), as well as lakes of the Great Plains region $\left(\mathrm{R}^{2}=0.91\right.$; Fritz et al. 1991), and this value was nearly identical to one generated for Florida Bay at Florida's southern tip that also covered a broad salinity gradient $\left(\mathrm{R}^{2}=0.97\right.$; Wachnicka et al. 2010). The prediction error in the salinity estimation model is quite low (RMSEP $=0.1)$, supporting salinity as 
the primary controlling variable across the watershed even though other variables have differing influences in different regions. Therefore, a transfer function for salinity provides a reliable tool for quantitative predictions of salinity values across the watershed and for paleoecological reconstructions from diatoms preserved in sediment cores. The distance model was also strong $\left(\mathrm{R}^{2}=0.93, \mathrm{RMSEP}=1.6\right)$ but significantly correlated with salinity. Employed in concert, these models could provide useful insights into historic sea level position and predictions about sea level rise.

Nutrient models were also strong enough to provide useful inferences. In almost all cases, the nutrient models were stronger within regional catchments than in the watershed as a whole, suggesting that different regions respond to nutrient gradients in different ways. Regionality in transfer function strength has interesting implications for water management strategies because of the scope of the watershed. For example, models to predict phosphorus concentration using diatom assemblages from the Peace River do not apply well to the watershed as a whole because they over- or under-estimate some values along the gradient, but they do show a strong ability to predict conditions in the Peace River. Within-region strength could be an indication that the salinity gradient is a confounding effect on nutrient models on the larger spatial scale, but in the smaller river reaches nutrient models can be powerful. Regional inference models are limited by their relatively small sample size (the Peace River, the largest river subset, contained only 16 sites), but additional sampling could further refine the predictive models and provide valuable information for managing each catchment individually.

This study provides evidence that different environmental characteristics of freshwater inflows to an estuary generate distinct diatom assemblages that can be used to 
characterize regional differences and the spatial patterns of environmental gradients across the watershed. Results from this study demonstrate that diatoms are excellent indicators of the relationships between the interacting influences of salinity and nutrient gradients in estuarine ecosystems. As changes in freshwater flow result from climate change and/or human alterations to hydrologic regimes, understanding the nature of environmental changes on different spatial scales will be increasingly important to predict ecosystem responses. These models provide a powerful tool for quantifying these changes independent of direct measurements, allowing for interpretation of environmental changes not only across spatial gradients but also through time; the ability to infer conditions about periods prior to and throughout anthropogenic impacts will help to inform water quality management goals, particularly at the sub-regional scale.

\section{Acknowledgments}

Financial support for this study was provided by the Cristina Menendez Fellowship administered by the Southeast Environmental Research Center at Florida International University in conjunction with the Miccosukee Tribe. The research was developed in collaboration with the Florida Coastal Everglades Long-Term Ecological Research Program under National Science Foundation Grants No. DBI-0620409 and DEB-1237517. This is contribution number 643 from the Southeast Environmental Research Center at Florida International University. I would like to thank my advisor, Dr. Evelyn Gaiser, for direction and assistance with field collections; Sylvia Lee, Franco Tobias, and Rafael Travieso for laboratory assistance and thoughtful comments on the 
manuscript; and family and friends who volunteered assistance with field collections, including Paul Nodine, Patricia Frankenberger, Mara Woosley, and Timothy Loyd. I would also like to thank Dr. Sherri Cooper and an anonymous reviewer for their detailed and helpful comments. 
Table 1. Analysis of similarity (ANOSIM) comparing regions by a) diatom assemblage composition, and b) environmental measurements. ${ }^{*}$ Significantly different at $\mathrm{p}<0.001 ;{ }^{*}$ significantly different at $\mathrm{p}<0.05$.

\begin{tabular}{lccc}
\hline Assemblage composition & & & \\
\hline a. & Harbor & Myakka River & Peace River \\
Myakka River & $0.27^{*}$ & & \\
Peace River & $0.58^{* *}$ & $0.24^{*}$ & \\
Caloosahatchee River & $0.56^{* *}$ & $0.24^{*}$ & $0.22^{*}$ \\
\hline Environmental variables & & & \\
\hline b. & Harbor & Myakka River & Peace River \\
Myakka River & 0.06 & & \\
Peace River & $0.47^{* *}$ & 0.09 & \\
Caloosahatchee River & $0.69^{* *}$ & $0.58^{* *}$ & $0.20^{*}$ \\
\hline
\end{tabular}

Table 2. Analysis of similarity (ANOSIM) comparing diatom assemblages in a) upstream river reaches, b) downstream river reaches, and environmental characteristics in c) upstream river reaches, and d) downstream river reaches. ${ }^{*}$ Significantly different at $\mathrm{p}<0.001 ; *$ significantly different at $\mathrm{p}<0.05$.

\begin{tabular}{|c|c|c|}
\hline \multicolumn{3}{|c|}{ Assemblage composition upstream } \\
\hline a. & Myakka River & Peace River \\
\hline Peace River & $0.50^{*}$ & \\
\hline Caloosahatchee River & 0.35 & $0.83 * *$ \\
\hline \multicolumn{3}{|c|}{ Assemblage composition downstream } \\
\hline b. & Myakka River & Peace River \\
\hline Peace River & 0.14 & \\
\hline Caloosahatchee River & $0.31 *$ & $0.24 *$ \\
\hline \multicolumn{3}{|c|}{ Environmental variables upstream } \\
\hline c. & Myakka River & Peace River \\
\hline Peace River & $0.80 *$ & \\
\hline Caloosahatchee River & $0.94 *$ & 0.17 \\
\hline \multicolumn{3}{|c|}{ Environmental variables downstream } \\
\hline$\overline{\mathrm{d}}$. & Myakka River & Peace River \\
\hline Peace River & $0.52 *$ & \\
\hline Caloosahatchee River & $0.83^{*}$ & $0.80^{*}$ \\
\hline
\end{tabular}


Table 3. Mean relative abundance of the most abundant taxa in site assemblages grouped by region. Taxa that comprise at least $5 \%$ mean relative abundance in a region are shown.

\begin{tabular}{|c|c|c|c|c|c|}
\hline & $\begin{array}{c}\text { Whole } \\
\text { watershed } \\
\end{array}$ & $\begin{array}{c}\text { Caloosahatchee } \\
\text { River }\end{array}$ & $\begin{array}{c}\text { Myakka } \\
\text { River }\end{array}$ & $\begin{array}{l}\text { Peace } \\
\text { River }\end{array}$ & Harbor \\
\hline Taxon & \multicolumn{5}{|c|}{ Mean relative abundance in site assemblages $(\%)$} \\
\hline Catenula adhaerens & 12 & 11 & 13 & 11 & 12 \\
\hline Staurosirella martyii & 7 & 14 & 3 & 10 & 0 \\
\hline Opephora pacifica & 6 & 2 & 1 & 1 & 17 \\
\hline Planothidium delicatulun & 6 & 13 & 5 & 6 & 5 \\
\hline Amphicocconeis disculoides & 5 & 1 & 9 & 2 & 9 \\
\hline Staurosirella dubia & 5 & 2 & 7 & 10 & 2 \\
\hline Achnanthes lanceolata & 4 & 11 & 1 & 4 & 0 \\
\hline Cocconeis euglypta & 3 & 2 & 1 & 6 & 1 \\
\hline Staurosira construens var. venter & 3 & 0 & 7 & 6 & 0 \\
\hline Fragilaria sopotensis & 2 & 0 & 2 & 5 & 0 \\
\hline Hyalodiscus scoticus & 2 & 0 & 7 & 2 & 0 \\
\hline Navicula cf. abunda & 2 & 5 & 2 & 1 & 2 \\
\hline Dimmeregramma minor & 1 & 0 & 0 & 0 & 5 \\
\hline
\end{tabular}


Table 4. Optima (Opt.) and tolerances (Tol.) for salinity (Sal.), total phosphorus (TP), total nitrogen (TN), and distance (Dist.) for abundant and indicator diatom species. Significant regional indicator species are designated by region (C Caloosahatchee, M Myakka River, P Peace River, H Harbor sites). All are significant at $\mathrm{p}<0.05 ; *$ designates $\mathrm{p}<0.01 ; *$ designates $\mathrm{p}<0.001$.

\begin{tabular}{|c|c|c|c|c|c|c|c|c|c|}
\hline Taxon & $\begin{array}{l}\text { Indicator } \\
\text { for region }\end{array}$ & $\begin{array}{l}\text { Sal } \\
\text { Opt. }\end{array}$ & $\begin{array}{l}\text { (ppt) } \\
\text { Tol. }\end{array}$ & $\begin{array}{l}\mathrm{T} \\
\text { Opt. }\end{array}$ & $\begin{array}{r}(\mu \mathrm{g} / \mathrm{g}) \\
\text { Tol. }\end{array}$ & $\begin{array}{l}\text { TN } \\
\text { Opt. }\end{array}$ & $\begin{array}{c}\text { (mg/g) } \\
\text { Tol. }\end{array}$ & $\begin{array}{l}\text { Dist. } \\
\text { Opt. }\end{array}$ & $\begin{array}{l}(\mathrm{km}) \\
\text { Tol. }\end{array}$ \\
\hline Dimmeregramma minor & & 33.3 & 0.3 & 261 & 3.1 & 0.6 & 1.9 & 22.5 & 2 \\
\hline Cocconeis discrepans & M & 30.5 & 0.3 & 638 & 2.4 & 2.4 & 6.2 & 9.9 & 5.6 \\
\hline Amphora exigua & M & 27.7 & 1 & 361 & 3.1 & 1 & 2.8 & 22 & 1.4 \\
\hline Amphicocconeis disculoides & & 25.7 & 0.8 & 843 & 2.3 & 1.6 & 3.1 & 20.6 & 3.2 \\
\hline Desikaneis gessneri & M & 23.9 & 1.2 & 594 & 3 & 0.9 & 1.8 & 27.8 & 2 \\
\hline Halamphora subholsatica & $\mathrm{H}$ & 23 & 3.7 & 329 & 3.4 & 1.2 & 4.2 & 30.6 & 5.7 \\
\hline Fallacia nyella & $\mathrm{H}^{* *}$ & 22.6 & 1.7 & 518 & 3.8 & 1.1 & 3.1 & 26.4 & 3.9 \\
\hline Amphora pseudoholsatica & $\mathrm{H}$ & 20.8 & 4.3 & 275 & 3.6 & 1.1 & 3.3 & 32.2 & 6.9 \\
\hline Nitzschia coarctata & $\mathrm{M}^{* *}$ & 20.7 & 1.9 & 871 & 2.7 & 1.4 & 2.2 & 28.3 & 1.2 \\
\hline Catenula adhaerens & & 19.3 & 1.2 & 899 & 2.3 & 1.1 & 2.1 & 34.5 & 2 \\
\hline Hyalodiscus scoticus & & 17.7 & 0.8 & 1499 & 1.8 & 1.3 & 2 & 32.5 & 0.3 \\
\hline Navicula cf. abunda & & 12.5 & 4.1 & 629 & 3.6 & 1.7 & 3.4 & 50.4 & 6.1 \\
\hline Nitzschia cf. perindistincta & M & 10.6 & 5 & 1158 & 3.1 & 1.5 & 2.5 & 47.4 & 7.9 \\
\hline Planothidium delicatulun & & 9.7 & 4.9 & 831 & 5 & 0.9 & 2.2 & 53.9 & 6.2 \\
\hline Navicula cf. hamiltonia & $\mathrm{C}^{*}$ & 3.1 & 2.7 & 1372 & 3.9 & 0.9 & 2.3 & 74 & 4.6 \\
\hline Achnanthes laevis & $\mathrm{C}$ & 2.7 & 4.4 & 838 & 7.2 & 1 & 2.4 & 78.9 & 6.3 \\
\hline Cocconeis euglypta & $\mathrm{P}$ & 2.7 & 3.8 & 2653 & 3.6 & 0.9 & 2.9 & 89.8 & 5.7 \\
\hline Staurosira martyi & & 2.4 & 2.8 & 1069 & 5 & 0.7 & 2.4 & 82.7 & 3.5 \\
\hline Staurosirella dubia & $\mathrm{P}$ & 2.2 & 3.6 & 1796 & 4.2 & 0.9 & 2.8 & 79.3 & 4.2 \\
\hline Staurosira construens var. venter & $\mathrm{P}$ & 1.4 & 1.2 & 1693 & 3.6 & 0.9 & 2.8 & 76.4 & 3.7 \\
\hline Cocconeis placentula var. placentula & $\mathrm{P}$ & 0.9 & 1.4 & 2793 & 3.4 & 0.6 & 1.7 & 90.5 & 2.8 \\
\hline Fragilaria sopotensis & $\mathrm{P} * *$ & 0.7 & 0.8 & 3293 & 3.6 & 0.9 & 2.9 & 87.5 & 3.1 \\
\hline Achnanthes lanceolata & & 0.6 & 1 & 524 & 9.4 & 0.8 & 2.3 & 100.1 & 2.5 \\
\hline Navicula capitoradiata & $\mathrm{P} * *$ & 0.6 & 0.5 & 3176 & 4.2 & 1.8 & 3.4 & 109.3 & 2.5 \\
\hline Cocconeis cf. distans & $\mathrm{P} * *$ & 0.5 & 0.8 & 4619 & 1.8 & 0.8 & 3.4 & 109.2 & 1.8 \\
\hline Gomphonema brasiliense & $\mathrm{C}^{*}$ & 0.3 & 0 & 4390 & 4.6 & 0.5 & 2 & 83.4 & 0.4 \\
\hline
\end{tabular}


Table 5. Mean, standard deviation (in parentheses below), and range (in italics below) of environmental variables for each region and for all sites: conductivity (Cond.), salinity (Sal.), total phosphorus (TP), total nitrogen (TN), total carbon (TC), and distance (Dist.) from site in harbor center where sediment cores were collected.

\begin{tabular}{|c|c|c|c|c|c|c|c|}
\hline Sites & Cond. (mS) & Sal. (ppt) & $\mathrm{pH}$ & $\mathrm{TP}(\mu \mathrm{g} / \mathrm{g})$ & TN (mg/g) & TC (mg/g) & Dist. $(\mathrm{km})$ \\
\hline Peace River & $\begin{array}{c}7.0 \\
(10.6) \\
0.3 \text { to } 31.2 \\
\end{array}$ & $\begin{array}{c}4.2 \\
(6.5) \\
0.1 \text { to } 19.4 \\
\end{array}$ & $\begin{array}{c}9.3 \\
(1.3) \\
7.8 \text { to } 11.0 \\
\end{array}$ & $\begin{array}{c}4670 \\
(3869) \\
1016 \text { to } 12995 \\
\end{array}$ & $\begin{array}{c}1.6 \\
(2.9) \\
0 \text { to } 10.3 \\
\end{array}$ & $\begin{array}{c}24.1 \\
(46.3) \\
0.1 \text { to } 176.5\end{array}$ & $\begin{array}{c}86.4 \\
(42.6) \\
29.2 \text { to } 149.1 \\
\end{array}$ \\
\hline $\begin{array}{c}\text { Caloosahatchee } \\
\text { River }\end{array}$ & $\begin{array}{c}13.0 \\
(14.6) \\
0.5 \text { to } 36.6 \\
\end{array}$ & $\begin{array}{c}7.9 \\
(9.1) \\
0.3 \text { to } 23.0\end{array}$ & $\begin{array}{c}9.8 \\
(0.5) \\
8.5 \text { to } 10.6\end{array}$ & $\begin{array}{c}1255 \\
(1835) \\
23 \text { to } 5111 \\
\end{array}$ & $\begin{array}{c}0.3 \\
(0.6) \\
0 \text { to } 1.6\end{array}$ & $\begin{array}{c}13.9 \\
(18.1) \\
2.4 \text { to } 65.9\end{array}$ & $\begin{array}{c}80.1 \\
(24.0) \\
47.1 \text { to } 118.6 \\
\end{array}$ \\
\hline Myakka River & $\begin{array}{c}26.6 \\
(17.6) \\
0.9 \text { to } 45.1 \\
\end{array}$ & $\begin{array}{c}16.7 \\
(11.5) \\
0.4 \text { to } 29.2 \\
\end{array}$ & $\begin{array}{c}8.2 \\
(0.3) \\
7.7 \text { to } 8.6\end{array}$ & $\begin{array}{c}1080 \\
(733) \\
303 \text { to } 2400\end{array}$ & $\begin{array}{c}1.2 \\
(1.0) \\
0 \text { to } 2.4 \\
\end{array}$ & $\begin{array}{c}13.5 \\
(10.4) \\
3.2 \text { to } 34.8 \\
\end{array}$ & $\begin{array}{c}35.0 \\
(10.8) \\
21.4 \text { to } 47.8 \\
\end{array}$ \\
\hline Harbor & $\begin{array}{c}47.9 \\
(6.2) \\
34.9 \text { to } 56.1 \\
\end{array}$ & $\begin{array}{c}31.2 \\
(4.5) \\
21.9 \text { to } 37.2\end{array}$ & $\begin{array}{c}8.4 \\
(0.5) \\
7.9 \text { to } 10.0 \\
\end{array}$ & $\begin{array}{c}591 \\
(607) \\
48 \text { to } 1930 \\
\end{array}$ & $\begin{array}{c}3.0 \\
(7.0) \\
0 \text { to } 26.0 \\
\end{array}$ & $\begin{array}{c}25.9 \\
(45.2) \\
1.3 \text { to } 173.4 \\
\end{array}$ & $\begin{array}{c}19.7 \\
(9.4) \\
0 \text { to } 36.2 \\
\end{array}$ \\
\hline All sites & $\begin{array}{c}23.6 \\
(20.9) \\
0.3 \text { to } 56.1\end{array}$ & $\begin{array}{c}15.0 \\
(13.7) \\
0.1 \text { to } 37.2\end{array}$ & $\begin{array}{c}9.0 \\
(1.0) \\
7.34 \text { to } 11.0\end{array}$ & $\begin{array}{c}2113 \\
(2953) \\
23 \text { to } 12995\end{array}$ & $\begin{array}{c}1.6 \\
(4.1) \\
0 \text { to } 26.0\end{array}$ & $\begin{array}{c}20.3 \\
(36.4) \\
0.1 \text { to } 176.5\end{array}$ & $\begin{array}{c}58.4 \\
(40.4) \\
0.0 \text { to } 149.1\end{array}$ \\
\hline
\end{tabular}


Table 6. Pearson's correlation coefficients of the environmental variables across the Charlotte Harbor watershed: conductivity (Cond.), salinity (Sal.), total phosphorus (TP), total nitrogen (TN), total carbon (TC), and distance (Dist.) from site in harbor center where sediment cores were collected. *Significant correlations at $\alpha<0.05$.

\begin{tabular}{lllllll}
\hline Variables & Cond. $(\mathrm{mS})$ & Sal. $(\mathrm{ppt})$ & $\mathrm{pH}$ & $\mathrm{TP}(\mu \mathrm{g} / \mathrm{g})$ & $\mathrm{TN}(\mathrm{mg} / \mathrm{g})$ & $\mathrm{TC}(\mathrm{mg} / \mathrm{g})$ \\
\hline Cond. $(\mathrm{mS})$ & & & & & \\
Sal. $(\mathrm{ppt})$ & $0.59^{*}$ & & & & \\
$\mathrm{pH}$ & $0.62^{*}$ & $0.57^{*}$ & & & \\
$\mathrm{TP}(\mu \mathrm{g} / \mathrm{g})$ & -0.09 & $-0.48^{*}$ & -0.21 & & \\
$\mathrm{TN}(\mathrm{mg} / \mathrm{g})$ & -0.02 & 0.06 & 0.18 & 0.23 & & \\
$\mathrm{TC}(\mathrm{mg} / \mathrm{g})$ & -0.19 & -0.00 & -0.19 & 0.16 & $0.55^{*}$ & \\
Dist. $(\mathrm{km})$ & $-0.66^{*}$ & $-0.89^{*}$ & $-0.75^{*}$ & $0.43^{*}$ & -0.09 & 0.09
\end{tabular}

Table 7. Pearson's correlation coefficients for each environmental variable with the species ordination. *designates statistical significance at $\mathrm{p}<0.05 ; * *$ denotes statistical significance at $\mathrm{p}<0.001$.

\begin{tabular}{lccccc}
\hline Region & $\begin{array}{c}\text { Whole } \\
\text { watershed }\end{array}$ & $\begin{array}{c}\text { Caloosahatchee } \\
\text { River }\end{array}$ & $\begin{array}{c}\text { Myakka } \\
\text { River }\end{array}$ & $\begin{array}{c}\text { Peace } \\
\text { River }\end{array}$ & Harbor \\
\hline Salinity & $0.89^{* *}$ & $0.64^{*}$ & $0.96^{* *}$ & $0.74^{*}$ & 0.52 \\
Distance & $0.88^{* *}$ & 0.54 & $0.95^{*}$ & $0.89^{* *}$ & 0.30 \\
TP & $0.41^{*}$ & 0.44 & $0.80^{*}$ & $0.56^{*}$ & 0.45 \\
TN & 0.25 & 0.54 & 0.36 & 0.40 & 0.53 \\
pH & $0.60^{* *}$ & 0.05 & 0.67 & $0.80^{* *}$ & 0.49 \\
TC & 0.07 & $0.67^{*}$ & 0.36 & $0.55^{*}$ & $0.61^{*}$ \\
Conductivity & $0.51^{* *}$ & 0.42 & $0.97^{* *}$ & $0.51^{*}$ & 0.31
\end{tabular}


Table 8. Three strongest correlations of combinations of variables with species dissimilarity matrices when a) all environmental variables are included, and b) with salinity, distance, and conductivity excluded: Salinity (S), distance (D), conductivity (C), total phosphorus (TP), total nitrogen (TN), total carbon (TC). *designates statistically significant correlation at $\mathrm{p}<0.05 ; * *$ denotes statistically significant correlation at $\mathrm{p}<0.01$.

\begin{tabular}{|c|c|c|c|c|c|}
\hline & Whole watershed & Caloosahatchee River & Myakka River & Peace River & Harbor \\
\hline \multirow[t]{2}{*}{ a. } & $\mathrm{S}$ & $\mathrm{S}$ & $\mathrm{C}$ & $\mathrm{S}+\mathrm{D}$ & $\mathrm{pH}$ \\
\hline & $0.69 * *$ & $0.45^{*}$ & $0.92 * *$ & $0.84 * *$ & 0.36 \\
\hline \multirow[t]{4}{*}{$\begin{array}{l}\text { All variables } \\
\text { included }\end{array}$} & $\mathrm{S}+\mathrm{D}$ & $\mathrm{S}+\mathrm{D}$ & $\mathrm{S}+\mathrm{D}+\mathrm{C}$ & $\mathrm{D}$ & $\mathrm{pH}+\mathrm{TC}$ \\
\hline & $0.68 * *$ & $0.43 *$ & $0.90 * *$ & $0.81 * *$ & 0.27 \\
\hline & $\mathrm{S}+\mathrm{D}+\mathrm{C}$ & $\mathrm{S}+\mathrm{TC}$ & $\mathrm{S}+\mathrm{D}+\mathrm{C}+\mathrm{pH}$ & $\mathrm{S}+\mathrm{D}+\mathrm{pH}$ & $\mathrm{S}+\mathrm{pH}+\mathrm{TP}+\mathrm{TC}$ \\
\hline & $0.63 * *$ & $0.36^{*}$ & $0.89 * *$ & $0.81 * *$ & 0.25 \\
\hline \multirow[t]{2}{*}{ b. } & $\mathrm{pH}+\mathrm{TP}+\mathrm{TC}$ & $\mathrm{TC}$ & $\mathrm{TP}$ & $\mathrm{pH}$ & $\mathrm{pH}$ \\
\hline & $0.31 * *$ & 0.16 & $0.68 *$ & $0.59 * *$ & 0.36 \\
\hline \multirow[t]{5}{*}{$\begin{array}{l}\text { S, D, C } \\
\text { excluded }\end{array}$} & $\mathrm{pH}+\mathrm{TP}$ & $\mathrm{TN}+\mathrm{TC}$ & $\mathrm{pH}$ & $\mathrm{pH}+\mathrm{TC}$ & $\mathrm{pH}+\mathrm{TC}$ \\
\hline & $0.30 * *$ & 0.12 & $0.64 *$ & $0.50 * *$ & 0.27 \\
\hline & & & & $\mathrm{pH}+\mathrm{TP}+$ & \\
\hline & $\mathrm{pH}+\mathrm{TC}$ & $\mathrm{pH}+\mathrm{TC}$ & $\mathrm{pH}+\mathrm{TP}$ & $\mathrm{TC}$ & $\mathrm{pH}+\mathrm{TP}+\mathrm{TC}$ \\
\hline & $0.28 * *$ & 0.06 & $0.60 *$ & $0.46^{* *}$ & 0.22 \\
\hline
\end{tabular}


Fig. 1. Map showing location of study sites in Charlotte Harbor, Florida, and three major river inflows.

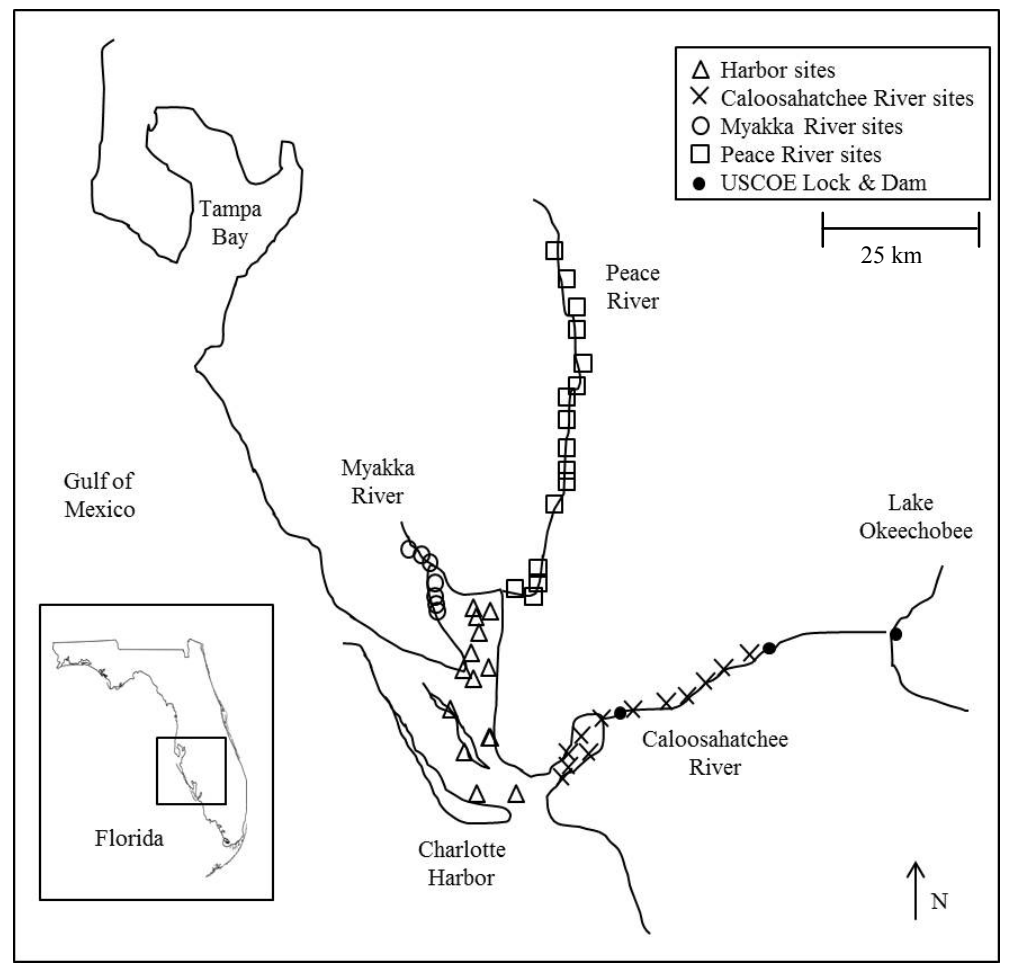


Fig. 2. Nonmetric multidimensional scaling ordination diagrams based on Bray-Curtis similarity in diatom composition of a) the whole Charlotte Harbor watershed dataset, b) Caloosahatchee River sites, c) Myakka River sites, d) Peace River sites, and e) Harbor sites. Overlaid trajectories show the magnitude and direction of the correlation of the species ordination with environmental variables: salinity (SAL), conductivity (COND), distance from the Harbor center (DIST), total phosphorus (TP), total nitrogen (TN), total carbon (TC), and pH. Each diagram is oriented with salinity aligned on the horizontal axis.
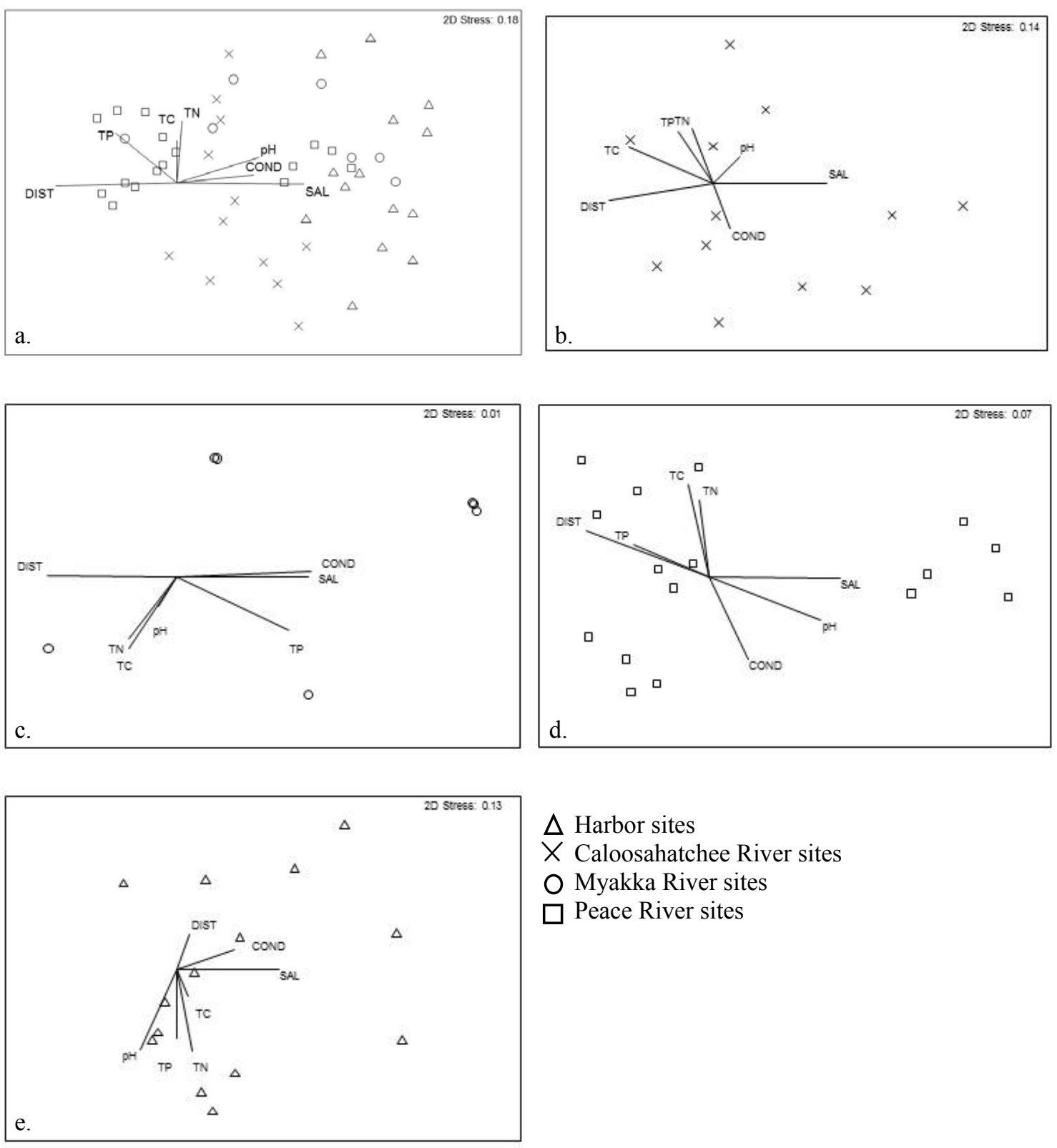

$\triangle$ Harbor sites

$X$ Caloosahatchee River sites

O Myakka River sites

$\square$ Peace River sites 
Fig. 3. Plots of observed vs. diatom predicted a) salinity, b) distance, c) total nitrogen, and d) total phosphorus using weighted averaging partial least squares regression with cross validation on the dataset of all Charlotte Harbor watershed sites.
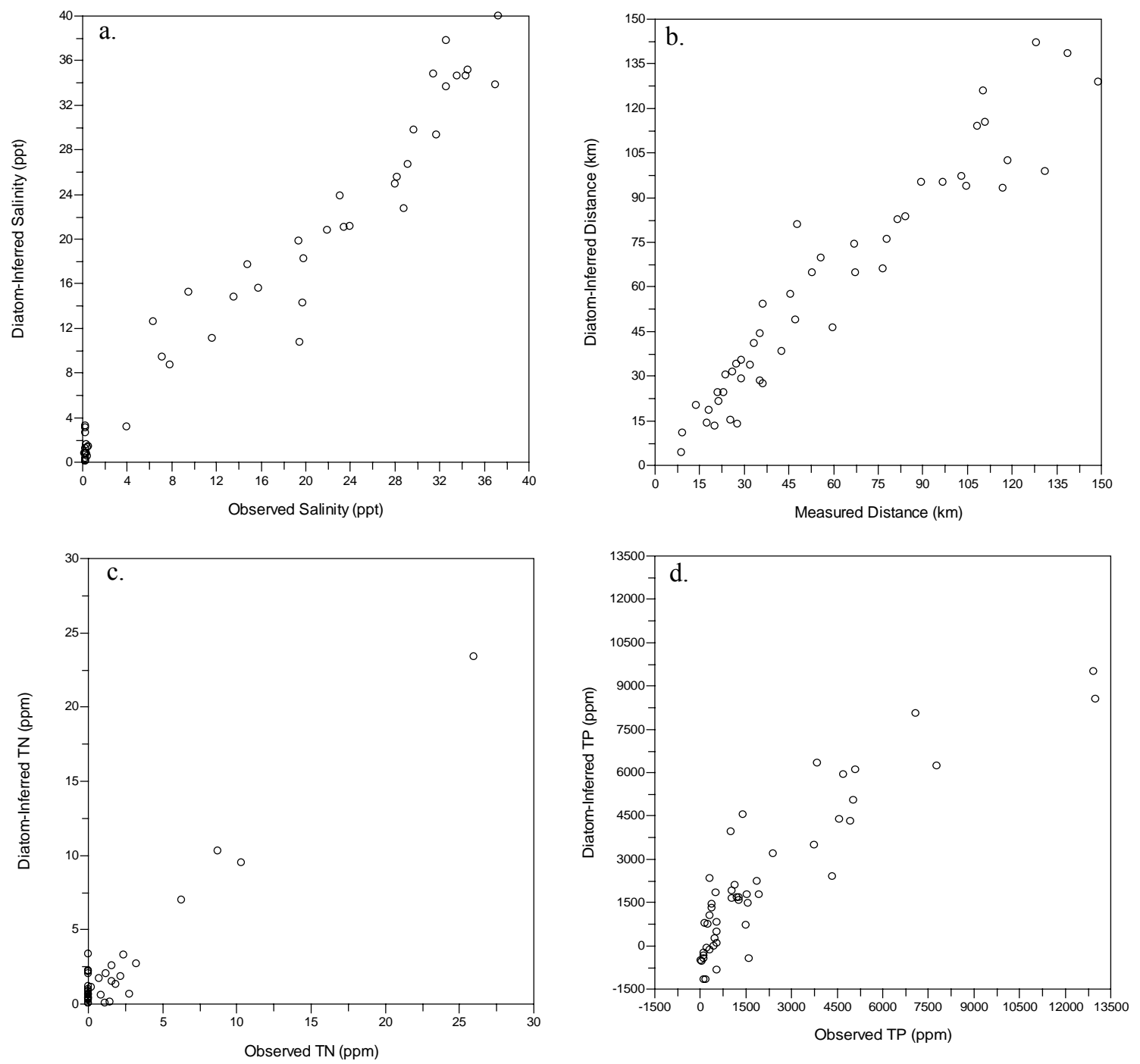


\section{References}

Anderson, D., P. Glibert, and J. Burkholder. 2002. Harmful algal blooms and eutrophication: Nutrient sources, composition, and consequences. Estuaries 25: 704-726.

Armitage, A.R., T.A. Frankovich, J.W. Fourqurean. 2006. Variable responses within epiphytic and benthic microalgal communities to nutrient enrichment. Hydrobiologia 569: 423-435

Baas-Becking, L.G.M. 1934. Geobiologie of inleiding tot de milieukunde. The Hague, the Netherlands: W.P. Van Stockum \& Zoon (in Dutch).

Battarbee, R.W. 1986. Diatom analysis. In B.E. Berglund (Editor), Handbook of Holocene palaeoecology and palaeohydrology. Caldwell: Blackburn, 527-570.

Battarbee, R.W., D.F. Charles, S.S. Dixit, and I. Renberg. 1999. Diatoms as indicators of surface water acidity. In E.F. Stoermer and J.P. Smol (Editors), The Diatoms: Applications for the Environmental and Earth Sciences. Cambridge: Cambridge University Press, pp. 85-127.

Birks, H.J.B. 1995. Quantitative paleoenvironmental reconstructions. In D. Maddy and J.S. Brew (Editors), Statistical modeling of quaternary science data. Technical guide no. 5. Cambridge: Quarternary Research Association, pp. 161-236.

Birks, H.J.B. 1998. Numerical tools in paleolimnology - Progress, potentialities, and problems. Journal of Paleolimnology 20: 307-332.

Cahoon, L.B., J.E. Nearhoof, and C.L. Tilton. 1999. Sediment grain size effect on benthic microalgal biomass in shallow aquatic ecosystems. Estuaries 22: 735-741.

Camp, Dresser, and McKee, Inc. 1998. The study of seasonal and spatial patterns of hypoxia in Upper Charlotte Harbor. Final Report to Surface Water Improvement and Management Section. Record Number QH 541.5 E8 S68. Tampa: Southwest Florida Water Management District.

Chamberlain, R.H. and P.H. Doering. 1998. Freshwater inflow to the Caloosahatchee Estuary and the resource-based method for evaluation. Charlotte Harbor National Estuary Program Technical Report No. 98-02. Punta Gorda: Proceedings of the Charlotte Harbor Public Conference and Technical Symposium.

Clarke, K.R., and R.N. Gorley. 2006. Primer v6: user manual/tutorial. Plymouth: Primer-E Ltd.

Clarke, K.R., and W.M. Warwick. 2001. Change in marine communities: An approach to statistical analysis and interpretation. Plymouth: Primer-E Ltd. 
Cooper, S.R. 1995. Diatoms in sediment cores from the mesohaline Chesapeake Bay, U.S.A. Diatom Research 10: 39-89.

Cooper, S.R. 1999. Estuarine paleoenvironmental reconstructions using diatoms. In E.F. Stoermer and J.P. Smol (Editors), The Diatoms: Applications for the Environmental and Earth Sciences, $1^{\text {st }}$ edition ed., pp. 352-373.

Cooper, S.R. 2000. The History of Water Quality in North Carolina Estuarine Waters as Documented in the Stratigraphic Record. Report 2000-327. Raleigh: University of North Carolina Water Resources Research Institute.

Cooper, S., E. Gaiser, and A. Wachnicka. 2010. Estuarine paleoenvironmental reconstructions using diatoms. In E.F. Stoermer and J.P. Smol (Editors), The Diatoms: Applications for the Environmental and Earth Sciences, $2^{\text {nd }}$ edition. Cambridge: Cambridge University Press, pp. 324-345.

Cottenie, K. 2005. Integrating environmental and spatial processes in ecological community dynamics. Ecology Letters 8: 1175-82.

Craig, J.K., and S.H. Bosman. 2013. Small spatial scale variation in fish assemblage structure in the vicinity of the northwestern Gulf of Mexico hypoxic zone. Estuaries and Coasts 36: 268-285.

Cremer, H., F. Sangiorgi, F. Wagner-Cremer, V. McGee, A.F. Lotter, and H. Visscher. 2007. Diatoms (Bacillariophyceae) and dinoflagellate cysts (Dinophyceae) from Rookery Bay, Florida, U.S.A. Caribbean Journal of Science 43: 23-58.

Day, J.W., C.A.S. Hall, W.M. Kemp, and A. Yanez-Arancibia. 1989. Estuarine Ecology. New York: John Wiley.

Dorsey, T., and R. Barry. 1990. Myakka River. In D. Marth and M. Marth (Editors), The Rivers of Florida. Sarasota: Pineapple Press, Inc., pp.83-86.

Fisher, D.C., and M. Oppenheimer. 1991. Atmospheric Nitrogen Deposition and the Chesapeake Bay Estuary. Ambio 20: 102-108.

Foged, N. 1984. Freshwater and littoral diatoms from Cuba. Bibliotheca Diatomologica 5: $1-243$.

Frankovich, T.A., E. Gaiser, J.C. Zieman, and A.H. Wachnicka. 2006. Spatial and temporal distributions of epiphytic diatoms growing on Thalassia testudinum Banks ex König: Relationships to water quality. Hydrobiologia 569: 259-271. 
Fritz, S.C., S. Juggins, R.W. Battarbee and D.R. Engstrom. 1991. Reconstruction of past changes in salinity and climate using a diatom-based transfer function. Nature 352: 706708.

Fritz, S.C., B.F. Cumming, F. Gasse and K.R. Laird. 2010. Diatoms as indicators of hydrologic and climatic change in saline lakes. In E.F. Stoermer and J.P. Smol (Editors), The Diatoms: Applications for the Environmental and Earth Sciences, $2^{\text {nd }}$ edition. Cambridge: Cambridge University Press, pp. 186-208.

Gaiser, E.E., T.E. Philippi, and B.E. Taylor. 1998. Distribution of diatoms among intermittent ponds on the Atlantic Coastal Plain: development of a model to predict drought periodicity from surface-sediment assemblages. Journal of Paleolimnology 20: 71-90.

Gaiser, E.E., A. Wachnicka, P. Ruiz, F.A Tobias, and M.S. Ross. 2005. Diatoms indicators of ecosystem change in coastal wetlands. In S. Bortone (Editor), Estuarine Indicators. Boca Raton: CRC, pp. 127-144.

Gaiser. E.E., J.H. Richards, J.C. Trexler, R.D. Jones, and D.L. Childers. 2006. Periphyton responses to eutrophication in the Florida Everglades: Cross-system patterns of structural and compositional change. Limnology and Oceanography 51: 617-630.

Garcia, M. 2003. Observations on the diatom genus Fallacia (Bacillariophyta) from southern Brazilian sandy beaches. Nova Hedwigia 77: 309-330.

Glibert P.M., J. Harrison, C. Heil, S. Seitzinger. 2006. Escalating worldwide use of urea a global change contributing to coastal eutrophication. Biogeochemistry 77: 441-463.

Grunwald. M. 2006. The Swamp: The Everglades, Florida, and the Politics of Paradise. New York: Simon \& Schuster.

Guccione, M.J. 1995. Indirect response of the Peace River, Florida, to episodic sea-level change. Journal of Coastal Research 11: 637-650.

Hammett, K.M. 1988. Land use, water use, streamflow and water-quality characteristics of the Charlotte Harbor inflow area, Florida. Record Number QH 541 U526. Tampa: Southwest Florida Water Management District.

Haubois, A.-G., F. Sylvestre, J.-M. Guarini, P. Richard, and G.F. Blanchard. 2005. Spatio-temporal structure of the epipelic diatom assemblage from an intertidal mudflat in Marennes- Oléron Bay, France. Estuarine, Coastal and Shelf Science 64: 385-394.

Heil, C.A., M. Revilla, P.M. Glibert, and S. Murasko. 2007. Nutrient quality drives differential phytoplankton community composition on the southwest Florida shelf. Limnology and Oceanography 52: 1067-1078. 
Hein, M.K., B.M. Winsborough, and M.J. Sullivan. 2008. Bacillariophyta (Diatoms) of the Bahamas. Iconographia Diatomologica 19: 1-300.

Hendey, N.I. 1964. An introductory account of the smaller algae of British coastal waters, Part V. Bacillariophyceae. In Fisheries Investigations (Series IV). London: Great Britain Ministry of Agriculture.

Huvane, J.K. 2002. Modern diatom distributions in Florida Bay: A preliminary analysis. In J.W. Porter and K.G. Porter (Editors), The Everglades, Florida Bay, and coral reefs of the Florida Keys: An ecosystem sourcebook. Boca Raton: CRC, pp. 479-493.

Juggins, S. 2011. C2 data analysis v. 1.7.2 software for ecological and palaeoecological data analysis and visualization. Newcastle-upon-Tyne: University of Newcastle.

Juggins, S. 2013. Quantitative reconstructions in palaeolimnology: new paradigm or sick science? Quaternary Science Reviews 64: 20-32.

Kim, T., Y.P. Sheng, and K. Park. 2010. Modeling water quality and hypoxia dynamics in Upper Charlotte Harbor, Florida, U.S.A. during 2000. Estuarine, Coastal and Shelf Science 90: 250-263.

Kociolek, J.P., and S.A. Spaulding. 2000. Freshwater diatom biogeography. Nova Hedwigia 71: 223-241.

Kruskal, J.B., and M. Wish. 1978. Multidimensional scaling. In J.L. Sullivan and R.G. Niemi (Editors), Quantitative applications in social sciences series 11, Sage University Series, vol. 92. Beverly Hills: Sage, 1-91.

Lane, G. Jr. 1990. Caloosahatchee River. In D. Marth and M. Marth (Editors), The Rivers of Florida. Sarasota: Pineapple Press, Inc., pp. 41-44.

Mallin, M., H. Paerl, J. Rudek, and P. Bates. 1993. Regulation of estuarine primary production by watershed rainfall and river flow. Marine Ecology Progress Series 93: 199-203.

Manoylov, K.M., E.A. Morales, and E.F. Stoermer. 2003. Staurosira stevensonii sp. nov. (Bacillariophyta), a new taxon from Florida, USA. European Journal of Phycology 38: $65-71$.

Martin, D.F., and Y.S. Kim. 1977. Long term Peace River characteristics as a measure of a phosphate slime spill impact. Water Research 11: 963-970.

McCune, B., and J.B. Grace, with a contribution from D.L. Urban. 2002. Analysis of ecological communities. Gleneden Beach: MjM Software Design. 
McCune, B., and M.J. Mefford. 1999. PC-ORD. Multivariate analysis of ecological data, version 4. Gleneden Beach: MJM Software Design.

McPherson, B.F., and R.L. Miller. 1990. Nutrient distribution and variability in the Charlotte Harbor estuarine system, Florida. Paper No. 89077 of the Water Resources Bulletin. Journal of the American Water Resources Association 26: 67-80.

McPherson, B.F., R.L. Miller, and E.E. Emmons. 1990. Phytoplankton productivity and biomass in the Charlotte Harbor estuarine system, Florida. Paper No. 90027 of the Water Resources Bulletin. Journal of the American Water Resources Association 26: 787-800.

McVoy, C.W., W.P. Said, J. Obeysekera, J. Van Arman, and T. Dreschel. 2011. Landscapes and Hydrology of the Predrainage Everglades. Gainesville: University Press of Florida.

Montgomery, R.T., B.F. McPherson, and E.E. Emmons. 1991. Effects of nitrogen and phosphorus additions on phytoplankton productivity and chlorophyll a in a subtropical estuary, Charlotte Harbor, Florida. U.S. Geological Survey Water Resources Investigation Report 91-4077. Tallahassee: Florida Department of Environmental Protection.

Morales, E.A. 2002. Studies in selected fragilarioid diatoms of potential indicator value from Florida (USA) with notes on the genus Opephora Petit (Bacillariophyceae). Limnologica - Ecology and Management of Inland Waters 32: 102-113.

Morales, E.A. 2005. Observations of the morphology of some known and new fragilarioid diatoms (Bacillariophyceae) from rivers in the USA. Phycological Research 53: 113-133.

Morrison, G., R. Montgomery, A. Squires, R. Starks, E. DeHaven, and J. Ott. 1998. Nutrient, chlorophyll and dissolved oxygen concentrations in Charlotte Harbor: Existing conditions and long-term trends. In S,F. Treat (Editor), Charlotte Harbor National Estuary Program Technical Report No. 98-02. Punta Gorda: Proceedings of the Charlotte Harbor Public Conference and Technical Symposium, pp. 201-218.

Navarro, J.N. and R. Torres. 1987. Distribution and community structure of marine diatoms associated with mangrove prop roots in the Indian River, Florida, U.S.A. Nova Hedwigia 45: 101-112.

Nixon, S.W. 1995. Coastal marine eutrophication: A definition, social causes, and future concerns. Ophelia 41: 199-219.

Noss, R.F. 2011. Between the devil and the deep blue sea: Florida's unenviable position with respect to sea level rise. Climatic Change 107: 1-16. 
O’Donnell, B. 1990. Peace River. In D. Marth and M. Marth (Editors), The Rivers of Florida. Sarasota: Pineapple Press, Inc., pp. 51-54.

Paerl, H.W. 1995. Coastal eutrophication in relation to atmospheric nitrogen deposition: Current perspectives. Ophelia 41: 237-259.

Paerl, H.W. 2006. Assessing and managing nutrient-enhanced eutrophication in estuarine and coastal waters: Interactive effects of human and climatic perturbations. Ecological Engineering 26: 40-54.

Pan, Y., R.J. Stevenson, B.H. Hill, and A.T. Herlihy. 2000. Ecoregions and benthic diatom assemblages in Mid-Atlantic Highlands streams, USA. Journal of the North American Benthological Society 19: 518-540.

Parsons, M., Q. Dortch, R. Turner, and N. Rabalais. 1999. Salinity history of coastal marshes reconstructed from diatom remains. Estuaries and Coasts 22: 1078-1089.

Peragallo, H., and M. Peragallo. 1908. In M.J. Tempere (Editor), Diatomees de France, 2. Grez-sur-Loing: Micrographe-Editeur.

Perillo, G.M.E. 1995. Geomorphology and Sedimentology of Estuaries: An Introduction. In G.M.E. Perillo (Editor), Geomorphology and Sedimentology of Estuaries. Developments in Sedimentology 53. Amsterdam: Elsevier Science, pp. 1-16.

Pierce, R.H., D.L. Wetzel, and E.D. Estevez. 2004. Charlotte Harbor Initiative: Assessing the ecological health of Southwest Florida's Charlotte Harbor estuary. Ecotoxicology 13: 275-284.

Rabalais, N. N., R.J. Díaz, L.A. Levin, R.E. Turner, D. Gilbert, and J. Zhang. 2010. Dynamics and distribution of natural and human-caused hypoxia. Biogeosciences 7: 585619.

Reid, M. and R. Ogden. 2009. Factors affecting diatom distribution in floodplain lakes of the southeast Murray Basin, Australia, and implications for palaeolimnological studies. Journal of Paleolimnology 41: 453-470.

Ross, M.S., J.J. O'Brien, G. Ford, K. Zhang, and A. Morkill. 2009. Disturbance and the rising tide: the challenge of biodiversity management on low-island ecosystems. Frontiers in Ecology and the Environment 7: 471-478.

Saha, A.K., S. Saha, J. Sadle, J. Jiang, M.S. Ross, R.M. Price, L.S.L. Sternberg, and K.S. Wendelberger. 2011. Sea level rise and South Florida coastal forests. Climatic Change 107: 81-108. 
Smol, J.P., and B.F. Cumming. 2000. Tracking long-term changes in climate using algal indicators in lake sediments. Journal of Phycology 36: 986-1011.

Snoejis, P. 1994. Distribution of epiphytic diatom species composition, diversity, and biomass on different macroalgal hosts along seasonal and salinity gradients in the Baltic Sea. Diatom Research 9: 189-211.

Soininen, J., R. Paavola, and T. Muotka. 2004. Benthic diatom communities in boreal streams: community structure in relation to environmental and spatial gradients.

Ecography 27: 330-342.

SFWMD. 2008. Lower Charlotte Harbor Surface Water Improvement \& Management Plan. West Palm Beach: South Florida Water Management District.

Stevens, P.W, D.A. Blewett, and J.P. Casey. 2006. Short-term effects of a low dissolved oxygen event on estuarine fish assemblages following the passage of hurricane Charley. Estuaries and Coasts 29: 997-1003.

Stevenson, R.J., Y. Pan, and H. Van Dam. 2010. Assessing environmental conditions in rivers and streams with diatoms. In E.F. Stoermer and J.P. Smol (Editors), The Diatoms: Applications for the Environmental and Earth Sciences, $2^{\text {nd }}$ edition. Cambridge: Cambridge University Press, pp. 57-85.

Stoermer, E.F., N.A. Andresen, and C.L. Schelske. 1992. Diatom succession in the recent sediments of Lake Okeechobee, Florida, USA. Diatom Research 7: 367-386.

Sullivan, M.J. 1978. Diatom community structure: taxonomic and statistical analyses of a Mississippi salt marsh. Journal of Phycology 14: 468-475.

Sullivan, M.J. 1982. Distribution of edaphic diatoms in a Mississippi salt marsh: a canonical correlation analysis. Journal of Phycology 18: 130-133.

Telford, R.J., V. Vandvik, and H.J.B. Birks. 2006. Dispersal limitations matter for microbial morphospecies. Science 19: 1015.

Ter Braak, C.J.E., S. Juggins, H.J.B. Birks, and H. Van der Voet. 1993. Weighted averaging partial least squares regression (WA-PLS): definition and comparison with other methods for species environment calibration. In G.R. Patil and C.R. Rao (Editors), Multivariate environmental statistics. Amsterdam: North-Holland, pp. 525-560.

Therriault, J.-C. and M. Levasseur. 1986. Freshwater runoff control of the spatiotemporal distribution of phytoplankton in the lower St. Lawrence Estuary (Canada). In S. Skreslet (Editor), The Role of Freshwater Outflow in Coastal Marine Ecosystems, NATO AS1 Series G, Vol. 7. Berlin: Springer-Verlag, 251-260. 
Thornton, D.C.O., L.F. Dong, G.J.C. Underwood, and D.B Nedwell. 2002. Factors affecting microphytobenthic biomass, species composition and production in the Colne estuary (UK). Aquatic Microbial Ecology 27: 285-300.

Tomasko, D.A., C. Anastasiou, and C. Kovach. 2006. Dissolved oxygen dynamics in Charlotte Harbor and its contributing watershed, in response to Hurricanes Charley, Frances, and Jeanne - Impacts and recovery. Estuaries and Coasts 29: 932-938.

Turner, R.E., N.N. Rabalais, B. Fry, N. Atilla, C.S. Milan, J.M. Lee, C. Normandeau, T.A. Oswald, E.M. Swenson, and D.A. Tomasko. 2006. Paleo-indicators and water quality change in the Charlotte Harbor estuary (Florida). Limnology and Oceanography 51: $518-533$.

Underwood, G.J., C. Phillips, and J.K. Saunders. 1998. Distribution of estuarine benthic diatom species along salinity and nutrient gradients. European Journal of Phycology 33: 173-183.

Vanormelingen, P., E. Verleyen, and W. Vyverman. 2008. The diversity and distribution of diatoms: from cosmopolitanism to narrow endemism. Biodiversity and Conservation 17: 393-405.

Van Soelen, E.E., E.I. Lammertsma, H. Cremer, T.H. Donders, F. Sangiorgi, G.R. Brooks, R.A. Larson, J.S. Sinninghe Damste, F. Wagner-Cremer, and G.J. Reichart. 2010. Late Holocene sea-level rise in Tampa Bay: Integrated reconstruction using biomarkers, pollen, organic-walled dinoflagellate cysts, and diatoms. Estuarine, Coastal, and Shelf Science 86: 216-224.

Van Soelen, E.E., G.R. Brooks, R.A. Larson, J.S. Sinninghe Damste, and G.J. Reichart. 2012. Mid- to late-Holocene coastal environmental changes in southwest Florida, USA. The Holocene 22: 929-938.

Wachnicka, A., E.E. Gaiser, L. Collins, T.A. Frankovich, J. Boyer. 2010. Distribution of diatoms and development of diatom-based models for inferring salinity and nutrient concentrations in Florida Bay and adjacent coastal wetlands of South Florida (USA). Estuaries and Coasts 33: 1080-1098.

Wachnicka, A., and E.E. Gaiser. 2011. Ecology and distribution of diatoms in Biscayne Bay, Florida (USA): Implications for bioassessment and paleoenvironmental studies. Ecological Indicators 11: 622-632.

Wiseman, W.J. Jr., N.N. Rabalais, M.J. Dagg, and T.E. Whitledge. 1999. Nutrient Enhanced Coastal Ocean Productivity in the Northern Gulf of Mexico -- Understanding the Effects of Nutrients on a Coastal Ecosystem. Decision Analysis Series No. 14. Silver Spring: NOAA Coastal Ocean Program. 
Witkowski, A., H. Lange-Bertalot, and D. Metzeltin. 2000. Diatom flora of marine coasts. I. Iconographia Diatomologica 7: 1-925.

Zhang, J.-Z., C.R. Kelble, C.J. Fischer, and L. Moore. 2009. Hurricane Katrina induced nutrient runoff from an agricultural area to coastal waters in Biscayne Bay, Florida. Estuarine, Coastal, and Shelf Science 84: 209-218. 


\section{SEASONAL DIFFERENCES AND RESPONSE TO A TROPICAL STORM REFLECTED IN DIATOM ASSEMBLAGE CHANGES IN A SOUTHWEST FLORIDA WATERSHED}

\section{Abstract}

The dynamic nature of estuarine ecosystems can make it difficult to differentiate changes that result from slow and regular fluctuations from those driven by more erratic pulse events such as severe storms. Diatom assemblages respond rapidly to changing environmental conditions and can characterize variability on multiple time scales. The climate of south Florida features a strong and regular seasonal hydrological pattern distinguished by wet summers and dry winters and is also frequently affected by tropical cyclones. I examined diatom assemblage patterns and environmental changes across the Charlotte Harbor, Florida, watershed to identify differences between the wet and dry seasons and changes that occurred following Tropical Storm Debby in 2012, to understand patterns of response to changing salinity and nutrient concentrations on different time scales. Indicator taxa were identified that were significantly affiliated with each season and post-storm conditions. Diatom assemblages across the watershed were relatively stable between the wet and dry seasons, and dissimilarity among them decreased following the tropical storm. The reduction in sample dispersion following the storm was more pronounced when major drainage areas of the watershed were examined separately, and assemblages in each sub-basin correlated with environmental parameters with varying strength at different times. The indicator taxa and reduction in dispersion 
among assemblages may provide reliable signals that will enable detection of intense storm activity prior to anthropogenic impacts using sediment records, allowing for better understanding of long-term cycles in a rapidly changing landscape.

\section{Introduction}

Estuaries are highly dynamic on many spatial and temporal scales, changing in response to tides, seasonal hydrological and biological patterns, multidecadal climate and land use changes, as well as erratic storms and other pulse events. Distinguishing effects of unpredictable events from cyclical patterns in such dynamic systems can be challenging but important to predict the influence of altered press and pulse drivers related to climate change (Glasby and Underwood 1996; Angeler and Moreno 2007). Estuarine algal communities respond to and influence estuarine dynamics on all scales, but because they respond relatively quickly to fluctuating drivers, their communities may be useful sentinels of event-based impacts against a changing backdrop of ecosystem dynamics. In aquatic systems, diatom assemblages generally have strong relationships with environmental conditions and rapidly respond to change because of their short generation times (Battarbee 1986). Different diatom assemblages may therefore characterize changes driven by large-scale cycles such as the El Niño Southern Oscillation (Lange et al. 1987; Bull et al. 2000), seasonal changes such as the onset and intensity of monsoon season (Zong et al. 2006), and pulse events like tsunamis and hurricanes (Hemphill-Haley 1996; Parsons 1998). 
Competitive dynamics among diatom taxa are expected to be relatively stable during times of little environmental change, given the homogeneity of the habitat and the similar resource requirements characteristic of the group (Hutchinson 1961). However, environmental homogeneity is dynamic both spatially and temporally, which allows taxa to coexist in diverse assemblages (Hutchinson 1961). As environmental conditions fluctuate, the tolerance ranges and optima of different taxa can be exceeded or shift, causing changes to the relative abundance of diatom taxa present. In the present study, I examine diatom assemblages in a coastal southwest Florida watershed during different seasons and following a tropical storm to investigate the magnitude and direction of change in the assemblages and their relationships with changing environmental conditions.

The climate of south Florida is subject to a strong and regular seasonal contrast in hydrological pattern; wet summers contribute approximately $60 \%$ of yearly precipitation, resulting in large changes in the quantity of freshwater flow to coastal estuaries throughout the year (Flannery et al. 2002). Estuarine organisms, including diatoms, are sensitive to the changing quantity of freshwater inflow, which occurs naturally with the seasons in south Florida but has also been strongly influenced by anthropogenic alteration during early efforts to drain Everglades wetlands for agricultural and urban development (summarized in Grunwald 2006; McVoy et al. 2011). Anthropogenic impacts can reduce ecosystem resilience and hinder recovery from natural disturbances by compounding pressures related to pollution, climate change, and reductions in biodiversity (Gunderson 2000, 2001; Folke et al. 2004). In south Florida, interactions between anthropogenic alteration of nutrient cycles and hydrological regimes appear to have contributed to state 
shifts in Everglades wetlands and Florida Bay, possibly as a result of eroding ecosystem resilience (Fourqurean and Robblee 1999; Gunderson 2001).

Tropical storms and hurricanes (tropical cyclones) also affect Florida during many summer seasons, and occasionally in other months. Accompanying increases in precipitation, nutrient influx from runoff, and mixing because of wind all cause changes to biogeochemical variables that affect phytoplankton communities at varying time scales (Williams et al. 2008; Briceño and Boyer 2010). These extreme events often result in regional flooding and coastal hypoxia in response to the nutrient loading and stratification caused by increased freshwater flow to the estuaries (Tomasko et al. 2006; Stevens et al. 2006; Kim et al. 2010). Tropical cyclones are a natural and important component of global heat distribution, and can be locally important in redistributing nutrients in estuarine habitats (Kang and Trefry 2003; Castañeda-Moya et al. 2010); however, other ecosystem stresses such as pollution and coastal land use can compound the effects of the natural disturbance and alter resilience regimes of ecosystem components (Mallin et al. 1999; Greening et al. 2006).

Documenting changes in diatom assemblages related to regular seasonal cycles and in response to a tropical cyclone in south Florida will help to distinguish patterns of background variability from extreme events, potentially providing a tool for interpretation of change on broad temporal scales. The frequency, intensity, and spatial landfall patterns of tropical cyclones tend to vary with global climate cycles that operate on various time scales (Landsea et al. 1999; Kerr 2000; Goldenberg et al. 2001) and are expected to change with increasing levels of greenhouse gases in the atmosphere (Landsea et al. 1999; Bender et al. 2010). Understanding long-term trends will become 
increasingly difficult in a time of unprecedented climate change (Schiermeier 2011), as changing conditions may disguise or accentuate poorly understood natural cycles (Enfield and Cid-Serrano 2010). If sensitivity to events can be distinguished from other dynamics, then diatom assemblages preserved in sediments may provide records of past event frequencies to improve future forecasts.

To better understand patterns of change through the seasons and following a tropical cyclone in a south Florida watershed, I examined diatom assemblages collected at four different times during 2012: at the height of the dry season, at the end of the wet season, within a few days of a tropical storm's passage, and a few weeks after the storm had passed. With these diatom samples, I investigated three key questions: 1) are there differences between diatom assemblages between the wet and dry seasons in a coastal, hydrologically-dynamic watershed?; 2) do tropical cyclones alter community composition, and if so, on what time scale?; and 3) what are the key environmental drivers of these changes?

\section{Methods}

Study site

Charlotte Harbor, on southwest Florida's Gulf Coast, has a spatially extensive and heterogenous watershed. The harbor has an estuary surface area of approximately 700 $\mathrm{km}^{2}$ (Hammett 1988), and it receives freshwater from three major rivers, the Caloosahatchee, Peace, and Myakka, as well as numerous small creeks and streams. The 
Caloosahatchee River was channelized and connected to Lake Okeechobee as part of an effort to drain the Everglades in the late nineteenth century, and its freshwater flow is now strictly managed through a series of lock and dam structures. The lock that is farthest downstream provides a barrier to tidal action and mixing with marine waters except when it is occasionally breached during severe events, where historically marine influence extended farther upstream (Lane 1990; Chamberlain and Doering 1998). Its drainage basin is dominated by agriculture upstream and coastal urban development downstream. The Peace River is naturally enriched in phosphorus, and its drainage area includes extensive phosphate mining and extraction, as well as agriculture (Pierce et al. 2004). In contrast, the Myakka River is relatively pristine with much of its watershed in permanent conservation land, including expansive freshwater and tidal wetlands (Dorsey and Barry 1990).

A previous study of diatom assemblages and environmental features of this estuary during the dry season revealed compositional, salinity, and nutrient gradients in the harbor and each river (Chapter 2). In order to evaluate assemblage patterns and environmental dynamics at different times throughout the watershed, the present study used a subset of 16 sample sites that capture the full environmental gradient. Sites extend from Charlotte Harbor upstream through the Caloosahatchee, Myakka, and Peace Rivers (Fig. 4). 
Sample collection, preparation, and laboratory analysis

To determine seasonal variability in diatom assemblages, I sampled during the height of the dry season in March 2012 and at the end of the wet season in November 2012. On June 20, a low pressure system formed in the Gulf of Mexico as a result of the confluence of the Inter-Tropical Convergence Zone, an anomalous low-level flow from the Pacific, and a tropical wave (Stewart 2013). It remained in the southeastern portion of the Gulf of Mexico for several days, causing large amounts of rainfall across the Charlotte Harbor watershed. On June 23, the storm developed into Tropical Storm Debby and slowly intensified and moved northeastward, making landfall well north of Charlotte Harbor late on June 26. Although rainfall and flooding were not as severe as in other parts of the state, Tropical Storm Debby generated approximately 5-10 inches of precipitation over parts of the Charlotte Harbor watershed (Kimberlain 2013), and caused minor regional flooding. To evaluate changes that occur quickly following a severe rainfall event, I collected samples between June 28 and July 1 and then sampled again approximately two weeks later, between July 12 and 14, to evaluate changes that occur in response to changing water chemistry conditions following a storm. During the June 28 to July 1 sampling event, there were difficulties with accessibility at four of the 16 sites, three in the Myakka River and one in the Caloosahatchee River, so sampling was not completed; those four sites were sampled at the other three times and the remaining 12 sites were sampled on all four occasions.

Diatoms were collected by towing a 20-micron plankton net through the water column after tossing it from the shoreline three times at each site. Water depths were 
very shallow $(<1 \mathrm{~m})$, so the net made contact with the substrate on each tow, disturbing the sediment. Diatom samples therefore included planktonic, tychoplanktonic, and some benthic taxa. Surface water samples were collected for nutrient analysis using a clean bottle rinsed thoroughly and then filled at each site. Salinity and conductivity were measured at approximately $30 \mathrm{~cm}$ depth in the water column using a YSI multiparameter Sonde.

In the laboratory, diatom samples were cleaned using a series of acid baths following the oxidation technique described by Battarbee (1986) and then diluted until a neutral $\mathrm{pH}$ was achieved. A measured aliquot of 0.01 to $1.0 \mathrm{ml}$ (depending on diatom concentration) of the resulting mixture was removed by calibrated pipette, placed on a coverslip, and dried. Coverslips were then permanently mounted onto glass slides using Naphrax ${ }^{\circledR}$. A minimum of 500 diatom valves were identified from each sample along measured, random transects using a Nikon E4000 light microscope at x1000 magnification. Identification of diatoms was determined by regional and standard diatom taxonomic literature (e.g., Peragallo and Peragallo 1908; Foged 1984; Hendey 1964; Hein et al. 2008; Witkowski et al. 2000). Water samples were analyzed for total phosphorus (TP) with a UV-2101PC Scanning Spectrophotometer, total nitrogen (TN) with an ANTEK 9000 N Nitrogen Analyzer, and total organic carbon (TOC) with a SHIMADZU TOC-L Analyzer by the Southeast Environmental Research Center Nutrient Analysis Laboratory following EPA methods. 


\section{Data analysis}

The abundance of all taxa in each sample was calculated relative to total abundance of diatom valves counted. Taxa occurring in at least three samples with a relative abundance of at least $0.5 \%$ in at least one sample were included for statistical analyses, because inclusion of potentially undersampled taxa can increase noise in the dataset (McCune et al. 2002). Relative abundances were fourth-root transformed to more closely approximate a normal distribution and to downweight the relative importance of very abundant taxa. Indicator species analysis (ISA) was used to identify taxa that were strongly associated with post-storm sampling periods or the wet or dry season on the basis of taxon persistence in the group (in most samples from that group) and exclusivity to that group (not found in most other groups) (McCune et al. 2002). Similarity matrices were created using Bray-Curtis similarity to evaluate diatom assemblage differences among sites.

Environmental variables were transformed using the method that best reduced the skewness for each variable. Conductivity and salinity values were arcsine transformed, TN concentrations were inverse transformed, TP concentrations were inverse square-root transformed, and TOC concentrations were square-root transformed. All environmental data were normalized (mean subtracted and divided by standard deviation) to equalize values to a common scale (Clarke and Warwick 2001). Similarity matrices were created using Euclidean distance to evaluate environmental relationships among sites.

Nonmetric multi-dimensional scaling (NMDS) ordination (Kruskal and Wish 1978) was used to visualize assemblage and environmental patterns among sites at 
different sampling times. After evaluating the stress of ordinations with up to five axes, two-dimensional NMDS was selected to ease interpretability of results, given that stress values did not decrease greatly with additional axes. Stress is a measure of the departure from fit of the sample dissimilarity to distance in the ordination; it tends to decrease with additional axes, as more of the sample variance is represented, but additional dimensions make interpretation increasingly difficult (McCune et al. 2002). Multi-response permutation procedures (MRPP) were used to test for differences among groups observed in the ordination (McCune et al. 2002), and visually-estimated convex hulls were superimposed around groups to ease interpretability. The MRPP analysis provides both a statistical metric $(\mathrm{p}<0.05$ was considered significantly different), and an ecological effect size (A), or group homogeneity as compared to random expectation (McCune et al. 2002). Environmental vectors representing the direction and strength of each variable's correlation with sample differences were also overlaid on the ordinations.

An index of multivariate dispersion (IMD) was calculated to examine the relative variability among assemblages from each sampling event and in each sub-basin. The IMD values contrast the average rank of similarities within groups to provide a metric of dispersion, but do not provide a statistical framework appropriate for testing (Clarke and Warwick 2001). Differences among sampling events were assessed with analysis of similarity (ANOSIM) to determine the relative similarity of diatom assemblages and environmental conditions at each time period. The $\mathrm{R}$ values reported represent the difference of mean ranks of variables and ranges from 0 to 1 with increasing dissimilarity (Clarke and Warwick 2001), and comparisons having a $\mathrm{p}<0.05$ were considered statistically significant. 
Kendall's tau correlation coefficients were calculated representing the rank relationships between each variable and the NMDS ordination of diatom assemblages for each sampling event in each sub-basin. Kendall's tau represents a probability of dependence between non-normally distributed variables (Bolboaca and Jäntschi 2006). These correlations are strictly descriptive, as ordination scores are not independent of one another, violating one of the assumptions that validate a p-value (McCune et al. 2002). Correlations with variables therefore represent relative and interacting effect sizes related to the diatom assemblages, and these range from 1 to -1 , with 0 representing no correlation. The above analyses were all conducted using the software Primer version 6 (Clarke and Gorley 2006) and PC-ORD version 5 (McCune and Mefford 1999).

\section{Results}

Diatom assemblage differences

A total of 254 taxa were identified from all samples, with 176 present in the dry season (March), 169 in the wet season (November), 152 in the days after Tropical Storm Debby (June), and 166 two weeks after the storm passed (July). Species richness and diversity were not significantly different among sampling times. Many of the dominant taxa were prevalent at all sampling times, including Staurosirella martyi (Héribaud) Morales and Manoylov, Staurosirella leptostauron var. dubia (Grunow) Edlund, Fragilaria sopotensis Witkowski \& Lange-Bertalot, Planothidium delicatulum (Kützing) Round and Bukhtiyarova, Catenula adhaerens Mereschkowsky, and Cyclotella cf. 
meneghiniana F.T. Kützing, all of which were in the top ten most abundant taxa at every sampling time.

The NMDS ordinations reflect this taxonomic overlap among sampling times (Fig. 5). While environmental variables showed a distinction between post-storm sampling times and the wet/dry seasons (a storm effect vs. no storm effect dichotomy), diatom assemblages showed a convergence in similarity following the storm and wider dispersion with intermixing among wet and dry season sampling. These differences were quantified using MRPP analysis, which revealed that diatom assemblages were not significantly different between the wet and dry seasons $(\mathrm{p}=0.11 ; \mathrm{A}=0.01)$, but were different between storm effect and no storm effect periods $(\mathrm{p}<0.02 ; \mathrm{A}=0.01)$. The MRPP of environmental characteristics were significantly different between both wet vs. dry season $(\mathrm{p}<0.01 ; \mathrm{A}=0.11)$ and between storm effect and no storm effect periods $(\mathrm{p}<$ $0.01 ; \mathrm{A}=-0.05)$.

Dispersion analysis showed that dissimilarity among diatom assemblages was lower following the storm compared to the seasons with no storm effect, in the whole watershed as well as in each sub-basin (Fig. 6). The biggest differences were in the Myakka River and the Harbor, with index differences of 0.67 and 0.61 , respectively, and the smallest difference occurred when all sites in the watershed were included (difference of 0.19). There was also a relatively small difference in the Caloosahatchee River (0.27) compared to other sub-basins. The IMD for each of the four sampling times shows slightly more complex patterns across the sub-basins (Fig. 7). All sub-basins had the highest dispersion index values in the wet and dry seasons, with lower values following the storm; however, Harbor sites had the lowest dispersion immediately after the storm, 
and dispersion increased two weeks later, while in the Caloosahatchee and Peace Rivers, dispersion decreased immediately after the storm and was further reduced two weeks later. When all sites in the watershed were included, differences in dispersion following the storm and in the wet season were negligible.

The ANOSIM showed that diatom assemblages were significantly different across the watershed between the dry season and the wet season and between the dry season and two weeks following the storm, but not between other sample periods (Table 9). Environmental conditions differed between the dry season and all other sample periods, but there were no significant differences among post-storm samples and the wet season. Indicator species were identified for the wet and dry seasons, as well as for the post-storm sampling events for each sub-basin and in the watershed as a whole; 13 taxa were significant indicators across all sites in the watershed, as well as within at least one of the sub-basins (Table 10).

Relationships with environment

Environmental changes in the watershed through the sampling periods showed different patterns in the sub-basins (Fig. 8). Salinity changes were as expected across the watershed; salinity decreased from the highest values in the dry season to lower values following the storm that were maintained into the wet season. One site in the mid-Peace River had extremely high concentrations of TN in the dry and wet season and showed a dramatic reduction following the storm that persisted for the two weeks after the storm. Other sites across the watershed had highly variable patterns of TN concentration; some 
$\mathrm{TN}$ concentrations decreased from higher dry season values following the storm and then increased again in the wet season, and other sites saw TN concentrations as much as double from dry season levels after the storm and then decreased again in the wet season. Most sites across the watershed had elevated TP concentrations following the storm and maintained comparatively low levels in the dry and wet seasons. The Peace River, which is naturally enriched in TP, had a flashier TP response pattern than the other sub-basins, with concentrations that increased in the days following the storm but dropped dramatically two weeks later and returned to elevated concentrations in the wet season. Most sites across the watershed showed increases in TOC following the storm with relatively low levels in the dry and wet seasons, with the exception of the Caloosahatchee River sites. Most of the Caloosahatchee River sites showed slight decreases in TOC from dry season levels following the storm and highest concentrations in the wet season.

The relative strength of the relationships between the diatom assemblages and these environmental variables shifted among the different sampling times (Fig. 9). Salinity and conductivity maintained a relatively high and stable correlation with the diatom assemblage at each sampling time, but relationships with nutrient concentrations changed. The correlation with TP concentrations increased dramatically in the days following the storm compared to the dry season, quickly declined two weeks later, and fell to near zero (no relationship) in the wet season. The correlation between diatom assemblages and $\mathrm{TN}$ concentrations was highest two weeks after the storm.

Relationships with nutrient concentrations through time also differed among subbasins (Fig. 10). In the Harbor sites, the relationship of the diatom assemblages with TN concentrations was opposite that of salinity and conductivity in the dry season, but 
similar to them at all other times. In the Caloosahatchee River sites, the correlation of assemblages with TN concentration was elevated in the dry season, increased slightly in the days following the storm, and declined to near zero in the wet season, while the relationship with TP concentrations declined to zero following the storm and was relatively strong in the dry and wet seasons. In the Myakka River, the correlation of the assemblages with $\mathrm{TN}$ concentrations changed direction following the storm and then increased in the wet seasons, while the opposite pattern occurred in the relationship with TP concentrations. The Peace River site assemblages had very low correlations with TN concentrations during the dry season and two weeks after the storm, with relatively high correlations in the days after the storm and during the wet season; correlations of diatom assemblages with TP concentrations were strongest following the storm.

\section{Discussion}

Given the strong natural seasonality to south Florida's freshwater flow, I expected that different taxa would dominate at different sampling times; however most of the dominant taxa were persistent at all sampling times, likely because they are cosmopolitan and can tolerate a broad range of conditions. Many of the most abundant taxa have been documented to have relatively broad salinity tolerances (Chapter 2), appearing in Florida rivers (Morales 2002 and 2005) and eastern USA estuaries like the Chesapeake Bay (Cooper 1995) and the Pamlico and Neuse estuaries of North Carolina (Cooper 2000). The persistence of dominant taxa reduced the ability to detect assemblage differences between the dry and wet seasons; the difference was significant in ANOSIM, which 
analyzes rank dissimilarity, but not significant in MRPP, which evaluates average dissimilarity. Less common taxa account for the significant differences among seasons and before and after storms. For example, the indicator species for the periods following the storm were relatively rare (among them, the highest average relative abundance was $2.5 \%$ ) and only one, A. exigua, was also detected during both the dry and wet seasons.

Other indicators for the periods following the storm included Cocconeis speciosa, Navicula phylleptosoma, Nitzschia angularis, and Tabularia gaillonii, which are generally considered cosmopolitan in marine to brackish habitats in the Atlantic, Mediterranean, and Baltic Seas (Witkowski et. al 2000). It is therefore likely that they are also present in the Charlotte Harbor watershed during the dry and wet seasons, but in such small numbers that they were not sampled at those times. If the passage of the storm caused an increase in their abundance, these taxa may provide evidence of past storm activity in sediment records where they are relatively abundant. That these are predominantly benthic taxa may also be an indication that habit is important to poststorm assemblages; diatoms attached to a substrate may be better able to persist following disturbance relative to planktonic taxa (Townsend et al. 1997).

Dry season indicators Nitzschia lanceola and Navicula hagelsteinii are generally associated with strictly marine environments on warmer coasts, but $N$. lanceola also occurs in freshwaters with high ion content (Witkowski et. al 2000). In my study it was a significant dry season indicator for the whole watershed, as well as for the Harbor subbasin. Navicula hagelsteinii has previously been reported in Cuba and other parts of the Caribbean (Navarro 1983; Foged 1984), and was also an indicator for the watershed and the Harbor but not for the river sub-basins, likely because these two taxa occur less 
frequently at the river sites. Wet season indicators include both planktonic and benthic, and marine and freshwater, taxa that are generally associated with pollution or high nutrient content. Cocconeis placentula is an epilithic taxon associated with high nutrients in streams (Jones 1978; Kelly et al. 1995), and members of the planktonic Cyclotella striata complex have been associated with pollution from agriculture in the Mediterranean (Ismael and Dorgham 2003).

Tropical cyclones can be important mechanisms of dispersal and distribution of phytoplankton in shallow subtropical ecosystems (McKinnon et al. 2003). The present study, diatom assemblages across the watershed generally became more similar to one another following the tropical storm, but patterns of recovery were site specific. For example, the NMDS shows that some sites have a similar wet and dry season composition that changes following the storm, while others shift following the storm and continue to diverge into the wet season. There were no consistent regional patterns. Previous studies have documented increased diatom dominance (Delesalle et al. 1993; Son et al. 2007) and diversity (McKinnon et al. 2003) following a tropical cyclone, which suggests that changes in diatom diversity and assemblage composition can provide a reliable signal of tropical cyclone occurrence in some ecosystems.

Diatom assemblage dispersion was lower across the watershed following the storm, and differences were greater when constrained by sub-basin. Evaluating all of the sites in the watershed together therefore dampened the observable effects on dispersion, and interpreting changes on a sub-basin spatial scale may be more relevant for understanding patterns of assemblage change following disturbance. The diminished contrast when all sites were analyzed together was consistent when evaluating storm 
effect (June and July sampling) vs. no storm effect (dry and wet season sampling) periods or comparing all four sample times individually, which provides evidence that the subbasins recover from such a disturbance on different time scales. For example, the Harbor sites returned to pre-storm assemblage dispersion within a couple weeks of the storm; their lowest dispersion values occurred after the storm and were relatively constant at the other three sampling times. In contrast, dispersion in the Caloosahatchee River sites decreased only very slightly in the few days following the storm but continued to decrease and reached their lowest values two weeks following the storm, which may be influenced by the greater physical distance and transport that affect change across those sites, or by management of water flow.

. It appears that a reduction in assemblage dissimilarity following a major storm and comparatively high dispersion during normal seasonal periods, regardless of the hydrological state, is a normal pattern in this watershed. The smallest overall changes in dispersion occurred in the Caloosahatchee River sites, where water flow is highly managed, and were highest in the relatively pristine Myakka River, which raises interesting questions about how management has influenced ecosystem resilience in this watershed. If management practices have dampened the expected response to disturbance, it could have broader impacts for resilience of the greater ecosystem. Effects on trophic systems, for example, have been documented in other studies; an increase in pelagic diatom diversity found following a tropical cyclone off the coast of Australia was coincident with a decrease in copepod diversity and overall increases in zooplankton and larval fish diversity (McKinnon et al. 2003). A change in the response of diatom assemblages, which occur on time scales of a few days, may further affect 
responses in zooplankton and fish assemblages, which occur on longer time scales, thus having cascading effects on the system.

Relationships between the diatom assemblages and the measured suite of potential environmental drivers were complex, both spatially and temporally. On the basis of rank similarity of the measured environmental variables (ANOSIM), conditions during the dry season were significantly different from the three other sampling times, which is not surprising because of the increase in freshwater flow during the other periods. However, NMDS ordination showed that wet and dry season measurements are more similar to each other than to post-storm conditions at almost all sites, whereas diatom assemblages become more similar following the storm. By evaluating the correlation of environmental variables with the diatom assemblages in each sub-basin, it is clear that assemblages relate to different variables at different times, and that these controls vary across the watershed. An examination of the diatom assemblages of the Three Gorge Reservoir in China similarly showed that relationships with nutrient concentrations varied by season and by location within the system, including proximity to the anthropogenically modified portion (Zeng et al. 2006).

The different sub-basins of the Charlotte Harbor watershed provided an excellent opportunity to characterize the variations in environmental controls on diatom assemblages and their relevance to spatial characteristics. Phosphorus, for example, has been shown to have a significant relationship with diatom assemblage differences in the watershed (Chapter 2), but the present study demonstrates that the time and spatial scale of this relationship is important. Throughout the watershed, diatom assemblages had a relatively high correlation $(\sim 0.6)$ with $\mathrm{TP}$ immediately following the storm, but in the 
wet season there was almost no correlation. However subsets of each sub-basin analyzed separately show different trends. The smaller sample size of each of the sub-basins (3 to 5 sites each) reduces the power of the correlations, but interesting patterns are suggested nonetheless. Among the Harbor and Caloosahatchee River sites, the assemblage relationship with TP is low following the storm compared to the dry and wet seasons, exhibiting almost the opposite pattern of the watershed as a whole. Instead, the strongest correlation $(\sim 0.9)$ following the storm in these sub-basins is with $\mathrm{TN}$, which may indicate differences in nutrient limitation related to terrestrial runoff patterns in the watershed. In the Peace River sites, for example, the $\mathrm{N}$ to $\mathrm{P}$ ratio was lowest immediately after the storm and highest two weeks later, which is opposite the pattern of their correlation between the diatom assemblages and TP. The $\mathrm{N}$ to $\mathrm{P}$ ratio was highest in the Harbor in the dry season and lowest in the wet season, while in the Caloosahatchee and Myakka Rivers it was lowest following the storm, which matches the pattern of correlation with TP in the Myakka but not in the Caloosahatchee River.

It is possible that unassessed habitat differences among the sub-basins also contribute to changing relationships with nutrient concentrations, as benthic assemblages associated with different substrate types (such as epilithic, epipsammic, epiphytic, etc.) can respond differently to environmental controls (Soininen and Eloranta 2004). My samples likely included entrained benthic diatoms from a variety of shallow water habitats, so variable responses to nutrients by functional groups were not detected. Habitat characteristics may also affect ecosystem resistance and resilience, because diatoms affixed to substrates may persist following disturbance in greater proportion than 
planktonic taxa (Townsend et al. 1997), which could explain some of the differences in the magnitude of the change across the sampling times in each sub-basin.

Results from the present study provide evidence of the resilience of aquatic ecosystems in this watershed. This hydrologically dynamic system, which exhibits considerable spatio-temporal variation in salinity and nutrient concentrations, supports relatively stable diatom assemblages. Flooding following a tropical cyclone reduces assemblage dispersion on regional scales. As changes in freshwater flow and nutrient influx result from climate change and/or anthropogenic effects, it is important to understand how response regimes are affected by management so that we can make informed decisions that may help to mitigate negative impacts on the ecosystem. My results suggest that the reduction in dispersion of diatom assemblages following the disturbance of a tropical cyclone is a natural occurrence in the watershed that may be dampened with intensive management. The changes in dispersion may therefore provide a tool for interpreting changes on longer time scales, through analysis of diatom assemblages in sediment cores. By identifying periods of lower dispersion that occurred prior to anthropogenic impacts in the watershed, we may be able to identify times of intense storm activity that pre-date modern records, thus providing information that can be used to identify long-term patterns and climate cycles that can improve predictions of future changes. 
Table 9. ANOSIM of diatom assemblage composition (a) and environmental variables (b) between the dry season (March), the days following TS Debby (June), two weeks following TS Debby (July), and the wet season (November). ${ }^{*}$ indicates statistically significant at $\mathrm{p}<0.05$.

\begin{tabular}{lccc}
\hline a. Assemblage composition & March & June & July \\
\hline June & 0.05 & & \\
July & $0.12^{*}$ & 0.02 & \\
November & $0.12^{*}$ & 0.06 & 0.06 \\
\hline b. Environmental variables & & & \\
\hline June & $0.19^{*}$ & & \\
July & $0.14^{*}$ & -0.03 & \\
November & $0.09^{*}$ & 0.08 & 0 \\
\hline
\end{tabular}

Table 10. Indicator species for dry season, wet season, and period following storm that are significant in all sites taken together and at least one sub-basin.

Indicators for dry season Significant in sub-basin(s)

Cocconeis peltoides Hustedt

Navicula hagelsteinii Hustedt Harbor, Caloosahatchee, Peace

Nitzschia lanceola Grunow Harbor

Staurosirella cf. subrobusta Morales

Harbor

Caloosahatchee, Peace

Indicators for wet season

Bacteriastrum cf. elongatum Cleve

Cocconeis placentula var. placentula Ehrenberg

Harbor

Cyclotella cf. striata (Kützing) Grunow

Nitzschia grossestriata Hustedt

Myakka

Harbor

Harbor, Caloosahatchee, Myakka

Indicators for post-tropical storm

\begin{tabular}{lc}
\hline Achnanthes exigua Grunow & Peace \\
Cocconeis speciosa Gregory & Peace \\
Navicula phylleptosoma Lange-Bertalot & Harbor \\
Nitzschia angularis W.Smith & Harbor \\
Tabularia gaillonii (Bory de Saint-Vincent) Bukhtiyarova & Peace
\end{tabular}


Fig. 4. Map showing location of sampling sites across the Charlotte Harbor watershed.

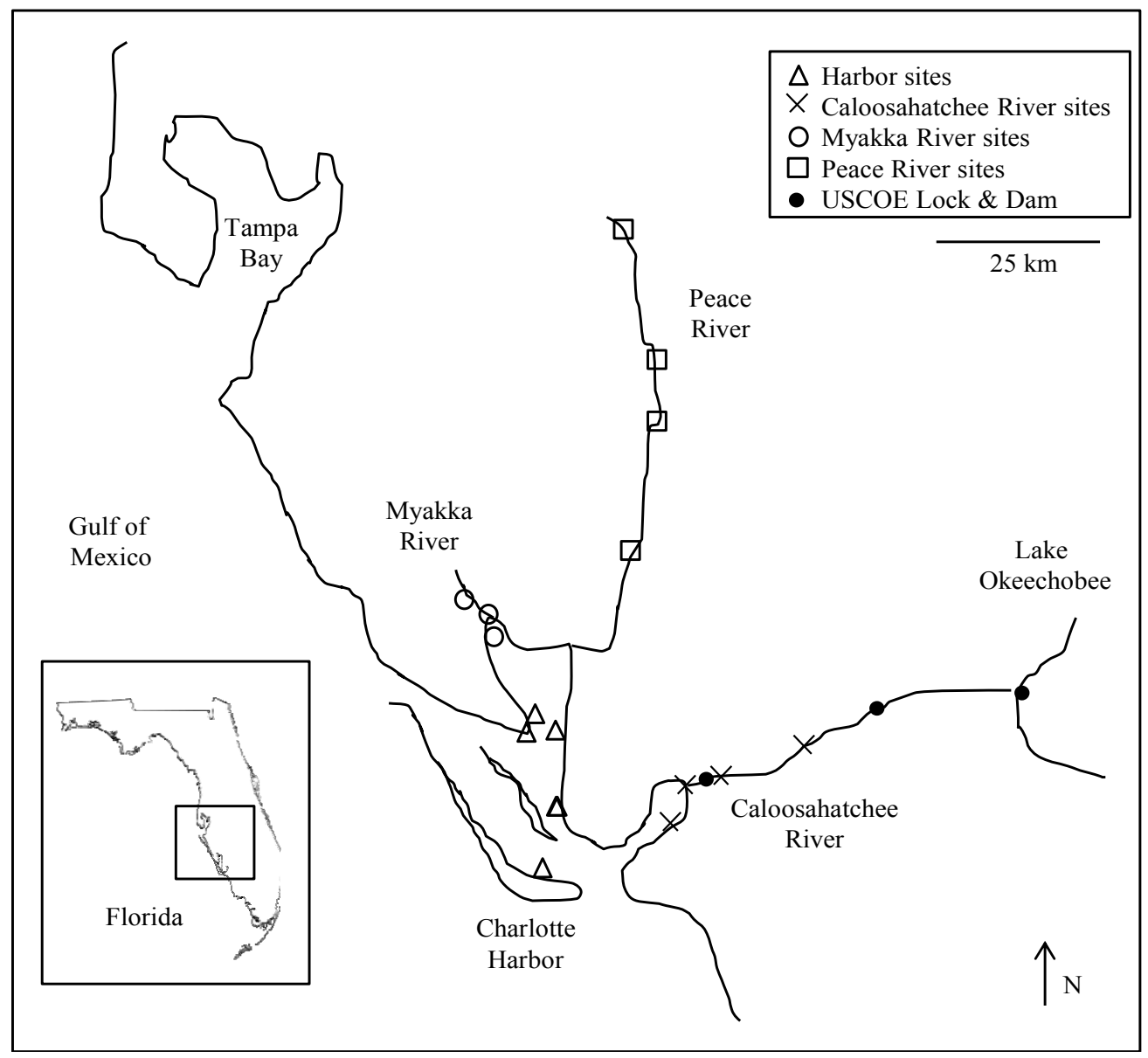


Fig. 5. NMDS ordination biplots showing differences in diatom assemblage composition (a and b) and environmental variables (c and d) for all sites (plotted points) over time. The same ordination is shown in a and b with two overlays: a) solid line surrounding samples from wet and dry seasons and dotted line surrounding samples from the two post-storm sampling events, and $b$ ) vectors showing the magnitude and direction of correlations of environmental variables with diatom assemblage dissimilarity. The ordination of environmental variables is shown with the same two overlays: c) solid line surrounding wet and dry season sampling events and dotted line surrounding the two post-storm sampling events, and d) correlations of environmental variables with the sample dissimilarity among sites.
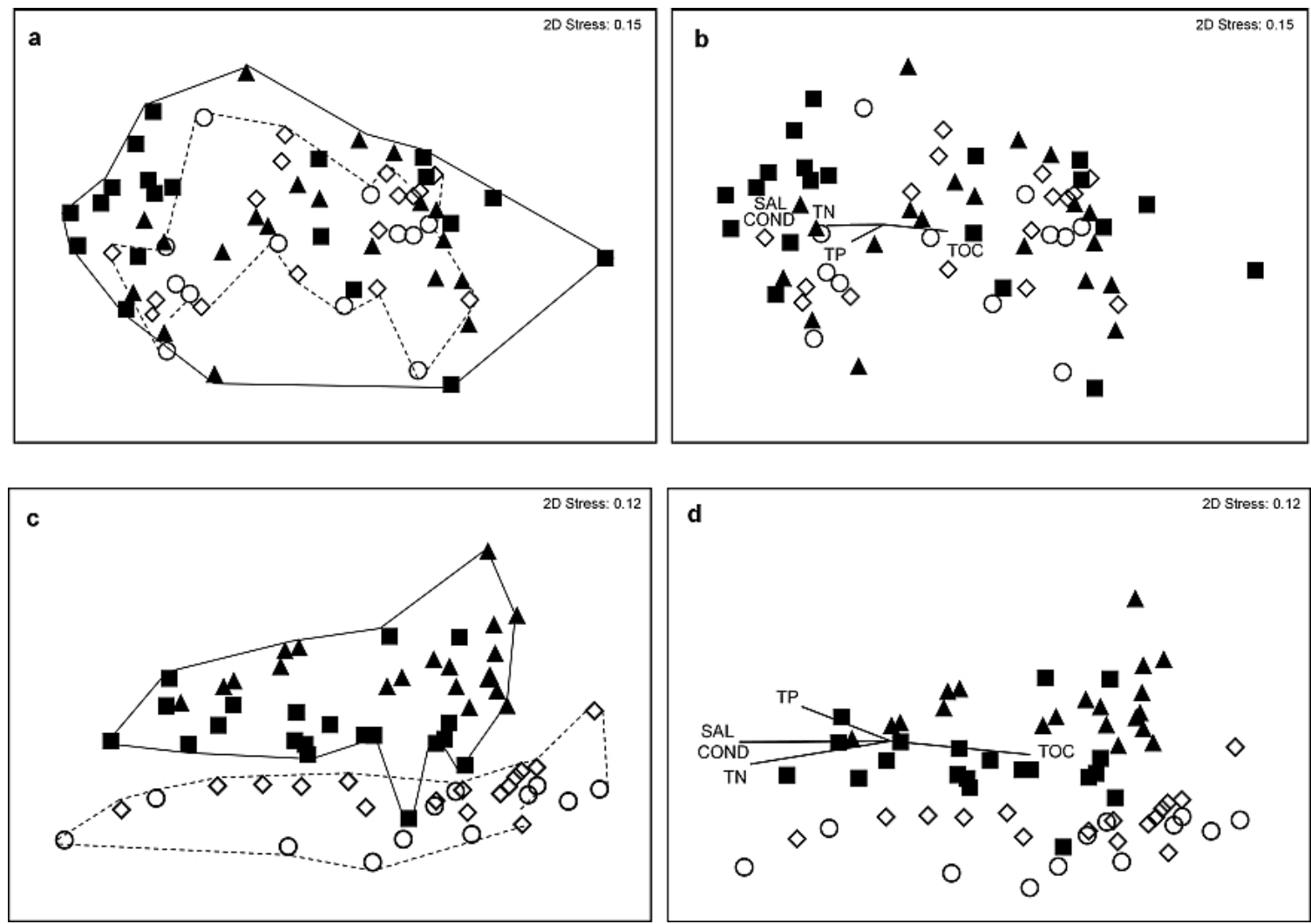

$\begin{array}{ll}\square & \text { Mar } \\ 0 & \text { Jun } \\ \diamond & \text { Jul } \\ \bullet & \text { Nov }\end{array}$


Fig. 6. Bar graph showing the index of multivariate dispersion (IMD) for diatom assemblages in all sites and each sub-basin during the seasons not affected by the storm (light gray) and the sampling period following the storm (dark gray).

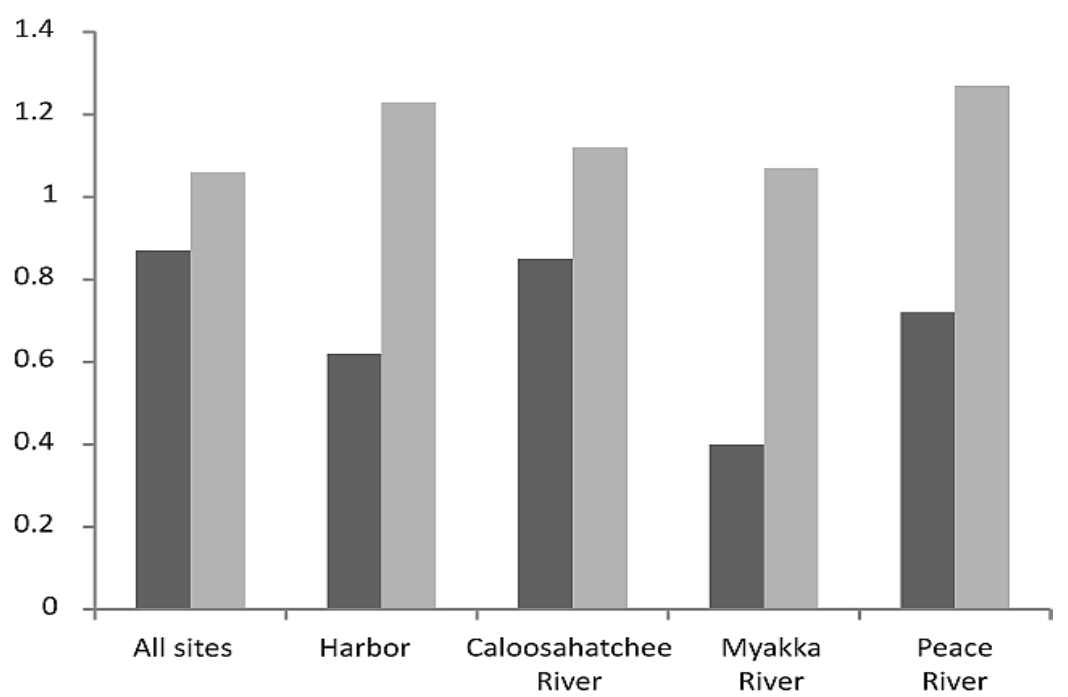


Fig. 7. Bar graphs of the IMD value (number above each bar) for each region at each sampling time: Mar (dry season), Jun (within 4 days after TS Debby), Jul (2 weeks following TS Debby), and Nov (wet season).
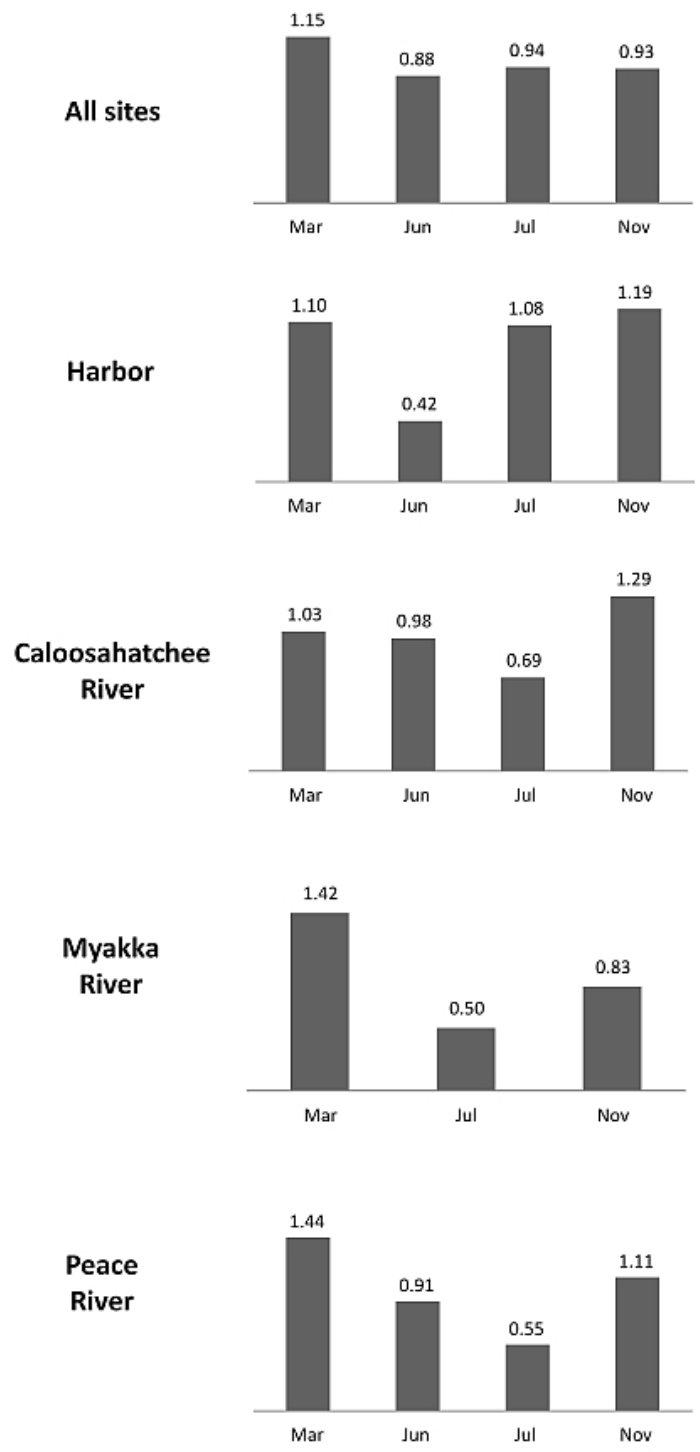
Fig. 8. Plots of environmental changes at each sampling time by region.

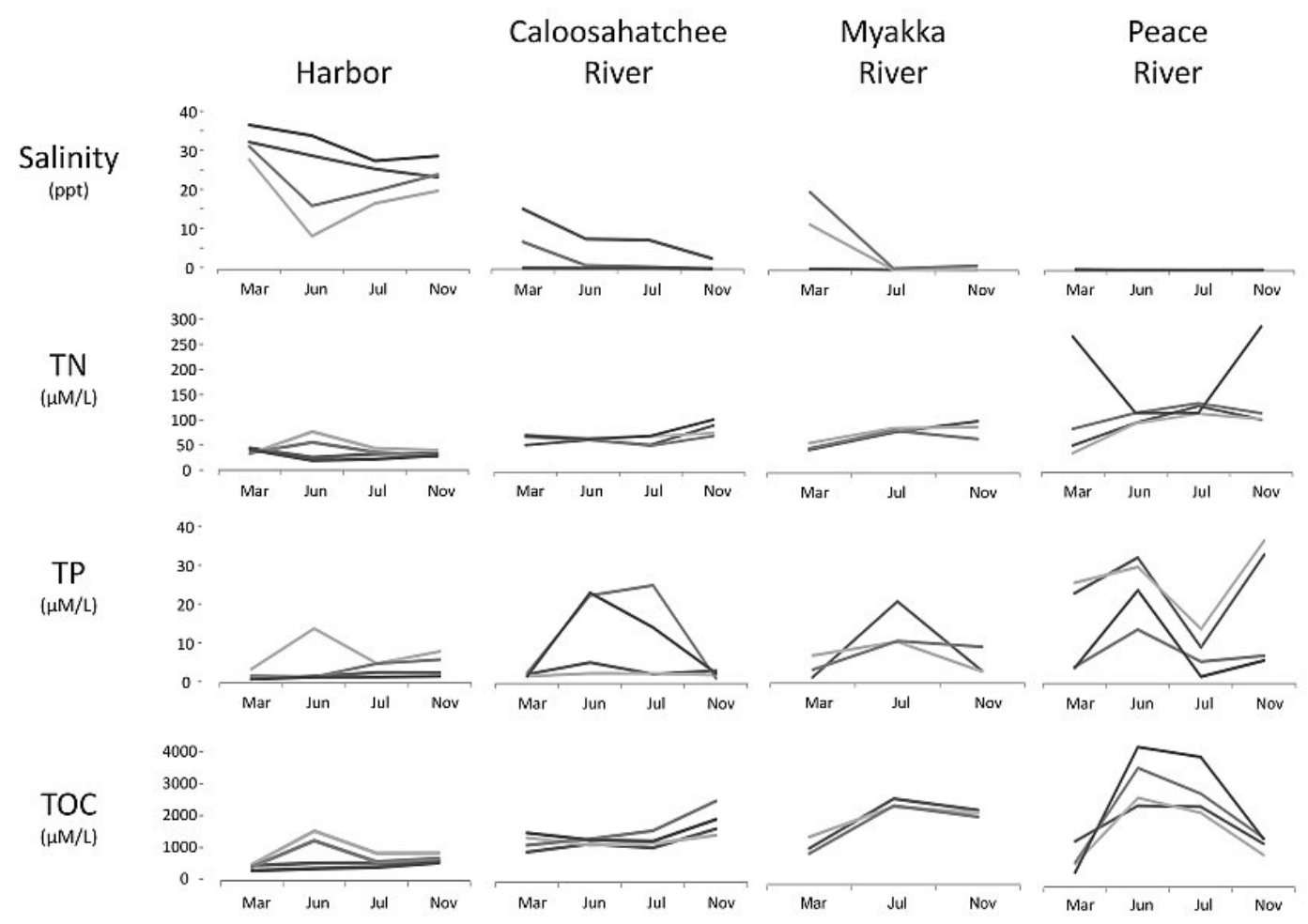

Fig. 9. Kendall's tau correlations of diatom assemblage composition with environmental variables through the seasons. Greater distance from the zero line (no correlation) represents a stronger correlation.

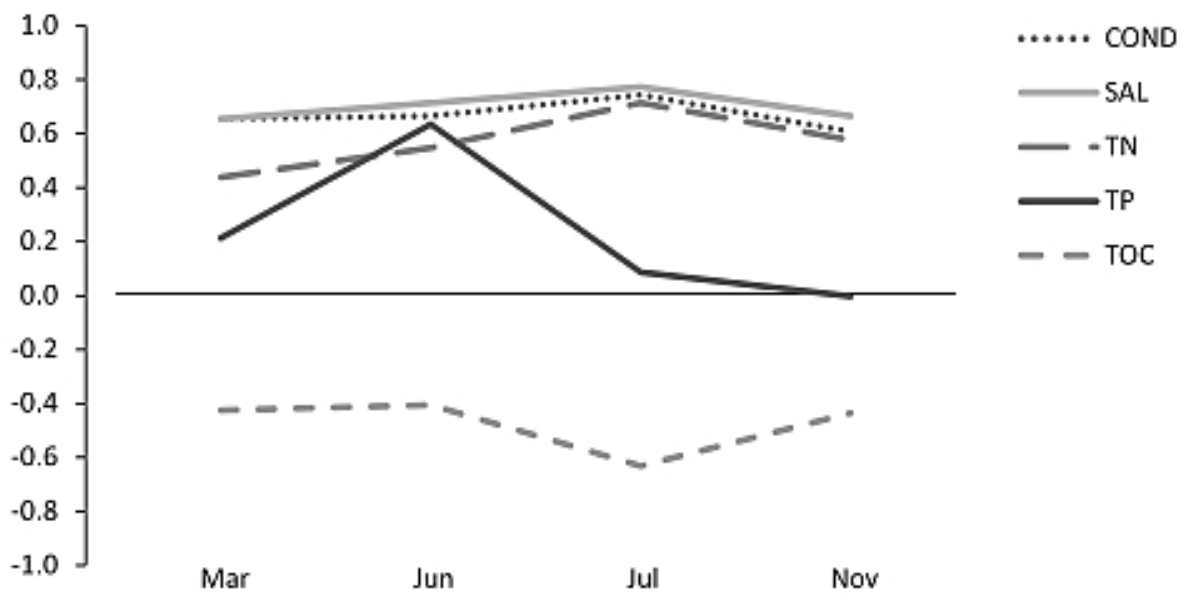


Fig. 10. Kendall's tau correlations of diatom assemblage composition with environmental variables through the seasons in each sub-basin: Harbor sites (a), Caloosahatchee River (b), Myakka River (c), and Peace River (d). Greater distance from the zero line (no correlation) represents a stronger correlation.
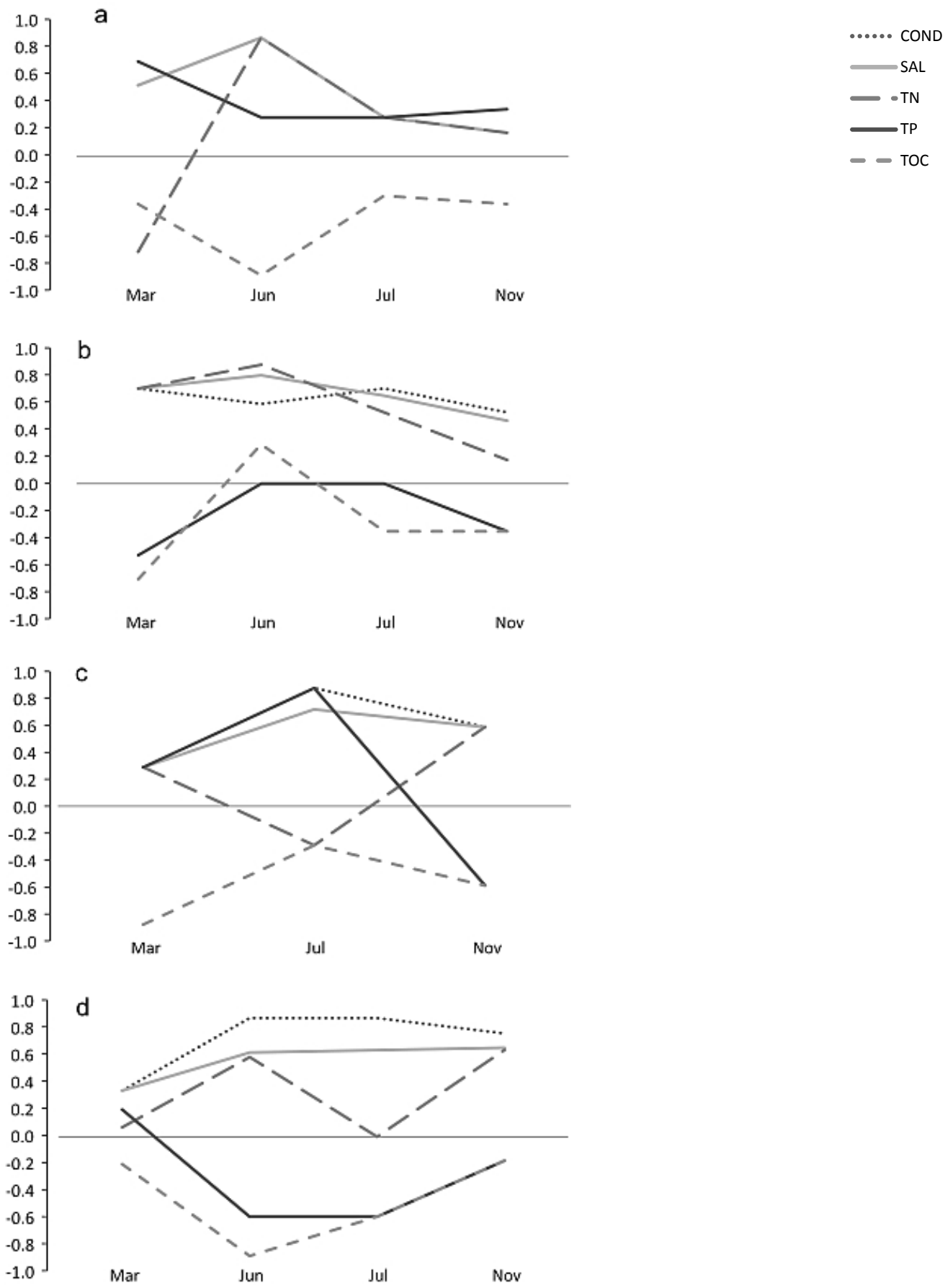


\section{References}

Angeler, D.G. and J.M. Moreno. 2007. Zooplankton Community Resilience after Presstype Anthropogenic Stress in Temporary Ponds. Ecological Applications 17:1105-1115.

Battarbee, R.W. 1986. Diatom analysis. In B.E. Berglund (Editor), Handbook of Holocene palaeoecology and palaeohydrology. Caldwell: Blackburn, 527-570.

Bender, M.A., T.R. Knutson, R.E. Tuleya, J.J. Sirutis, G.A. Vecchi, S.T. Garner and I.M. Held. 2010. Modeled Impact of Anthropogenic Warming on the Frequency of Intense Atlantic Hurricanes. Science 327: 454-458.

Bolboaca, S.D. and L. Jäntschi. 2006. Pearson versus Spearman, Kendall's tau correlation analysis on structure-activity relationships of biologic active compounds. Leonardo Journal of Sciences 9: 179-200.

Briceño, H., and J. Boyer. 2010. Climatic Controls on Phytoplankton Biomass in a Subtropical Estuary, Florida Bay, USA. Estuaries and Coasts 33: 541-553.

Bull, D., A.E.S. Kemp, and G.P. Weedon. 2000. A 160-k.y.-old record of El NinoSouthern Oscillation in marine production and coastal runoff from Santa Barbara Basin, California, USA. Geology 28: 1007-1010.

Castañeda-Moya, E., R.R. Twilley, V.H. Rivera-Monroy, K. Zhang, S.E. Davis III, and M. Ross. 2010. Sediment and Nutrient Deposition Associated with Hurricane Wilma in Mangroves of the Florida Coastal Everglades. Estuaries and Coasts 33: 45-58.

Chamberlain, R.H. and P.H. Doering. 1998. Freshwater inflow to the Caloosahatchee Estuary and the resource-based method for evaluation. Charlotte Harbor National Estuary Program Technical Report No. 98-02. Punta Gorda: Proceedings of the Charlotte Harbor Public Conference and Technical Symposium.

Clarke, K.R., and R.N. Gorley. 2006. Primer v6: user manual/tutorial. Plymouth: Primer-E Ltd.

Clarke, K.R., and W.M. Warwick. 2001. Change in marine communities: An approach to statistical analysis and interpretation. Plymouth: Primer-E Ltd.

Cooper, S.R. 1995. Diatoms in sediment cores from the mesohaline Chesapeake Bay, U.S.A. Diatom Research 10: 39-89.

Cooper, S.R. 2000. The History of Water Quality in North Carolina Estuarine Waters as

Documented in the Stratigraphic Record. Report 2000-327. Raleigh: University of North Carolina Water Resources Research Institute. 
Delesalle B., M. Pichon, M. Frankignoulle, and J.P. Gattuso. 1993. Effects of a cyclone on coral reef phytoplankton biomass, primary production and composition (Moorea Island, French Polynesia). Journal of Plankton Research 15:1413-1423.

Dorsey, T., and R. Barry. 1990. Myakka River. In D. Marth and M. Marth (Editors), The Rivers of Florida. Sarasota: Pineapple Press, Inc., pp.83-86.

Enfield, D.B., and L. Cid-Serrano. 2010. Secular and multidecadal warmings in the North Atlantic and their relationships with major hurricane activity. International Journal of Climatology 30: 174-184.

Flannery, M.S., E.B. Peebles, and R.T. Montgomery. 2002. A percent-of-flow approach for managing reductions of freshwater inflows from unimpounded rivers to Southwest Florida estuaries. Estuaries 25: 1318-1332.

Foged, N. 1984. Freshwater and littoral diatoms from Cuba. Bibliotheca Diatomologica 5: $1-243$.

Folke, C., S. Carpenter, B. Walker, M. Scheffer, T. Elmqvist, L. Gunderson, and C.S. Holling. 2004. Regime Shifts, Resilience, and Biodiversity in Ecosystem Management. Annual Review of Ecology, Evolution, and Systematics 35: 557-581.

Fourqurean, James W. and Michael B. Robblee. 1999. Florida Bay: A history of recent ecological changes. Estuaries 22: 345-357.

Glasby, T.M. and A.J. Underwood. 1996. Sampling to differentiate between pulse and press perturbations. Environmental Monitoring and Assessment 42: 241-252.

Goldenberg, S.B., C.W. Landsea, A.M. Mestas-Nuñez, and W.M. Gray. 2001. The Recent Increase in Atlantic Hurricane Activity: Causes and Implications. Science 293: 474-479.

Greening, H., P. Doering, and C. Corbett. 2006. Hurricane impacts on coastal ecosystems. Estuaries and Coasts 29: 877-879.

Grunwald. M. 2006. The Swamp: The Everglades, Florida, and the Politics of Paradise. New York: Simon \& Schuster.

Gunderson, L.H. 2000. Ecological Resilience in Theory and Application. Annual Review of Ecological Systems 31: 425-439.

Gunderson, L.H. 2001. South Florida: The Reality of Change and the Prospects for Sustainability: Managing surprising ecosystems in southern Florida. Ecological Economics 37: 371-378. 
Hammett, K.M. 1988. Land use, water use, streamflow and water-quality characteristics of the Charlotte Harbor inflow area, Florida. Record Number QH 541 U526. Tampa: Southwest Florida Water Management District.

Hemphill-Haley, E. 1996. Diatoms as an aid in identifying late-Holocene tsunami deposits. The Holocene 6: 439-448.

Hein, M.K., B.M. Winsborough, and M.J. Sullivan. 2008. Bacillariophyta (Diatoms) of the Bahamas. Iconographia Diatomologica 19: 1-300.

Hendey, N.I. 1964. An introductory account of the smaller algae of British coastal waters, Part V. Bacillariophyceae. In Fisheries Investigations (Series IV). London: Great Britain Ministry of Agriculture.

Hutchinson, G. E. 1961. The Paradox of the Plankton. The American Naturalist 95: 137145 .

Ismael, A.A. and M.M. Dorgham. 2003. Ecological indices as a tool for assessing pollution in El-Dekhaila Harbour (Alexandria, Egypt). Oceanologia 45: 121-131.

Jones, J.G. 1978. Spatial variation in epilithic algae in a stony stream (Wilfin Beck) with particular reference to Cocconeis placentula. Freshwater Biology 8: 539-546.

Kang, W.-J. and J.H. Trefry. 2003. Retrospective analysis of the impacts of major hurricanes on sediments in the lower Everglades and Florida Bay. Environmental Geology 44: 771-780.

Kelly, M.G., C.J. Penny, and B.A. Whitton. 1995. Comparative performance of benthic diatom indices used to assess river water quality. Hydrobiologia 302: 179-188.

Kerr, R. A. 2000. A North Atlantic Climate Pacemaker for the Centuries. Science 288: 1984-1985.

Kim, T., Y.P. Sheng, and K. Park. 2010. Modeling water quality and hypoxia dynamics in Upper Charlotte Harbor, Florida, U.S.A. during 2000. Estuarine, Coastal and Shelf Science 90: 250-263.

Kimberlain, T. 2013. Tropical Cyclone Report: Tropical Storm Debby (AL042012) 2327 June 2012. National Hurricane Center. Miami, Florida. http://consejo.bz/weather/2012/pdf/debby.pdf.

Kruskal, J.B., and M. Wish. 1978. Multidimensional scaling. In J.L. Sullivan and R.G. Niemi (Editors), Quantitative applications in social sciences series 11, Sage University Series, vol. 92. Beverly Hills: Sage, 1-91. 
Landsea, C. W., R. A. Pielke, A. M. Mestas-Nuñez, and J. A. Knaff. 1999. Atlantic Basin Hurricanes: Indices of Climatic Changes. Climatic Change 42: 89-129.

Lane, G. Jr. 1990. Caloosahatchee River. In D. Marth and M. Marth (Editors), The Rivers of Florida. Sarasota: Pineapple Press, Inc., pp. 41-44.

Lange, C.B., W.H. Berger, S.K. Burke, R.E. Casey, A. Schimmelmann, A. Soutar, and A.L. Weinheimer. 1987. El Nino in Santa Barbara Basin: Diatom, radiolarian, and foraminiferan responses to the "1983 El Nino" Event. Marine Geology 78: 153-160.

Mallin, M.A., M.H. Posey, G.C. Shank, M.R. McIver, S.H. Ensign, and T.D. Alphin. 1999. Hurrican Effects on Water Quality and Benthos in the Cape Fear Watershed: natural and anthropogenic impacts. Ecological Applications 9:350-362.

McCune, B., and J.B. Grace, with a contribution from D.L. Urban. 2002. Analysis of ecological communities. Gleneden Beach: MjM Software Design.

McCune, B., and M.J. Mefford. 1999. PC-ORD. Multivariate analysis of ecological data, version 4. Gleneden Beach: MJM Software Design.

McKinnon, A.D., M.G. Meekan, J.H. Carleton, M.J. Furnas, S. Duggan, and W. Skirving. 2003. Rapid changes in shelf waters and pelagic communities on the southern Northwest Shelf, Australia, following a tropical cyclone. Continental Shelf Research 23: 93-111.

McVoy, C.W., W.P. Said, J. Obeysekera, J. Van Arman, and T. Dreschel. 2011. Landscapes and Hydrology of the Predrainage Everglades. Gainesville: University Press of Florida.

Morales, E.A. 2002. Studies in selected fragilarioid diatoms of potential indicator value from Florida (USA) with notes on the genus Opephora Petit (Bacillariophyceae). Limnologica - Ecology and Management of Inland Waters 32: 102-113.

Morales, E.A. 2005. Observations of the morphology of some known and new fragilarioid diatoms (Bacillariophyceae) from rivers in the USA. Phycological Research 53: 113-133.

Navarro, J.N. 1983. A Survey of the Marine Diatoms of Puerto Rico VI. Suborder Raphidineae: Family Naviculaceae (Genera Haslea, Mastogloia and Navicula). Botanica Marina 26: 119-136.

Parsons, M. L. 1998. Salt Marsh Sedimentary Record of the Landfall of Hurricane Andrew on the Louisiana Coast: Diatoms and Other Paleoindicators. Journal of Coastal Research 14: 939-950. 
Peragallo, H., and M. Peragallo. 1908. In M.J. Tempere (Editor), Diatomees de France, 2. Grez-sur-Loing: Micrographe-Editeur.

Pierce, R.H., D.L. Wetzel, and E.D. Estevez. 2004. Charlotte Harbor Initiative: Assessing the ecological health of Southwest Florida's Charlotte Harbor estuary. Ecotoxicology 13: 275-284.

Schiermeier, Q. 2011. Can violent hurricanes, floods and droughts be pinned on climate change? Scientists are beginning to say yes. Nature 477: 148-149.

Siqueiros-Beltrones, D., F.O. López-Fuerte, and I. Gárate-Lizárraga. 2005. Structure of Diatom Assemblages Living on Prop Roots of the Red Mangrove (Rhizophora mangle) from the West Coast of Baja California Sur, México. Pacific Science 59: 79-96.

Soininen, J. and P. Eloranta. 2004. Seasonal persistence and stability of diatom communities in rivers: are there habitat specific differences? European Journal of Phycology 39: 153-160.

Son, S., T. Platt, C. Fuentes-Yaco, H. Bouman, E. Devred, Y. Wu, and S. Sathyendranath. 2007. Possible biogeochemical response to the passage of Hurricane Fabian observed by satellites. Journal of Plankton Research 29: 687-697.

Stevens, P.W, D.A. Blewett, and J.P. Casey. 2006. Short-term effects of a low dissolved oxygen event on estuarine fish assemblages following the passage of hurricane Charley. Estuaries and Coasts 29: 997-1003.

Stewart, S.R. 2013. Atlantic Hurricanes 2012: Northeastern United States Devastated by Sandy. Weatherwise 66: 28-39.

Tomasko, D.A., C. Anastasiou, and C. Kovach. 2006. Dissolved oxygen dynamics in Charlotte Harbor and its contributing watershed, in response to Hurricanes Charley, Frances, and Jeanne - Impacts and recovery. Estuaries and Coasts 29: 932-938.

Townsend, C., S. Doledec, and M. Scarsbrook. 1997. Species traits in relation to temporal and spatial heterogeneity in streams: a test of habitat templet theory. Freshwater Biology 37: 367-387.

Williams, C., J. Boyer and F. Jochem. 2008. Indirect Hurricane Effects on Resource Availability and Microbial Communities in a Subtropical Wetland-Estuary Transition Zone. Estuaries and Coasts 31: 204-214.

Witkowski, A., H. Lange-Bertalot, and D. Metzeltin. 2000. Diatom flora of marine coasts. I. Iconographia Diatomologica 7: 1-925. 
Zeng, H., S. Lirong, Y. Zhigang, and C. Hongtao. 2006. Distribution of phytoplankton in the Three-Gorge Reservoir during rainy and dry seasons. Science of the Total Environment 367: 999-1009.

Zong, Y., J.M. Lloyd, M.J. Leng, W.W.S. Yim, and G. Huang. 2006. Reconstruction of Holocene monsoon history from the Pearl River Estuary, southern China, using diatoms and carbon isotope ratios. The Holocene 16: 251-263. 


\title{
4. MID- TO LATE-HOLOCENE CHANGES IN LARGE-SCALE \\ HYDROLOGICAL PATTERNS AND GEOGRAPHICAL VARIABILITY \\ INFERRED FROM DIATOM ASSEMBLAGES IN TWO GULF COAST \\ FLORIDA ESTUARIES
}

\begin{abstract}
Across Florida, climatic controls have variable influence over relatively small spatial scales, requiring a high spatial resolution to interpret paleoecological patterns. Inference models for salinity and nutrient concentrations developed using modern diatom assemblages in Chapter 2 were applied to sediment core assemblages from two southwest Florida estuaries, Tampa Bay and Charlotte Harbor, to evaluate long-term hydrological changes during the Holocene. Diatom assemblages were used to characterize different periods in both sediment cores, identifying a significant change that occurred approximately 5.5 to $5 \mathrm{kyr} \mathrm{BP}$ in both estuaries and other significant changes that occurred asynchronously in each catchment. Reconstructed estimates of salinity and nutrient concentrations suggest a trend toward overall wet conditions approximately $5 \mathrm{kyr}$ BP, with low inferred salinity and high inferred nutrient concentrations. Both cores provide evidence of increased variability between 5 and $3.5 \mathrm{kyr}$ BP, which supports previous findings of large-scale hydrological pattern changes in the region at this time. Variability in agreement between the cores suggests that large-scale climate patterns across the Florida peninsula may have been dynamic through time; during some periods reconstructed variables suggest simultaneous, comparable changes in both estuaries,
\end{abstract}


while the temporal pacing and taxonomic changes during some periods were not as closely linked.

\section{Introduction}

Throughout the Holocene, changing rates of gradually rising sea level have shaped the Florida coastline. Small changes in the hydrologic cycle that influence precipitation and runoff coupled with sea level change can greatly influence coastal Florida as a result of its shallow topographical relief and, in the southern peninsula, porous karstic bedrock. Understanding ecosystem changes that occurred in response to climate-driven hydrological change is critical for predicting impacts of currently accelerating climate change. Not only is Florida particularly vulnerable to sea level rise (e.g. Ross et al. 2009; Saha et al. 2011; summarized in Noss 2011), its subtropical peninsular geography is situated in a confluence of climate cycles such as the El Niño Southern Oscillation (ENSO), Atlantic Multidecadal Oscillation (AMO), North Atlantic Oscillation (NAO), and Pacific Decadal Oscillation (PDO); these cycles control the hydrologic cycle in regionally-specific and interacting ways (Mestas-Nuñez and Enfield 2003; Moses et al. 2013). Improving regional resolution of the pace and pattern of climate-driven hydrological change is necessary to provide meaningful projections of future expectations at scales relevant to societies, ecosystems, and management.

The tropical and subtropical climate zones play an important role in global oceanic-atmospheric cycles, where incoming solar radiation drives the convection that results in global heat transfer and moisture transport. Proxy records suggest that large, 
century-scale migrations of the Inter-Tropical Convergence Zone (ITCZ), responsible for maximum convection and precipitation, have occurred throughout the Holocene, generating major changes in precipitation patterns in the Gulf of Mexico and Caribbean regions (Haug et al. 2001; Poore et al. 2003; Hillesheim et al. 2005). Mineral records from the northern Venezuelan coast suggest that the ITCZ shifted northward approximately 5.4 kyr BP, increasing precipitation in the northern Caribbean and Florida and generating dry conditions in the Venezuela coastal area (Haug et al. 2001). There is also evidence of changes during the Holocene in the cyclicity of large-scale oceanicatmospheric teleconnections that drive precipitation. Proxy records from South Florida and South America have suggested intensifications of the ENSO cycle and its teleconnections (Rodbell et al. 1999; Donders et al. 2005; Wanner et al. 2008), and models have indicated long-term changes in the NAO (Wanner et al. 2008); a tree-ring proxy has suggested that the mechanisms driving the AMO have remained stable for approximately the last 500 years (Gray et al. 2004), but longer records have proved difficult to obtain (Heslop and Paul 2011). These climate cycles interact in complex ways and influence the spatial and temporal distribution of precipitation and runoff in Florida (Enfield et al. 2001; Mestas-Nuñez and Enfield 2003; Moses et al. 2013).

Because the climatological drivers of hydrology vary spatially across the Florida peninsula, interpretations of broader regional patterns require satisfactory spatial resolution of long-term hydrological and ecosystem change. In particular, climate cycles such as ENSO and the AMO modulate the hydrological cycle differently in north, central, and southern portions of the peninsula (Enfield et al. 2001; Donders et al. 2005), and hydrological variability can be significant on spatial scales as small as $10 \mathrm{~km}$ (Moses et 
al. 2013). Paleoecological proxy records must therefore be considered in the context of their location within this climatological heterogeneity (Moses et al. 2013).

In the present study I evaluate diatom assemblages from two sediment cores from the southwest Gulf Coast, Tampa Bay and Charlotte Harbor, to resolve hydrological shifts and their probable climatological drivers in southwest Florida throughout the Holocene. The two estuaries are geographically relatively close ( $100 \mathrm{~km}$ apart), but are situated in the central-southern part of the peninsula which today is divided into different Climate Divisions by the National Climatic Data Center using precipitation and temperature data, with Tampa Bay in the South Central Division (4) and Charlotte Harbor in the Everglades and Southwest Division (5). Palynological studies have shown a shift toward relatively stable, wetter conditions in south and central Florida approximately 5.5 kyr BP (Watts and Stuiver 1980; Watts et al. 1996; Grimm et al. 2006), but in northern portions of the peninsula that today are classified as Climate Division 2, a comparable transition occurred earlier, between 8.5 and $7.5 \mathrm{kyr} \mathrm{BP}$ (Grimm et al. 2001). A study using diatoms suggested that major changes related to nutrient concentrations and organic matter in a central Florida lake (Climate Division 4 today) occurred 7.5 and 4 kyr BP, which would indicate changing hydrology in the watershed (Quillen et al. 2013). It remains unclear precisely where differences in climatic controls on hydrology occur across the peninsula, and whether these differences are persistent through time.

Because diatom taxa have measurable preferences and tolerances for different environmental parameters and preserve well in most types of sediment (Battarbee 1986; Cooper 1999), they can provide insight into past environmental conditions using the relative abundance of taxa present at different times. Where diatom assemblages have 
strong relationships with environmental variables, quantitative transfer functions can be developed to infer estimated values of variables potentially related to climate dynamics such as salinity and nutrient concentrations from their composition (Fritz et al. 1991 and 2010; Birks 1995 and 1998).

During times of increased precipitation and runoff, I expect that salinity in the two estuaries would have been reduced, concurrently increasing nutrient concentrations due to increased terrestrial connectivity. Salinity has been shown to be the predominant driver of diatom assemblage dissimilarity in Charlotte Harbor, although diatom assemblages also have strong relationships with concentrations of total nitrogen (TN), total phosphorus (TP), and total carbon (TC) (Chapter 2). I expect that synchronous evaluation of diatom-inferred salinity and nutrient concentrations will help resolve largescale hydrological changes that may not be evident through salinity reconstructions alone.

The objectives of this study were to 1) characterize the diatom assemblages in sediment cores from two Gulf Coast estuaries and identify times of compositional shifts; 2) use transfer functions to quantify past environmental changes; 3 ) interpret possible hydrological changes from diatom-inferred estimates of past salinity and nutrient concentrations; and 4) evaluate the regional applicability of locally-derived diatom inference models. I intend to improve understanding of regional patterns by comparing the two records that are geographically proximate but today fall into different climate divisions, and to evaluate evidence of the large-scale changes suggested by existing proxy records. 


\section{Methods}

Materials

Sediment cores were collected in summer 2004 and spring 2008 from Tampa Bay and Charlotte Harbor, respectively, on Florida's southwest Gulf Coast (Fig. 11). The cores were obtained through cooperation among the U.S. Geological Survey, Eckerd College, and the University of South Florida, using a vibracorer deployed from the R/V Gilbert. The Tampa Bay core comprises a little over $5 \mathrm{~m}$ of sediment collected from a water depth of $\sim 4 \mathrm{~m}$ in Hillsborough Bay, the northeast branch of the Tampa Bay estuary. These sediments represent deposition that occurred over approximately the last $10 \mathrm{kyr}$, on the basis of linear interpretation of two radiocarbon dates and pollen biostratigraphy (Van Soelen et al. 2010). Ten samples selected from the core based on the stratigraphy of sediment color were previously analyzed for diatoms and other paleoecological proxies (Van Soelen et al. 2010). For this study, ten additional samples were selected for diatom analysis that encapsulate the period of interest of this study.

The Charlotte Harbor core comprises nearly $5.5 \mathrm{~m}$ of sediment collected from a small sub-basin with a water depth of $\sim 6 \mathrm{~m}$ that currently is regularly hypoxic. It represents approximately $8.2 \mathrm{kyr}$ of deposition. The lithology of the core and the age model using 8 AMS ${ }^{14} \mathrm{C}$ dates and ${ }^{210} \mathrm{~Pb}$ radio-isotope analysis of the top $42 \mathrm{~cm}$ of sediment are described in Van Soelen et al. (2012). Twenty-four samples were selected for diatom analysis for the present study, ranging from $\sim 8.2 \mathrm{kyrs} \mathrm{BP}$ to $\sim 50$ years $\mathrm{BP}$. 


\section{Diatom processing}

Between 0.5 to $1 \mathrm{~g}$ of freeze-dried sediment from each sample was cleaned for diatom analysis using a series of acid baths following the oxidation technique described by Battarbee (1986). For the Tampa Bay core samples, slides were prepared using sedimentation trays (Battarbee 1973); for the Charlotte Harbor core samples, a measured aliquot of 0.01 to $1 \mathrm{ml}$ (depending on diatom concentration) of the diluted mixture was removed by calibrated pipette, placed on a coverslip, dried, and subsequently mounted onto glass slides using Naphrax ${ }^{\circledR}$. At least 500 valves were counted except in samples where poor preservation precluded full counts. In the Tampa Bay samples, between 200 and 250 valves were counted, but several samples had fewer ( 2 samples) or no diatoms evident (5 samples). In the Charlotte Harbor samples, a minimum of 500 valves was counted in all samples but one, where a scarcity of diatom valves dictated a total count of 65. Counts were made using a light microscope at 1000x magnification along measured transects. Identification was made using diatom taxonomic literature published by Peragallo and Peragallo (1908), Hustedt (1930; 1955), Hendey (1964), Witkowski et al. (2000), and Cremer et al. (2007).

Data analysis

For each sample, the abundance of all taxa relative to the total abundance of diatom valves counted and the total valves per gram of sediment were calculated. Taxa occurring in at least three samples with a relative abundance of at least $0.5 \%$ in at least 
one sample were included for statistical analyses, because inclusion of undersampled taxa may increase noise in the dataset (McCune et al. 2002). For each core, similarity matrices were constructed using Bray-Curtis similarity to compare diatom assemblage patterns among samples (Clarke and Warwick 2001). Samples with no diatom valves were excluded from analyses of assemblage similarity.

A constrained cluster analysis was performed on each core, applying a constrained incremental sum of squares (Ward's) method using the rioja package in R (Juggins 2012). The agglomerative hierarchical clustering algorithm only allows groups to form from adjacent samples, identifying change points through time down each sediment core. Analysis of similarity (ANOSIM) was used to determine the similarity of groups identified by cluster analysis (Clarke and Gorley 2006). The R values reported represent the difference of mean ranks of taxa by relative abundance and ranges from 0 to 1 with increasing dissimilarity; comparisons having a $p<0.05$ were considered significantly different (Clarke and Warwick 2001).

Non-metric multi-dimensional scaling (NMDS) ordination (Kruskal and Wish 1978) was used to visualize assemblage patterns throughout the cores. After evaluating the stress of ordinations with up to 5 axes, two-dimensional NMDS was selected to ease the interpretability of results, given that stress did not decrease greatly with additional axes. Stress is a measure of the departure from fit of the sample dissimilarity to distance in the ordination; it tends to decrease with additional axes, as more of the sample variance is represented, but additional dimensions make interpretation increasingly difficult (McCune et al. 2002). The ANOSIM and NMDS analyses were conducted using Primer version 6 (Clarke and Gorley 2006). 
Diatom optima and tolerances

The optimal environmental conditions and tolerances of diatom taxa in the cores were determined previously using a weighted averaging regression approach applied to modern diatom assemblages and measurements across broad environmental gradients in the Charlotte Harbor watershed (Chapter 2). The weighted averaging approach enables calculation of a quantitative model of environmental variables using the optima and tolerances of taxa present in a sample. The weighted-averaging regression approach assumes that taxa with optima closest to the observed value of an environmental parameter will be most abundant where that value occurs (Birks 1995). Optima and tolerances for salinity and concentrations of TN, TP, and TC were available for 36 taxa found in the Tampa Bay core and 39 taxa found in the Charlotte Harbor core; these taxa also occurred in the modern diatom assemblages. When contemporary taxa in the Charlotte Harbor watershed were used to model current environmental conditions and compared against real-time measurements, diatom inference models for salinity were very strong $\left(\mathrm{R}^{2}=0.96\right)$, with $\mathrm{TN}\left(\mathrm{R}^{2}=0.82\right), \mathrm{TP}\left(\mathrm{R}^{2}=0.83\right)$, and $\mathrm{TC}\left(\mathrm{R}^{2}=0.88\right)$ also well predicted (Chapter 2). These models were used to estimate past values of salinity and nutrient availability based on the optima of diatom assemblages found at the different sample depths in the sediment cores. These analyses were conducted using C2 version 1.7.2 software (Juggins 2011). 


\section{Results}

Diatom assemblage transitions

A total of 123 diatom taxa were found in the Tampa Bay sediment core, and 137 in the Charlotte Harbor core. Of these, 33 taxa were common to both cores. The most abundant taxa common to both cores were Amphicocconeis disculoides (Hustedt) De Stefano and Marino, Opephora pacifica (Grunow) Petit, and Petroneis marina (Ralfs) D.G. Mann. In the Tampa Bay core, diatom valves were not observed in samples from depths below $400 \mathrm{~cm}$, and were also absent from one sample at depth $341 \mathrm{~cm}$. Stratigraphically-constrained cluster analysis of the diatom assemblages revealed that each core could be divided into four zones that capture significant changes through time (Fig. 12). A major change occurred in both cores approximately 5.5 to $5 \mathrm{kyr} \mathrm{BP}$, and the assemblage change at this point in each core was statistically significant, determined by $\operatorname{ANOSIM}(\mathrm{R}=0.64$ in Tampa Bay and $\mathrm{R}=0.54$ in Charlotte Harbor $)$.

In Tampa Bay, zone 1 consists of 2 samples that represent approximately the last 1 kyr deposition. A statistically significant change $(\mathrm{R}=0.98)$ occurred between 2 and 1 kyr BP. Zone 2 consists of samples dating from this point to approximately 5.5 to $5 \mathrm{kyr}$ $\mathrm{BP}$, when a significant change occurred in both cores. Zone 3 consists of samples dating from this point to approximately $6.5 \mathrm{kyr} \mathrm{BP}$, and zone 4 consists of one sample representing approximately $7 \mathrm{kyr}$ BP that was overwhelmingly dominated by a single diatom taxon. The change between zones 3 and 4 was not statistically significant. 
In Charlotte Harbor, zone 1 consists of a single sample that represents approximately 50 yrs BP, deposited within the period of modern anthropogenic impacts. Zone 2 consists of samples dating from this period to approximately $3.5 \mathrm{kyr} \mathrm{BP}$, when a statistically significant change occurred $(R=0.93)$. Zone 3 is comprised of samples from this point to the significant change at approximately 5.5 to $5 \mathrm{kyr} \mathrm{BP}$, and zone 4 consists of all older samples, dating to approximately $8.2 \mathrm{kyr}$ BP.

In zone 1 of both cores, the assemblages are characterized by high relative abundance of Paralia sulcata (Ehrenberg) Cleve, A. disculoides, Actintoptychus senarius (Ehrenberg) Ehrenberg, and Cyclotella litoralis Lange \& Syvertsen (Fig. 12). In Charlotte Harbor, zone 2, comprising the period from approximately $3.5 \mathrm{kyr} \mathrm{BP}$ to the modern period of zone 1 , is overwhelmingly dominated by $P$. sulcata, with increases also in abundance of Actinoptychus splendens (Shadbolt) Ralfs ex Pritchard, Triceratium scitulum T. Brightwell, and Hyalodiscus scoticus (Kützing) Grunow (Fig. 12). In both cores, the period between approximately 5.5 and $3.5 \mathrm{kyr} \mathrm{BP}$ is characterized by high relative abundance of A. disculoides, O. pacifica, and P. marina. Zone 4, the oldest period, is dominated by a single taxon, Amphora cf gacialis W. Smith, in Tampa Bay, and by high relative abundance of Dimeregramma minor (Gregory) Ralfs ex Pritchard, Planothidium delicatulum (Kützing) Round \& Bukhtiyarova, P. marina, and O. pacifica in Charlotte Harbor.

Trajectories in diatom assemblage structure through time shown in NMDS ordination provide a visual representation of these changes (Fig. 13). In Tampa Bay, zones 1 and 4 are clearly distinctive, zone 2 forms a very tight cluster, representing greater similarity, and zone 3 appears to include more variability. Similarly, in Charlotte 
Harbor, zones 1 and 2 are distinctive, zone 3 appears to represent a period of transition, and zone 4 forms another cluster. The statistically significant change in assemblage that occurred approximately 5.5 to 5 kyr BP occurs between zone 2 and 3 in Tampa Bay and between zones 3 and 4 in Charlotte Harbor. The number of diatom valves found per gram of sample shows a substantial spike in productivity between 5.5 and $3 \mathrm{kyr}$ BP in Tampa Bay and between 5.5 and 5 kyr BP in Charlotte Harbor (Fig. 14), ending at this time of transition.

Estimates of past hydrology changes

Diatom-inferred estimates of past salinity and nutrient concentrations show similar fluctuations through time in the two cores (Fig. 15). Analysis of similarity of the reconstructed salinity estimates suggest a significant change in salinity in Tampa Bay between zones 2 and 3 , at the major transition period approximately 5.5 to $5 \mathrm{kyr} \mathrm{BP}(\mathrm{R}=$ 0.71; Fig. 16). In Charlotte Harbor, salinity estimates were only significantly different between zones 2 and 4 , with higher values in zone 4 (mean $=36.2 \mathrm{ppt}$ ) than in zone 2 $($ mean $=29.8 \mathrm{ppt})$. No significant differences in estimates of TP were found in Tampa Bay, but TP estimates suggest a significant change in Charlotte Harbor between zones 2 and 3, approximately $3.5 \mathrm{kyr} \mathrm{BP}(\mathrm{R}=0.98)$, and zones 2 and 4 were also significantly different $(\mathrm{R}=1)$. Estimates of TN suggest a significant change in in Tampa Bay between zones 1 and 2, between 2 and $1 \mathrm{kyr} \mathrm{BP}(\mathrm{R}=1)$; in Charlotte Harbor, estimates suggest significant changes in TN occurred between zones 2 and 3, approximately 3.5 kyr BP (R $=0.78)$, and between zones 3 and 4 , at the major transition time 5.5 to $5 \mathrm{kyr} \mathrm{BP}(\mathrm{R}=$ 
0.48). Zones 2 and 4 were also significantly different, with a mean of $19.35 \mathrm{mg} / \mathrm{g}$ in zone 2 and $3.90 \mathrm{mg} / \mathrm{g}$ in zone 4 . No significant changes in TC estimates occurred in Tampa Bay, but estimates of TC in Charlotte Harbor indicated a significant transition at approximately $3.5 \mathrm{kyr} \mathrm{BP}(\mathrm{R}=0.65)$, consistent with the changes in the TP and TN estimates. This transition also is significant in Charlotte Harbor using all four variables in concert $(\mathrm{R}=0.98)$.

\section{Discussion}

Diatom assemblage transitions

Major transitions in diatom assemblage structure in these two sediment cores suggest significant hydrological changes on Florida's Gulf Coast between approximately 5.5 to $5 \mathrm{kyr}$ BP, at $3.5 \mathrm{kyr}$, between 2 to $1 \mathrm{kyr}$, and with the onset of modern anthropogenic impacts. The change around 5.5 to $5 \mathrm{kyr}$ BP has been widely documented in the central and southern portions of the peninsula using diverse paleoecological proxies including pollen (Donders et al. 2005; Grimm et al. 2006; Lammertsma et al. 2013), mineral deposits (Haug et al. 2001), and biomarkers (Van Soelen et al. 2012), and is believed to represent a transition to overall wetter conditions brought on by northern migration of the ITCZ (Haug et al. 2001) and an intensification of the ENSO cycle (Donders et al. 2005). The major shift in diatom taxa at 5.5 to $5 \mathrm{kyr}$ BP was statistically significant in both southwest Florida cores but was characterized by changes in the relative abundance of different taxa in the two basins. 
In the Tampa Bay core, taxonomic changes across this transition (from zone 3 to 2) included an increase in relative abundance of some taxa that were common in both cores, particularly A. disculoides, O. pacifica, and P. sulcata, as well as Chaetocerous resting spores. Interestingly, across this same transition period in Charlotte Harbor, $O$. pacifica had a decrease in relative abundance and A. disculoides remained relatively stable. In Charlotte Harbor, notable taxonomic changes at this time (from zone 4 to 3 ) included decreases in abundance of D. minor and O. pacifica, which are generally considered to be marine species associated with tidal flat and seagrass environments (Sullivan 1978 and 1979; Hemphill-Haley 1995), and the appearance or increase in relative abundance of some indeterminate taxa not identified in the Tampa Bay core. Catchment characteristics may account for some of the different species responses during this period. The Charlotte Harbor catchment has a shallower gradient relative to the steeper topography of the Tampa Bay watershed, which may have resulted in different dynamics related to transitions between coastal wetland and marine habitats. The Tampa Bay core was also collected from an estuary inlet that today is shallower and closer to the shore than the Charlotte Harbor core location, which may also be related to differences in the timing of transitions.

The transition to zone 2 at $3.5 \mathrm{kyr}$ BP in Charlotte Harbor was characterized by a dramatic increase in the relative abundance of $P$. sulcata, and also the appearance of or increase in the relative abundance of T. scitulum, A. splendens, $H$. scoticus, and Eupodiscus radiatus J.W. Bailey. In spite of the presence of these other taxa, the dominance of $P$. sulcata is the most notable feature of zone 2 in Charlotte Harbor. This taxon is a heavily silicified diatom that forms long chains. Its dominance may be 
indicative of a poor environment for valve preservation rather than representative of its ideal conditions for success, because it is more resistant to dissolution and therefore preserves preferentially over other taxa (Hemphill-Haley 1995). Differential preservation may confound environmental interpretation during times when it is overwhelmingly dominant. T. scitulum and A. splendens, as well as P. sulcata, are generally considered to be cosmopolitan and polyhalobous (Cremer et al. 2007), so their increased abundance may also indicate increasing hydrological variability during this period.

The assemblage shift in Tampa Bay from zone 2 to zone 1 between 2 and $1 \mathrm{kyr}$ BP is largely defined by an increase in $P$. sulcata, with concurrent but smaller increases in the relative abundance of $A$. senarius and $C$. litoralis. It is possible that the transition between 2 and 1 kyr BP suggested by the Tampa Bay core more accurately represents the onset of modern anthropogenic inputs, because the linearly-interpolated age model of that core (described in Van Soelen et al. 2010) does not include a great deal of detail in the top portion of the core and sedimentation rates in Charlotte Harbor increased in the topmost section of that core (Van Soelen et al. 2012). However, previous studies have also demonstrated evidence from accumulation of pollen and dinoflagellate cysts of hydrological change during the period between 2 and 1 kyr BP in Charlotte Harbor (Lammertsma et al. 2012). The limited sample size from the Charlotte Harbor core during this period (one sample each dating to approximately $800 \mathrm{yrs} \mathrm{BP}$, and 1.7 and 2.5 kyr BP) are insufficient to corroborate or provide evidence against this transition in Charlotte Harbor.

Paralia sulcata is also the dominant taxon in zone 1 of the Tampa Bay core, representing approximately the last $1 \mathrm{kyr}$ BP. In Charlotte Harbor, it decreases 
dramatically in the single sample representing the last $\sim 100$ yrs. The other four taxa in Charlotte Harbor that help to define zone 2 are virtually absent from this sample, suggesting that although not statistically significant, an observable assemblage change did occur. Because of the small sample size representing the most modern period in each core (2 samples in Tampa Bay and 1 in Charlotte Harbor), it is difficult to draw conclusions about the exact timing and spatial differences that may have occurred in the area. Additional sampling on a finer temporal scale of cores across the last $2 \mathrm{kyr}$ is needed to better define smaller scale changes.

Past salinity and nutrient estimates/ inferred hydrological patterns

The major assemblage transitions identified by constrained cluster analysis occurred at $\sim 7$ to $6.5 \mathrm{kyrs}, 5.5$ to $5 \mathrm{kyrs}$, and 2-1 kyrs BP in Tampa Bay, and at $\sim 5.5-5$ kyrs, 3.5 kyrs, and 100 yrs BP in Charlotte Harbor. Reconstruction of diatom-inferred salinity and nutrient concentrations during the intervening periods reveal some patterns that suggest hydrological changes may have occurred and driven some of these major transitions.

Tampa Bay

Estimation of salinity and nutrient concentrations in the oldest samples from Tampa Bay (those older than $\sim 7$ kyrs) was hindered by poor preservation and small sample size (only one sample from this period contained diatom valves) as well as limited 
taxonomic overlap with the calibration set; the single sample was overwhelmingly

dominated by A. cf. gacialis, which did not occur in the calibration set (Chapter 2). As a result, only the calculations for salinity and TP produced plausible estimates (negative values were predicted for TN and TC) for this time period, and these should be interpreted cautiously.

Salinity estimates in the Tampa Bay core demonstrate a significant, but small decrease across the transition from 5.5 to $5 \mathrm{kyrs} \mathrm{BP}$, which would support an increase in precipitation at this time. The only other significant environmental change suggested by the reconstructions in the Tampa Bay core is a dramatic increase in TN across the transition modeled at 2 to 1 kyrs BP. In light of what is known about human influence on the nitrogen cycle (summarized in Vitousek et al. 1997), the dramatic increase at this transition supports the idea that it may more accurately represent the onset of modern anthropogenic effects. In order to clarify the timing of the shift across the most recent zones in Tampa Bay, additional samples from the upper core depths should be examined and dated.

\section{Charlotte Harbor}

The oldest zone in Charlotte Harbor consists of all samples deposited before the transitional period occurring at 5.5 to $5 \mathrm{kyrs} \mathrm{BP}$, and diatom-inferred estimates of salinity during this period are significantly higher than those from $\sim 3.5 \mathrm{kyrs} B P$ to the modern record (zone 2). These estimates support the idea that precipitation increased around 5.5 kyrs BP, and then increased again with an intensification of the ENSO cycle 
approximately 3.5 kyrs BP, as suggested by Donders et al. (2005). As expected, TN and TP estimates in zone 2 are significantly elevated as compared to zones 3 and/or 4 , which is also consistent with an increase in terrestrial runoff associated with more rainfall.

Estimates of TC suggest a decrease across the transition $\sim 3.5$ kyrs BP; however, diatom assemblages in this watershed generally correlate with TC gradients in an inverse direction from salinity gradients, which are the stronger drivers (Chapter 2). Therefore, the perceived decrease in TC is likely an artifact of assemblage relationships to salinity rather than an accurate estimation of TC levels. One assumption of the transfer function method is that variables other than the primary driver of assemblage dissimilarity either have negligible influence on the assemblage or a joint distribution with the primary driver that remains constant, and if this is not the case, then reconstructions of those secondary variables are unreliable (Juggins 2013). In this case, I believe that TN and TP each approximate a joint distribution with salinity, while reconstruction of TC is likely spurious because of its inverse relationship with salinity.

The substantial increase in diatom productivity that occurs in both cores at $\sim 5$ to 3 kyrs BP was not supported by evidence from the estimated reconstructions, and may be attributable to ex situ or other environmental conditions. No corresponding spike in any reconstructed variable was suggested by the reconstructions, nor was there a substantial shift in the ratios between variables that might explain such an increase, such as a shift toward the Redfield ratio. The reasons for this sudden increase remain unclear, but may be related to delivery from upstream; more research is needed, for example, to investigate whether increasing precipitation and overall wetter conditions may have initially increased runoff, promoting productivity and stratification in the estuaries, while 
subsequently the land to sea gradient decreased sufficiently to induce inland peat development, reducing peak runoff (T. Donders, pers. comm.).

\section{Regional differences}

The two cores illustrate generally similar patterns in the diatom-inferred variable estimates over time, but there are interesting taxonomic differences between them. Only about $25 \%$ of all taxa identified were common to both cores (33 of 123 and 137 total in Tampa Bay and Charlotte Harbor, respectively), a surprisingly low percentage for geographically proximate, connected estuaries. Some of the dissimilarity may be accounted for by poor preservation; in the Tampa Bay core, many samples had no diatom valves at all and in both cores, numerous diatom valves were present but not identifiable due to poor preservation. Some additional taxonomic overlap may therefore occur among valves that are delicate or prone to dissolution, or those that were identified only to the genus level, but any such overlap would be inherently unverifiable.

There is also evidence, however, that there are in fact important differences between the diatom flora of the two estuaries. Several taxa, including Stephanodiscus minitulus (Kützing) Cleve \& Möller and Aulacoseira subarctica (O. Müller) Haworth in the Tampa Bay core and E. radiatus in the Charlotte Harbor core, appeared in high relative abundance in several samples of one core but did not appear in any sample in the other. Other taxa that were common in both cores fluctuate in abundance at different times in the two estuaries, possibly due to differing catchment characteristics as well as hydrological changes. 
For example, A. disculoides, a marine littoral taxon that was one of the most abundant in many samples in both cores, was largely absent in the Tampa Bay core prior to $\sim 5.5$ kyrs BP, but then appeared and maintained a relatively stable abundance of $\sim$ $15 \%$ through modern times. In Charlotte Harbor, this taxon was common and abundant from the oldest sample ( $\sim 8.2$ kyrs old) up to $\sim 3.5 \mathrm{kyrs} B P$, when it virtually disappeared. It was largely absent during the period following $\sim 3.5$ kyrs BP, the time dominated by $P$. sulcata, and then reappeared (and co-occurred with P. sulcata) in the modern sample.

O. pacifica, a brackish taxon that was one of the most common and abundant in many samples of both cores, also fluctuated in different temporal patterns in the two cores. In Tampa Bay, it was virtually absent from the core until $\sim 5.5 \mathrm{kyrs}$ BP, when it surpassed $20 \%$ relative abundance in a few samples then slowly declined until it disappeared 2 kyrs BP. In Charlotte Harbor, it was most abundant in the oldest period (prior to $5.5 \mathrm{kyrs} \mathrm{BP}$ ), began to decline around $5.5 \mathrm{kyrs} \mathrm{BP}$, and then virtually disappeared $\sim 3.5$ kyrs BP.

These two taxa illustrate that while general environmental patterns between the two cores were similar through the Holocene, subtle changes in the timing of succession may have occurred. While the differential preservation and different depositional environments of the two cores may have some effect on relative abundance of individual taxa, these two that were common and abundant in both suggest that there was some difference in the temporal pacing of changes on the central-southwestern Florida coast.

Overall, the patterns of reconstructed variables are generally similar between the two cores across time, with the exception of TP, especially during the period of approximately 5.5 to 3 kyrs BP. The Peace River, part of the Charlotte Harbor watershed 
and the calibration dataset, is naturally extremely enriched in P (O’Donnell 1990) and likely has many taxa that are regionally adapted to high concentrations. For this reason, TP models from this watershed should be applied with caution on larger spatial scales. Both cores show a general increase in variability of all parameters during the period 5.5 to 3 kyrs BP, which is consistent with the idea of intensification of the ENSO cycle to its present day pattern (Donders et al. 2005) and northward migration of the ITCZ generating wetter conditions in peninsular Florida (Haug et al. 2001). The similarity may also suggest that during the period 5.5 to $3 \mathrm{kyrs} \mathrm{BP}$, the two estuaries were responding to the same climate forces, while during other periods they are not as closely linked.

This study provides evidence of the complex interactions between precipitation, runoff, and sea level rise in this region throughout the Holocene. Freshwater inflows to the two estuaries influence diatom assemblages that are surprisingly different and change at different times during the Holocene. It appears that large-scale climate patterns across central and south Florida may have been dynamic through time. Where today the two estuaries fall into different Climate Divisions based on their precipitation and temperature patterns, it is possible that during periods of the Holocene they were governed by the same pattern. The variable timing and spatial patterning have important implications for estimating modern day changes such as sea level rise, because understanding the nature of environmental changes on different spatial and temporal scales will be increasingly important to interpret local changes. 


\section{Acknowledgments}

This research was conducted in collaboration with the palaeoecology research group at Utrecht University. I would like to thank Drs. Friederike Wagner-Cremer, Timme Donders, Emmy Lammertsma, Gert-Jan Reichart, and especially Holger Cremer, for providing materials and invaluable advice and assistance throughout the project. 
Fig. 11. Map showing location of two sediment cores taken from Tampa Bay and Charlotte Harbor.

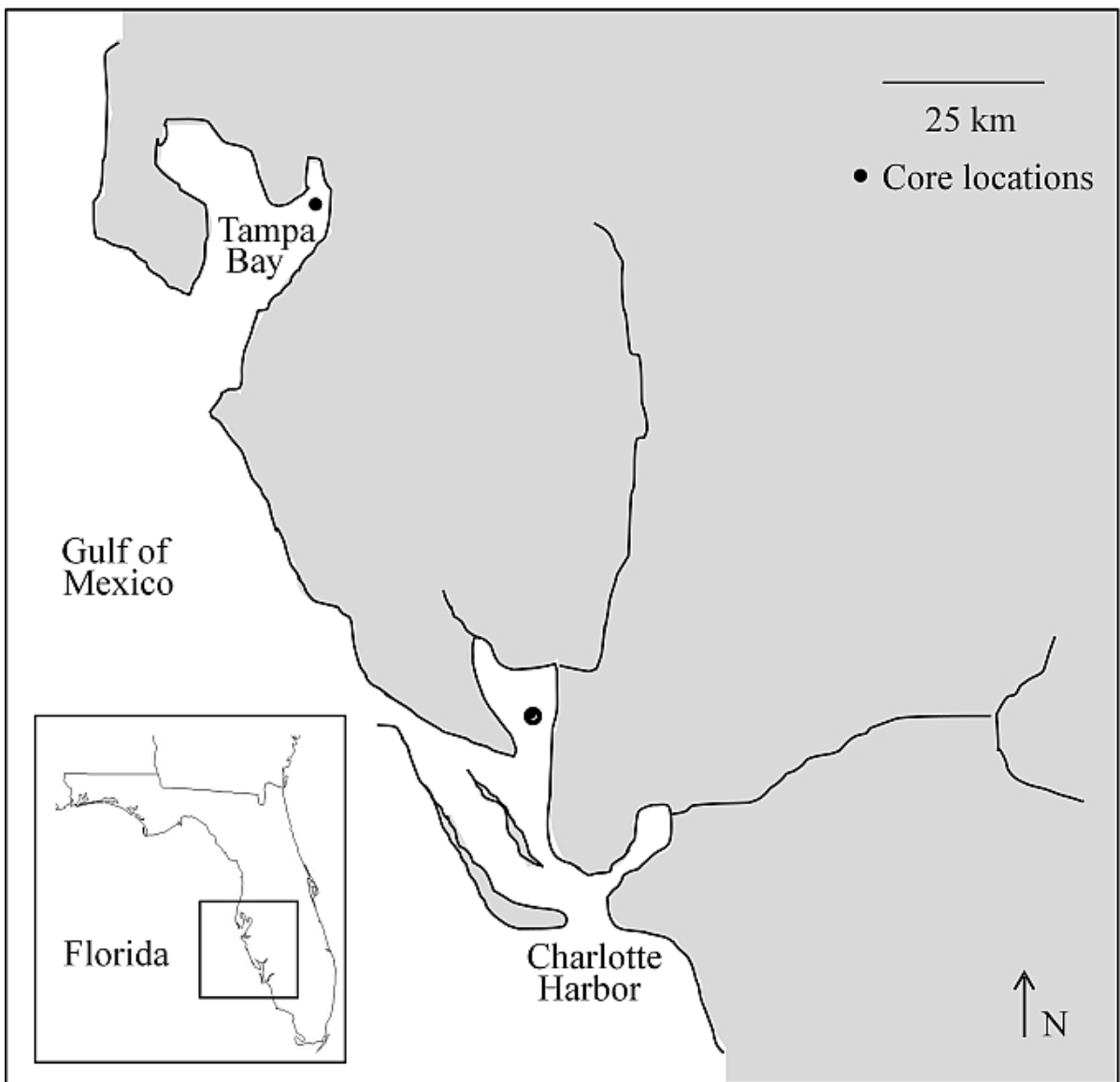


Fig. 12. Stratigraphy plots showing percent relative abundance of abundant diatom taxa with depth in core for Tampa Bay (top) and Charlotte Harbor (bottom). Gray and white bands illustrate zones defined by constrained cluster analysis.
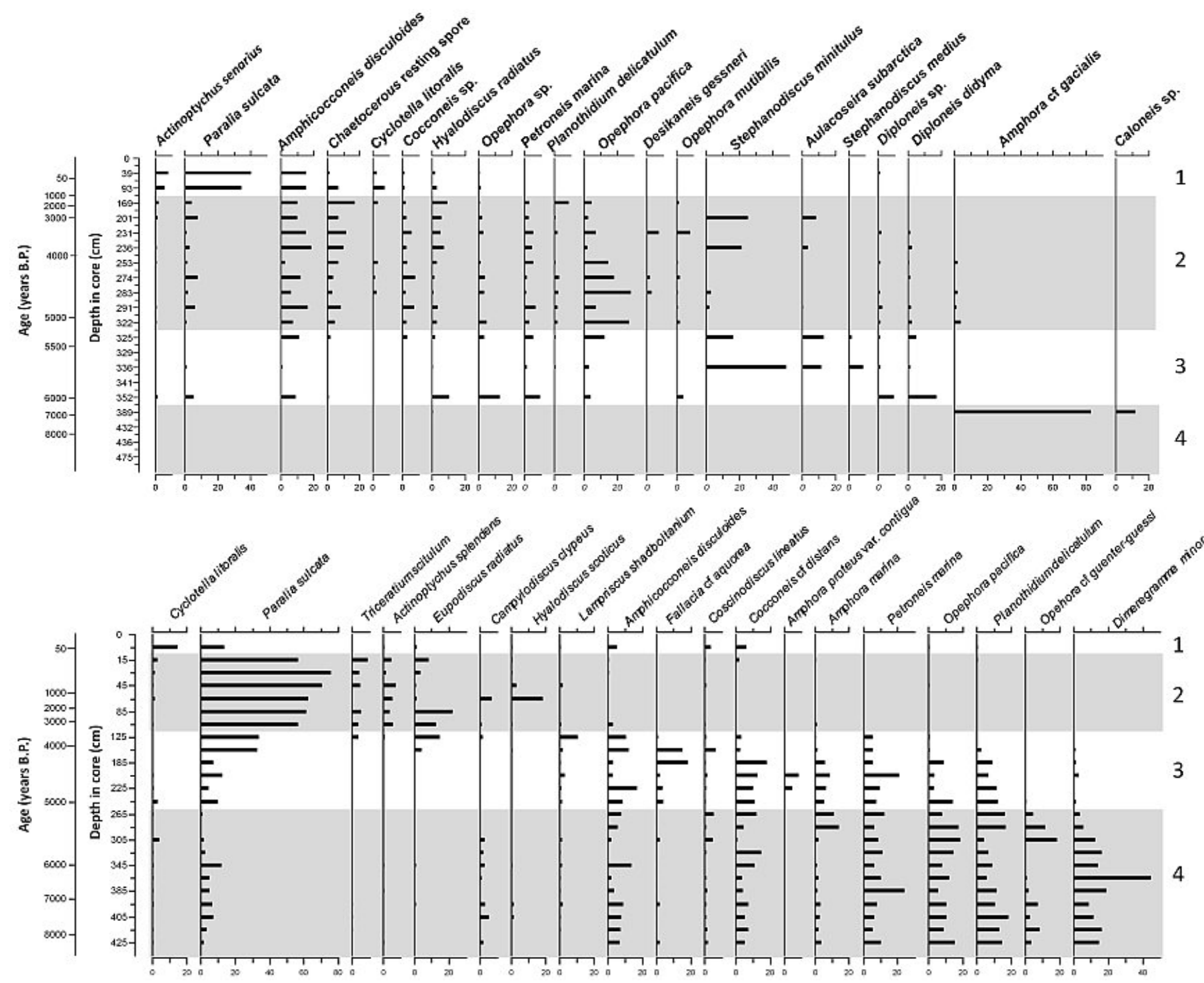
Fig. 13. Nonmetric multidimensional scaling ordination diagrams based on Bray-Curtis similarity of diatom assemblages in sediment cores from Tampa Bay (left) and Charlotte Harbor (right). Solid line represents the trajectory of time from the surface sample to the oldest; approximate dates are labeled along the trajectory. Dotted circles delineate zones defined by constrained cluster analysis.

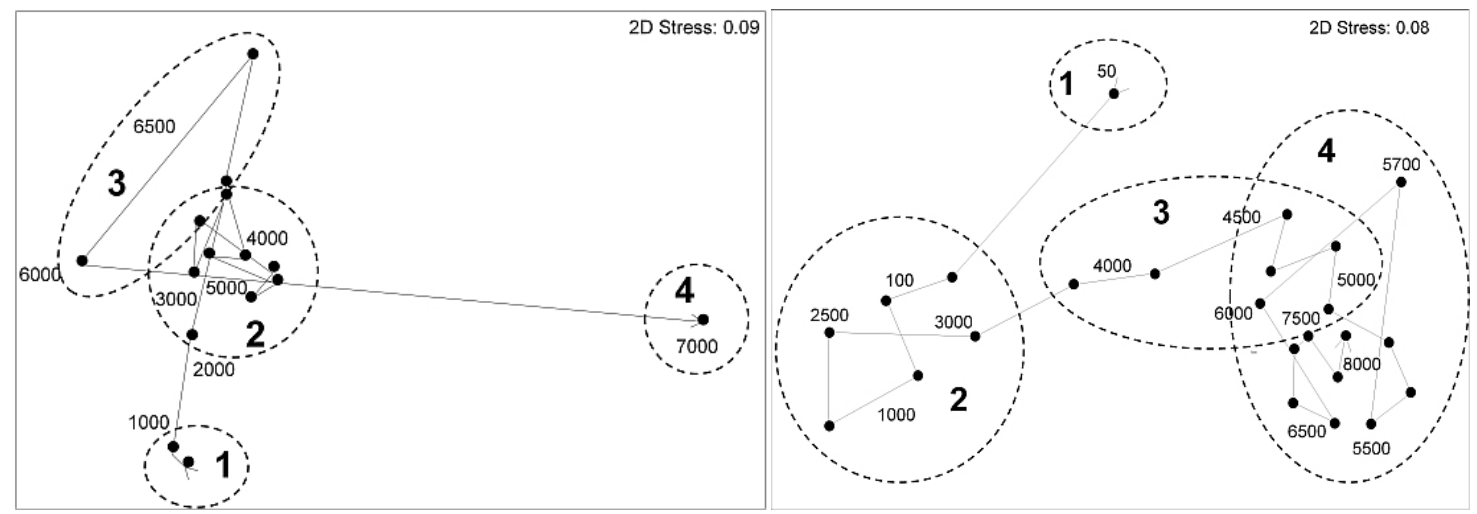

Fig. 14. Graph of diatom valves per gram of sample found in Tampa Bay (top) and Charlotte Harbor (bottom), where additional samples were analyzed to examine this period in greater detail.

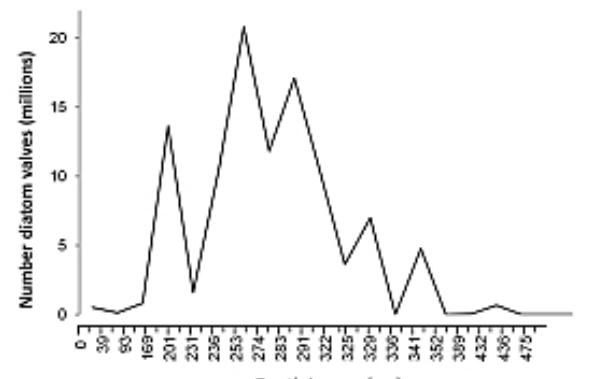

Depth in core $[\mathrm{cm}]$
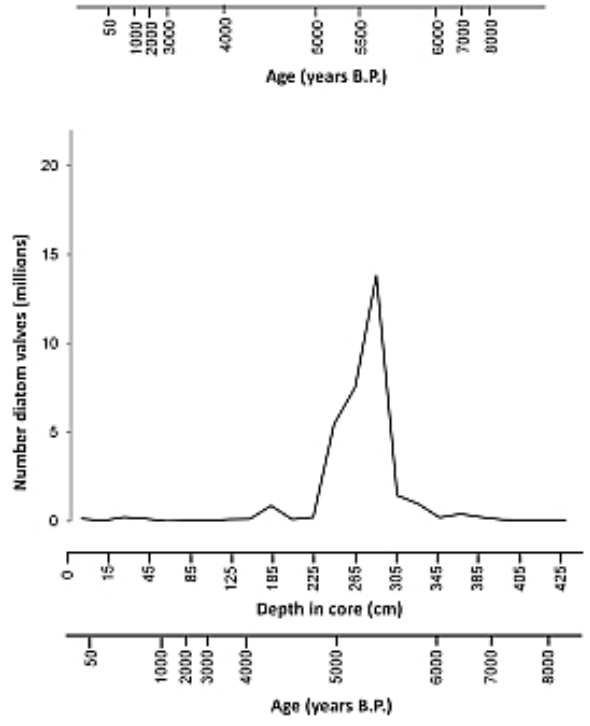
Fig. 15. Estimated values of variables inferred from the diatom assemblages in each core. Horizontal lines represent standard error; gray and white bands illustrate the zones defined by constrained cluster analysis in each core. Dotted lines connect levels in each core that represent the same time period.
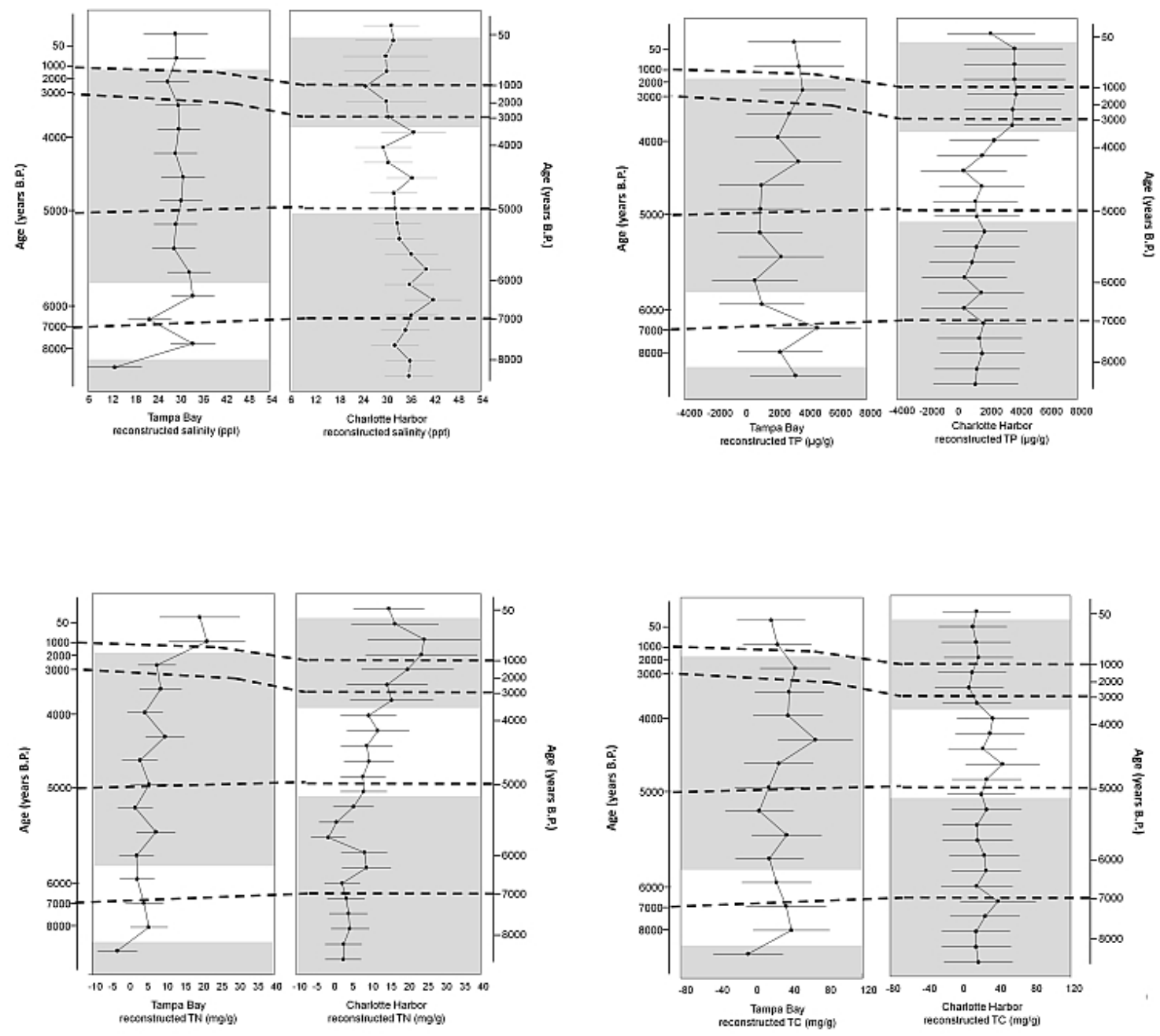
Fig. 16. Means of reconstructed salinity and nutrient concentration estimates by zone for each core. Letters indicate significant difference between pairs within each core.
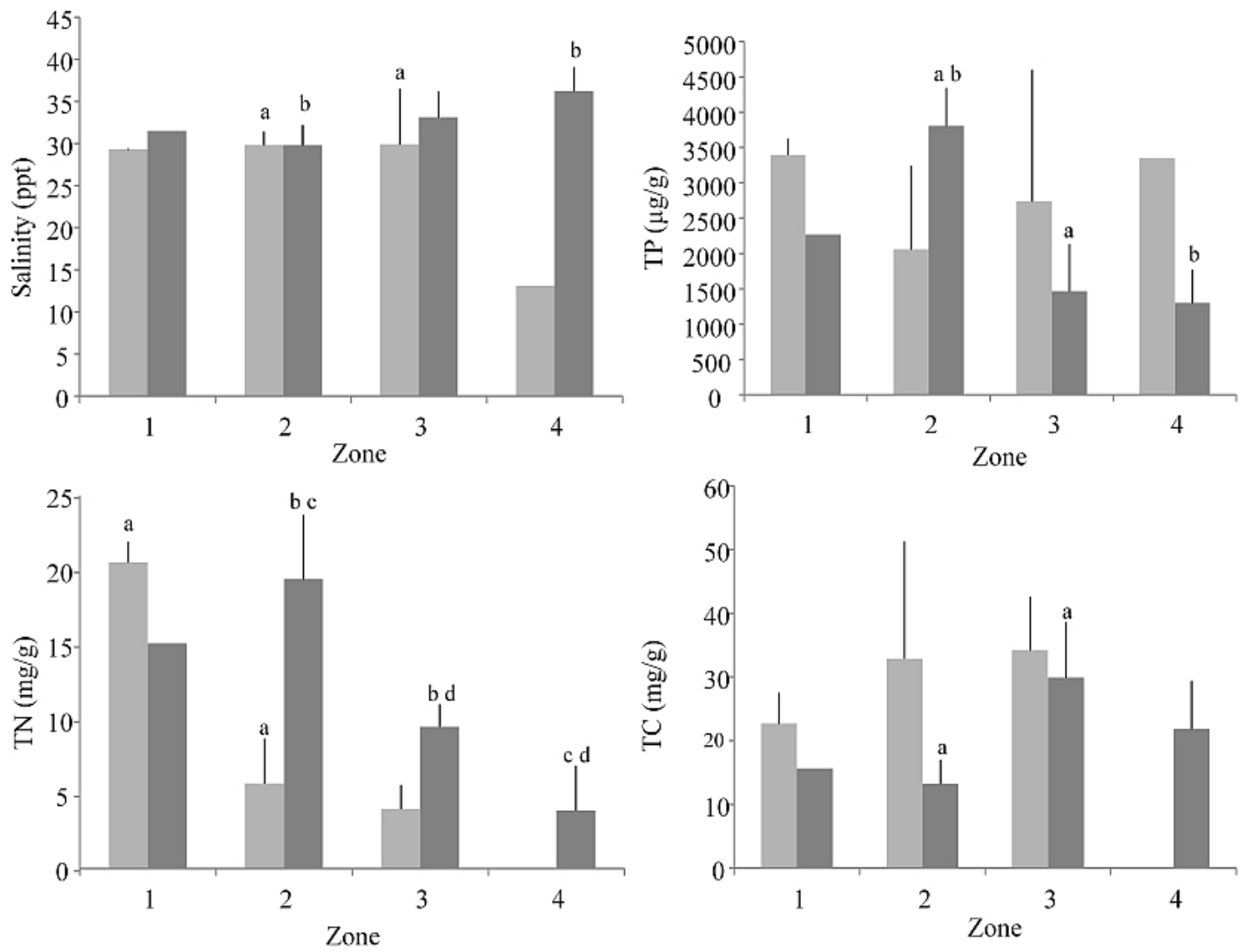

Tampa Bay

Charlotte Harbor 


\section{References}

Battarbee, R.W. 1986. Diatom Analysis. In B.E. Berglund (Editor), Handbook of Holocene Palaeoecology and Palaeohydrology. The Blackburn Press, Caldwell, New Jersey, pp. 527-570.

Battarbee, R.W. 1973. A new method for the estimation of absolute microfossil numbers, with reference especially to diatoms. Limnology and Oceanography 18: 647-653.

Birks, H.J.B. 1995. Quantitative paleoenvironmental reconstructions. In D.Maddy and J.S. Brew (Editors), Statistical Modelling of Quaternary Science Data, Technical Guide No. 5. Quaternary Research Association, Cambridge, pp. 161-236.

Birks, H.J.B. and H.J.B. Birks. 1998. D.G. Frey and E.S. Deevey Review 1: Numerical tools in palaeolimnology - Progress, potentialities, and problems. Journal of Paleolimnology 20: 307-332.

Clarke, K.R., and W.M. Warwick. 2001. Change in marine communities: An approach to statistical analysis and interpretation. Plymouth: Primer-E Ltd.

Clarke, K.R., and R.N. Gorley. 2006. Primer v6: user manual/tutorial. Plymouth: Primer-E Ltd.

Cooper, S.R. 1999. Estuarine paleoenvironmental reconstructions using diatoms. In E.F Stoermer and J.P. Smol (Editors), The Diatoms: Applications for the Environmental and Earth Sciences, $1^{\text {st }}$ edition, pp. 352-373.

Cremer, H., F. Sangiorgi, F. Wagner-Cremer, V. McGee, A.F. Lotter, and H. Visscher. 2007. Diatoms (Bacillariophyceae) and Dinoflagellate Cysts (Dinophyceae) from Rookery Bay, Florida, U.S.A. Caribbean Journal of Science 43: 23-58.

Donders, T.H., F. Wagner, D.L. Dilcher, and H. Visscher. 2005. Mid- to late-Holocene El Niño - Southern Oscillation dynamics reflected in the subtropical terrestrial realm. Proceedings of the National Academy of Sciences of the USA 102: 10904-10908.

Enfield, D.B., A.M. Mestas-Nuñez, and P.J. Trimble. 2001. The Atlantic Multidecadal Oscillation and its Relation to Rainfall and River Flows in the Continental U.S. Geophysical Research Letters 28: 2077-2080.

Fritz, S.C., S. Juggins, R.W. Battarbee and D.R. Engstrom. 1991. Reconstruction of past changes in salinity and climate using a diatom-based transfer function. Nature 352: 706708. 
Fritz, S.C., B.F. Cumming, F. Gasse and K.R. Laird. 2010. Diatoms as indicators of hydrologic and climatic change in saline lakes. In E. F. Stoermer and J. P. Smol (Editors), Diatoms: Applications for the Environmental and Earth Sciences, $2^{\text {nd }}$ edition. Cambridge University Press, Cambridge, GBR, pp. 186-208.

Gray, S.T., L.J. Graumlich, J.L. Betancourt, and G.T. Pederson. 2004. A tree-ring based reconstruction of the Atlantic Multidecadal Oscillation since 1567 A.D. Geophysical Research Letters 31: L12205.

Grimm, E.C., S. Lozano-Garcia, H. Behling, and V. Markgraf. 2001. Holocene vegetation and climate variability in the Americas. In: V. Markgraf (Editor), Interhemispheric climate linkages. Academic Press, San Diego, pp. 325-370.

Grimm E.C., W.A. Watts, G.L. Jacobson, B.C.S. Hansen, H.R. Almquist, A.C. Dieffenbacher-Krall. 2006. Evidence for warm wet Heinrich events in Florida. Quaternary Science Review 25: 2197-2211.

Haug, G.H., K.A. Hughen, D.M. Sigman, L.C. Peterson, and U. Röhl. 2001. Southward Migration of the Intertropical Convergence Zone Through the Holocene. Science 293: 1304-1308.

Hemphill-Haley, E. 1995. Diatom evidence for earthquake-induced subsidence and tsunami $300 \mathrm{yr}$ ago in southern coastal Washington. Geological Society of America Bulletin 107: 367-378.

Hendey, N.I. 1964. An introductory account of the smaller algae of British coastal waters, Part V. Bacillariophyceae. In Fisheries Investigations (Series IV). London: Great Britain Ministry of Agriculture.

Heslop, D. and A. Paul. 2011. Can oceanic paleothermometers reconstruct the Atlantic Multidecadal Oscillation? Climate of the Past 7: 151-159.

Hillesheim, M.B., D.A. Hodell, B.W. Leyden, M. Brenner, J.H. Curtis, F.S. Anselmetti, D. Ariztegui, D.G. Buck, T.P. Guilderson, M.F. Rosenmeier, and D.W. Schnurrenberger. 2005. Climate change in lowland Central America during the late deglacial and early Holocene. Journal of Quaternary Science 20: 363-376.

Hustedt, F. 1930. Die Kieselalgen Deutschlands, Österreichs und der Schweiz, 1. Teil. In L. Rabenhorst's Kryptogamen-Flora, Band 7/1:1-920. Champaign: Koeltz Scientific Books (Reprint 1991).

Hustedt, F. 1955. Marine littoral diatoms of Beaufort, North Carolina. Duke University Marine Station Bulletin 6: 1-67. 
Juggins, S. 2011. C2 data analysis v. 1.7.2 software for ecological and palaeoecological data analysis and visualization. Newcastle-upon-Tyne: University of Newcastle.

Juggins, S. 2012. rioja: Analysis of Quaternary Science Data, R package version (0.8-5). (http://cran.r-project.org/package=rioja).

Juggins, S. 2013. Quantitative reconstructions in palaeolimnology: new paradigm or sick science? Quaternary Science Reviews 64: 20-32.

Kruskal, J.B., and M. Wish. 1978. Multidimensional scaling. In J.L. Sullivan and R.G. Niemi (Editors), Quantitative applications in social sciences series 11, Sage University Series, vol. 92. Beverly Hills: Sage, pp. 1-91.

Lammertsma, E.I., F. Sangiorgi, T.H. Donders, and F. Wagner-Cremer. 2012. Mid- to late-Holocene hydrological changes at Charlotte Harbor (Florida) inferred from dinoflagellate cysts and pollen. In Biota-hyrdology interactions during the Holocene in Florida. Ph.D. dissertation. Utrecht University, Netherlands.

McCune, B., and J.B. Grace, with a contribution from D.L. Urban. 2002. Analysis of ecological communities. Gleneden Beach: MjM Software Design.

Mestas-Nuñez, A.M., and D.B. Enfield. 2003. Investigation of Intra-seasonal to Multidecadal Variability in South Florida Rainfall. NOAA/OAR Technical Memorandum Prepared for the South Florida Water Management District Under contract C-10806. Atlantic Oceanographic and Meteorological Laboratory Miami, Florida.

Moses, C.S., W.T. Anderson, C. Saunders, and F. Sklar. 2013. Regional climate gradients in precipitation and temperature in response to climate teleconnections in the Greater Everglades ecosystem of South Florida. Journal of Paleolimnology 49: 5-14.

Noss, R.F. 2011. Between the devil and the deep blue sea: Florida's unenviable position with respect to sea level rise. Climatic Change 107: 1-16.

O'Donnell, B. 1990. Peace River. In D. Marth and M. Marth (Editors), The Rivers of Florida. Sarasota: Pineapple Press, Inc., pp. 51-54.

Peragallo, H., and M. Peragallo. 1908. In Diatomees de France, ed. M.J. Tempere, 2. Grez-sur-Loing: Micrographe-Editeur.

Poore, R.Z., H. Dowsett, S. Verardo, and T.M. Quinn. 2003. Millenial- to century-scale variability in Gulf of Mexico Holocene climate records. Paleoceanography 18: 1048.

Quillen, A.K., E.E. Gaiser, and E.C. Grimm. 2013. Diatom-based paleolimnological reconstruction of regional climate and local land-use change from a protected sinkhole lake in southern Florida, USA. J Paleolimnol 49: 15-30. 
Rodbell, D.T., G.O. Seltzer, D.M. Anderson, M.B. Abbott, D.B. Enfield, and J.H. Newman. 1999. An 15,000-Year Record of El Niño-Driven Alluviation in Southwestern Ecuador. Science 283: 516-520.

Ross, M.S., J.J. O'Brien, G. Ford, K. Zhang, and A. Morkill. 2009. Disturbance and the rising tide: the challenge of biodiversity management on low-island ecosystems. Frontiers in Ecology and the Environment 7: 471-478.

Saha, A.K., S. Saha, J. Sadle, J. Jiang, M.S. Ross, R.M. Price, L.S.L. Sternberg, and K.S. Wendelberger. 2011. Sea level rise and South Florida coastal forests. Climatic Change 107: 81-108.

Sullivan, M.J. 1978. Diatom community structure: taxonomic and statistical analyses of a Mississippi salt marsh. Journal of Phycology 14: 468-475.

Sullivan, M.J. 1979. Epiphytic Diatoms of Three Seagrass Species in Mississippi Sound. Bulletin of Marine Science 29: 459-464.

Van Soelen, E.E., E.I. Lammertsma, H. Cremer, T.H. Donders, F. Sangiorgi, G.R. Brooks, R.A. Larson, J.S. Sinninghe Damste, F. Wagner-Cremer, and G.J. Reichart. 2010. Late Holocene sea-level rise in Tampa Bay: Integrated reconstruction using biomarkers, pollen, organic-walled dinoflagellate cysts, and diatoms. Estuarine, Coastal, and Shelf Science 86: 216-224.

Van Soelen, E.E., G.R. Brooks, R.A. Larson, J.S. Sinninghe Damste, and G.J. Reichart. 2012. Mid- to late-Holocene coastal environmental changes in southwest Florida, USA. The Holocene 22: 929-938.

Vitousek, Peter M., John D. Aber, Robert W. Howarth, Gene E. Likens, Pamela A. Matson, David W. Schindler, William H. Schlesinger, and David G. Tilman 1997. Human alterations of the global nitrogen cycle: sources and consequences. Ecological Applications 7: 737-750.

Wanner, H., J. Beer, J. Butikofer, T.J. Crowley, U. Cubasch, J. Fluckiger, H. Goosse, M. Grosjean, F. Joos, J.O. Kaplan, M. Kuttel, S.A. Muller, I.C. Prentice, O. Solomina, T.F. Stocker, P. Tarasov, M. Wagner, and M. Widmann. 2008. Mid- to Late Holocene climate change: an overview. Quaternary Science Reviews 27: 1791-1828.

Watts, W.A., and M. Stuiver. 1980. Late-Wisconsin climate of northern Florida and the origin of species-rich deciduous forest. Science 210:325-327.

Watts, W.A., E.C. Grimm, and T.C. Hussey. 1996. Mid-Holocene forest history of Florida and the coastal plain of Georgia and South Carolina. In K.E. Sassaman and D.G. Anderson (Editors). Archaeology of the Mid-Holocene Southeast. University Press of Florida, Gainesville, pp. 28-40. 
Witkowski, A., H. Lange-Bertalot, and D. Metzeltin. 2000. Diatom flora of marine coasts. I. Iconographia Diatomologica 7: 1-925. 


\section{DIATOM ASSEMBLAGE CHANGES REFLECT LARGE-SCALE CLIMATE CYCLES, TROPICAL CYCLONE ACTIVITY, AND ANTHROPOGENIC CHANGES DURING THE LAST 130 YEARS IN CHARLOTTE HARBOR, FLORIDA}

\section{Abstract}

Tropical cyclones occur in patterns driven by large-scale climate cycles. Paleoecological proxies for past tropical cyclone occurrence are being developed to elucidate these patterns, but most can provide only a coarse temporal resolution because they detect only the most severe storms. Diatom assemblages respond rapidly to water quality changes altered by climate phenomena and can provide a signal on multiple scales. Diatom assemblages were used to characterize different periods of the last $\sim 130$ years in a highly temporally-resolved sediment core from Charlotte Harbor, Florida, identifying major changes that occurred ca. 1890, 1980, and 1996. Assemblages throughout the core had significant correlations with the three-year average index value of the Atlantic Multidecadal Oscillation, and in the years since 1996, significant correlations with the three-year average index of the El Niño Southern Oscillation, both of which are large-scale cycles known to influence tropical cyclone activity and patterns. In order to evaluate evidence of past tropical cyclones, inference models for salinity and nutrient concentration developed in Chapter 2 were used to categorize samples and test groups for dispersion, which was shown to be reduced following a tropical storm in Chapter 3. Assemblages that suggested the lowest salinity and highest TP values also 
had the lowest dispersion; assemblages that indicate low salinity and also have low dispersion may provide a proxy for past tropical cyclone activity.

\section{Introduction}

The occurrence, intensity, and landfall patterns of hurricanes and tropical storms (tropical cyclones) are governed by several large-scale climate cycles related to global ocean-atmospheric changes, as well as smaller-scale weather patterns. Large-scale cycles, which can range from multi-annual to multi-decadal time scales, may cause climate anomalies across the globe such as severe drought in some areas with concurrent flooding in others, as well as changes in tropical cyclone activity. For example, the El Niño Southern Oscillation (ENSO) shifts on an approximate three- to five-year cycle and typically increases tropical cyclone activity in the eastern Pacific during its warm phase, while decreasing cyclone activity in the Atlantic, and generating the opposite conditions during its cool phase (summarized in Pielke Jr. and Landsea 1999). On a much larger temporal scale, the Atlantic Multidecadal Oscillation (AMO) shifts on an approximate 50 - to 90 -year cycle and generally causes increased tropical cyclone activity in the Atlantic, increased rainfall over India and the Sahel, and prolonged drought in the American Midwest during its warm phase (Landsea et al. 1999; Zhang and Delworth 2006; Nigam et al. 2011). Because reliable, instrumented weather measurements have only been recorded for at best 150 years in some localities, providing historical proxies that can extend evidence of climate changes and events further into the past and resolve 
the period of large-scale oscillations is critical to enable forecasting of both natural oscillations and how they may change with our changing climate.

Diatom assemblages preserved in sediments can provide evidence of past environmental changes based on the relative abundance of taxa present at different times (i.e. depths in a sediment core), because different taxa have measurable preferences and tolerances for different environmental parameters (Battarbee 1986; Cooper 1999). Their short generation times allow them to respond to changes in environmental conditions over time scales that integrate even shorter term fluctuations in driving variables, but also provide an early signal of directional change (Battarbee 1986; Stevenson et al. 2010). Because diatom taxa are sensitive to the types of physical and chemical properties of water that are altered by consequences of climate change, cycles, and events, the changing relative abundance of taxa may reflect climate phenomena occurring on multiple time scales.

Subtropical Florida is situated at the confluence of climate cycles that drive tropical cyclone patterns, including ENSO and the AMO, as well as the North Atlantic Oscillation (NAO) and Pacific Decadal Oscillation (PDO), which affect Florida's climate in interacting ways (Mestas-Nuñez and Enfield 2003; Moses et al. 2013). The phase changes of the AMO are reflected in Florida more significantly, but differently, than in other parts of the United States (Enfield et al. 2001). Previous paleoecological proxy records have revealed historical climate patterns such as intensifications of the ENSO cycle approximately 5,000 years ago (Rodbell et al. 1999; Donders et al. 2005) and relative stability of the AMO over the last 500 years (Gray et al. 2004), but longer records of AMO cyclicity have proved difficult to obtain (Heslop and Paul 2011). South Florida 
is also struck by tropical cyclones more frequently than any other part of the United States (Gentry 1974), and while paleoecological proxies of individual storm events have been developed, they are often at too coarse a scale to be broadly applicable (Lane et al. 2011).

Sediment-based proxies have provided evidence of past tropical cyclones from overwash deposits in sediment cores (e.g. Liu and Fearn 1993 and 2000; Donnelly et al. 2001; Lambert et al. 2003) and beach ridges constructed by surge action (Nott and Hayne 2001; Nott et al. 2009), but these phenomena only result from the most severe storms and surges, resulting in a coarse temporal resolution of storm occurrence (Lane et al. 2011). A time series analysis of sediment content stratigraphy developed the temporal resolution of tropical storm occurrence in coastal northwest Florida to the sub-decadal level, but also likely undercounted cyclone occurrence, because less severe storms were not detected (Lane et al. 2011). Additional proxies that provide evidence of change on multiple scales are needed to further improve resolution of the pace and pattern of tropical cyclone landfall across the region. Previous research has shown that diatom assemblages in a southwest Florida coastal watershed exhibit a reduction in compositional dispersion following a tropical storm; i.e., the spatial differences among assemblages are dampened (Chapter 3). The reduction in dispersion may provide a signal that can be detected on an annual scale in highly resolved sediment record and that captures activity across a broader region than occurs with a single overwash deposit.

In order to provide meaningful projections of future storm cyclicity at scales relevant to societies, ecosystems, and management, the spatial and temporal patterns of change caused by severe storms and their drivers needs to be better resolved through 
proxies that can extend evidence of events in the paleoecological record and encompass change on multiple scales. Changes in the relative abundance of diatom taxa that favor different environmental conditions may provide a signal on multiple time scales, from individual storm occurrence to broader climate cycles, and may be broadly regionally applicable. To further these goals, the specific objectives of this study were to 1) characterize the diatom assemblages in a highly temporally-resolved sediment core from a southwest Florida estuary and identify times of compositional shifts; 2) identify patterns in the timing of diatom assemblage changes that may be related to large-scale climate cycles, severe storms, and anthropogenic pressures; and 3) evaluate evidence of past storm events provided from diatom-based environmental inferences.

\section{Methods}

Materials

Push cores were collected in central Charlotte Harbor along Florida's southwest Gulf Coast (Fig. 17). Two cores were collected at each site, one using a 7.6 diameter aluminum barrel for sediment texture and composition analysis, and a companion core using $10 \mathrm{~cm}$ diameter acrylic barrel for short-lived radioisotope $\left({ }^{210} \mathrm{~Pb},{ }^{137} \mathrm{Cs},{ }^{7} \mathrm{Be}\right)$ geochronology. Analyses for geochronology were performed by Gamma emission at the USGS Short-Lived Isotope Lab, St. Petersburg, FL. Excess ${ }^{210} \mathrm{~Pb}$ was detected to a depth of $28.5 \mathrm{~cm}$ down core at 0.5 to $1.0 \mathrm{~cm}$ resolution. Dates were assigned for each data point by the Constant Rate of Supply (CRS) model described by Binford (1990). Sediment 
samples were selected for diatom analysis at $0.5 \mathrm{~cm}$ intervals to a depth of $42 \mathrm{~cm}$, for a total of 79 samples. The upper $28.5 \mathrm{~cm}$ of sediment represent approximately the last 130 years, which was used to evaluate relationships with known meteorological records.

Between 0.5 to $1 \mathrm{~g}$ of freeze-dried sediment from each sample was cleaned for diatom analysis using a series of acid baths following the oxidation technique described by Battarbee (1986). A measured aliquot of 0.02 to $0.2 \mathrm{ml}$ (depending on diatom concentration) of the diluted mixture was removed by calibrated pipette, placed on a coverslip, dried, and subsequently mounted onto glass slides using Naphrax ${ }^{\circledR}$. A minimum of 500 diatom valves were identified from each sample along measured, random transects using a Nikon E4000 light microscope at x1000 magnification. Identification of diatoms was based on diatom taxonomic literature published by Peragallo and Peragallo (1908), Hustedt (1930; 1955), Hendey (1964), Foged (1984), Witkowski et al. (2000), and Cremer et al. (2007).

Data analysis

For each sample, the abundance of all taxa relative to the total number of diatom valves counted was calculated. Taxa occurring in at least three samples with a relative abundance of at least $0.5 \%$ in at least one sample were included for statistical analyses, because inclusion of undersampled taxa may increase noise in the dataset (McCune et al. 2002). Similarity matrices were constructed using Bray-Curtis similarity to quantify and compare diatom assemblage differences among samples (Clarke and Warwick 2001). 
A constrained cluster analysis was performed by applying a constrained incremental sum of squares (Ward's) method using the rioja package in R (Juggins 2012). This agglomerative hierarchical clustering algorithm only allows groups to form from adjacent samples, identifying change points through time down a sediment core. Analysis of similarity (ANOSIM) was used to determine the similarity of groups identified by cluster analysis (Clarke and Gorley 2006). R values reported represent the difference of mean ranks of taxa by relative abundance and ranges from 0 to 1 with increasing dissimilarity; comparisons having a $p<0.05$ were considered significantly different (Clarke and Warwick 2001).

Non-metric multi-dimensional scaling (NMDS) ordination (Kruskal and Wish 1978) was used to visualize assemblage patterns throughout the core. After evaluating the stress of ordinations with up to 5 axes, two-dimensional NMDS was selected to ease the interpretability of results, given that stress did not decrease greatly with additional axes. Stress is a measure of the departure from fit of the sample dissimilarity to distance in the ordination; it tends to decrease with additional axes, as more of the sample variance is represented, but additional dimensions make interpretation increasingly difficult (McCune et al. 2002). Pearson's correlation coefficients were calculated to find the strength of the relationship between the diatom assemblage ordination and hypothesized drivers during the period of known meteorological records; variables included indices of climate drivers known to influence precipitation patterns in the watershed (AMO and multivariate ENSO index, as well as 3-year averages of each), and date and population of the surrounding area to evaluate the strength of anthropogenic influence. 
To evaluate evidence of past storm events, I calculated the dispersion of diatom assemblages grouped by reconstructed parameter estimates. In years with significant storm events, diatom inferences are expected to suggest low salinity and high nutrient concentrations for the harbor; if dispersion among samples is also reduced, as it was following a tropical storm event in the watershed (Chapter 3), it may support evidence that reduced assemblage dispersion provides an indication of storm activity. The optimal environmental conditions and tolerances of diatom taxa in the cores were determined previously using a weighted-averaging regression approach applied to modern diatom assemblages and measurements across broad environmental gradients in the Charlotte Harbor watershed (Chapter 2). This method enables calculation of a quantitative model of environmental variables based on the optima and tolerances of taxa present in a sample. The weighted-averaging regression approach assumes that taxa with optima closest to the observed value of an environmental parameter will be most abundant where that value occurs (Birks 1995). Using the diatom inference models developed in Chapter 2, salinity and TP and TN concentrations were estimated for each sample in the core. Based on these estimates, each sample was categorized as high, medium, or low, based on whether its parameter estimate fell above, within, or below (respectively) one standard deviation of the mean.

To evaluate dispersion among samples in each respective group, an index of multivariate dispersion (IMD) was calculated to examine the relative variability among assemblages from the high, medium, and low groups for each environmental parameter. IMD values contrast the average rank of similarities within groups to provide a metric of dispersion, but they do not provide a statistical framework appropriate for testing (Clarke 
and Warwick 2001). ANOSIM, NMDS, and IMD analyses were conducted using Primer version 6 (Clarke and Gorley 2006).

\section{Results}

Diatom assemblage transitions

A total of 203 diatom taxa were found in the sediment core, and approximately half of these were uncommon; 100 taxa met the criteria to be included in statistical analyses based on sample similarity. The most abundant taxa were Paralia sulcata (Ehrenberg) Cleve, Cyclotella litoralis Lange \& Syvertsen, Amphicocconeis disculoides (Hustedt) De Stefano and Marino, Rhizosolenia cf. setigera Brightwell, and Actinoptychus senarius (Ehrenberg) Ehrenberg. Stratigraphically-constrained cluster analysis of the diatom assemblages revealed that the core could be divided into four zones that capture significant changes through time (Fig. 18); there were additional points of significant change, but the four groups delineated by the first two branches of the dendrogram were selected in order to keep a meaningful number of samples in each zone (Borcard et al. 2011). The first branch occurred in approximately $1980(\mathrm{R}=0.86)$, and the second level branches occurred in approximately 1890 and 1996-1997 $(\mathrm{R}=0.38$ and 0.53, respectively). Additional significant changes occurred at branches three and four of the cluster dendrogram (Fig. 18).

Dominant taxa differed markedly among the four zones, with $C$. litoralis and $A$. disculoides being the only two abundant taxa that maintained comparatively consistent 
relative abundance throughout the core (Fig. 19). In Zone 4 P. sulcata was overwhelmingly dominant, with consistently high relative abundance that reached as great as $70 \%$. P. sulcata was also dominant in Zone 3, but with slightly lower relative abundance. At the transition to Zone 2 around 1980, both $P$. sulcata and A. senarius decreased in relative abundance, as did Dimmeregramma minor (Gregory) Ralfs ex Pritchard and Triceratium scitulum T. Brightwell. This transition was also marked by the appearance or increase in abundance of $R$. cf. setigera and Thalassionema nitzschioides (Grunow) Mereschkowsky. Zone 1, following the transition that occurred in the mid1990 s, is characterized by the further reduction in abundance of $P$. sulcata and the appearance or additional increase of $R$. cf. setigera, Chaetoceros resting spores, and Bacillaria paradoxa J.F.Gmelin.

The trajectory of diatom assemblage fluctuations through time shown in NMDS ordination provides a visual representation of the magnitude and direction of compositional changes (Fig. 20). From the oldest samples in Zone 4 to the most recent samples in Zone 1, there is increasing dissimilarity and variability among the samples. Zones 3 and 4 form relatively tight and overlapping clusters in the ordination, while Zones 1 and 2, representing the period since approximately 1980, are distinct from the older samples and form more expansive groups that indicate greater dissimilarity within and among them. Since time was strongly related to the assemblage changes (there is a general progression from past to present along the $\mathrm{x}$-axis of the ordination) and the sediment accumulation rate changed throughout the period, additional ordinations were generated for the period of known meteorological records and each zone to evaluate 
hypothesized drivers on smaller scales to minimize the variability driven by time (Fig. 21).

Relationships with drivers

Over the represented period from $\sim 1893$ to 2009 , diatom assemblages were significantly correlated with the 3-year averages of the AMO and ENSO indices, as well as time and the surrounding population, but not the AMO or ENSO index of the given year (Table 11). In Zone 1, assemblages were significantly correlated with the AMO, both in the given year and the 3-year average, as well as the ENSO 3-year average. Zone 2 diatom assemblages remained significantly correlated with time, and also the AMO 3year average, while Zone 3 assemblages were significantly correlated with both time and the surrounding population, as well as the AMO index for each year and its 3-year average. Zone 4 was not evaluated using this method, as sample dates and meteorological records were not available.

Samples were divided into two subsets, pre- and post-1980, for IMD analysis based on the reconstructed environmental estimates because the significant differences between the two groups resulted in large variability of parameter estimates. In both groups, dispersion was the lowest in the samples that predicted low salinity and high TP (Fig. 22). In most cases, the highest dispersion was found in the samples within one standard deviation of the mean parameter estimate. Patterns of dispersion related to TN were not clear, and differed before and since $\sim 1980$. Samples that resulted in predictions of both low salinity and high TP were all from relatively recent years, from 2000 to 2006, 
with the exception of two older samples from the period before $\sim 1890$. Low salinity was also predicted by diatom-inference models from samples from the mid-1930s, early 1950s, mid-1960s, and early 1970s, as well as four samples from before $\sim 1890$; high TP was also predicted by one sample representing approximately 1997 as well as two other samples from before $\sim 1890$.

\section{Discussion}

Diatom assemblage transitions

Diatom assemblage changes in the Charlotte Harbor watershed are related to both large-scale climate changes and anthropogenic factors at different times throughout the last $\sim 130$ years. One of the first recorded changes in diatom assemblage occurred ca. 1890, which is about a decade after one of the main drainages into Charlotte Harbor, the Caloosahatchee, began to be channelized and connected to Lake Okeechobee as part of early efforts to drain the Everglades. Over the next decades, the historically shallow, meandering flow-way was deepened and straightened to facilitate flood control and navigation (Lane 1990). During approximately the same period, the sedimentation rate in the region of Charlotte Harbor where the core was collected increased dramatically (Van Soelen et al. 2012). These factors may have influenced diatom assemblages as salinity and nutrient regimes changed with increased connectivity to Lake Okeechobee; deepening of the water column with channelization and loss of wetlands also altered hydrological patterns that influence sedimentation rates and diatom distribution. 
Prior to $\sim 1890$, the dominant diatom in all assemblages was $P$. sulcata, a cosmopolitan and polyhalobous species (Cremer et al. 2007). Importantly, this species has also been reported to preferentially preserve over other taxa due to its heavily silicified valves, so its dominance may be indicative of a poor environment for preservation (Hemphill-Haley 1995). Poor valve preservation can be attributed to numerous environmental characteristics, including water chemistry, basin morphology, and microhabitat, but notably it is also associated with low sedimentation rates due to prolonged exposure of valves to water and turbulence (Flower 1993). As the sedimentation rate in this basin increased from $0.02 \mathrm{~cm} /$ year to $0.74 \mathrm{~cm} /$ year approximately 100 years ago (Van Soelen et al. 2012), it seems likely that the dominance of $P$. sulcata in Zone 4 is at least partially attributable to poor preservation of other taxa.

P. sulcata remained the dominant taxon in Zone 3, but in slightly lower relative abundance because of the increases in other taxa, including A. disculoides and $A$. senarius. Late in Zone 3, a third level division in the constrained cluster dendrogram occurred in the late 1960s. This shift, which was also statistically significant, was characterized by the appearance of T. nitzschoides and T. pseudonitzschoides (G.Schuette \& H.Schrader) G.R.Hasle. These taxa have previously been associated with dry conditions and higher salinity in another eastern United States estuary (Mallin et al. 1991), but little has been published on their autecology in the region. The group of assemblages from the late 1960 s to 1980 ( 6 samples $)$ was not assigned to a zone distinct from the rest of Zone 3 due to its small sample size, but the timing of this significant shift is interesting in that it coincides with a transition to the cool phase of the AMO. The cool phase of the AMO decreases precipitation in South/Central Florida 
(Enfield et al. 2001), so the appearance of these taxa in the late 1960s provides additional evidence that they are associated with relatively drier conditions in estuarine systems and may be indicators of decreased precipitation. A fourth level branch occurs in the cluster dendrogram within Zone 3 in the late 1920s, when the AMO shifted from a cool phase to the warm phase that ended in the late 1960s; that these two phase shifts both occurred within Zone 3 may be the reason that diatom assemblages in Zone 3 were the most strongly correlated with AMO indices compared to other zones and to the whole time series. The only hypothesized drivers that were not significantly correlated with Zone 3 assemblages were the ENSO indices; the multivariate ENSO index is only available after 1950 , so it is possible that these correlations were weak due to the relatively small sample size of assemblages since 1950 (approximately half the samples in Zone 3).

The next significant assemblage change was the major transition between Zones 3 and 2 that occurred in approximately 1980. Throughout the 1900s, the sedimentation rate continued to increase in Charlotte Harbor, which is commonly attributed to increasing development in the watershed, as the population has doubled every decade since midcentury. However, there is evidence that the increasing sedimentation rate may not be consistent through time; in approximately 1980, a sudden pulse of organic-rich sediment resulted in deposition of a 3-cm layer over parts of the Charlotte Harbor basin, suggesting that increasing sedimentation may be event-based and episodic rather than constant (Brooks et al. 2006). Consistent with this concept, the age/depth model for this sediment core is consistent with this idea in that the recent record does not show a smooth increase, and the assemblage shifts in the late 1960s and 1980 appear to roughly correspond with pulse sedimentation events. 
The major assemblage change that occurred around 1980 cannot be easily explained by any known change to Charlotte Harbor at that time; although some conservation efforts did begin around that time, they were slow to be implemented (FDEP 2012). It is likely related to the sudden influx of sediment that appears to have originated in the Peace River, one of the major inflows to the harbor; the deposit occurs at the mouth of the Peace River as well as in the central harbor but not at the mouth of the other inflowing rivers (Brooks et al. 2006), but its direct cause is unknown. The early 1980s were also relatively active tropical cyclone years, which were then followed by a warm ENSO phase beginning in 1982. However, this portion of the core has high temporal resolution and the precise data suggest that the assemblage changes occurred earlier in the decade, around 1980. Zone 2 was not significantly correlated with ENSO indices, but the whole time series of the sediment core was correlated with the ENSO 3year average. It has been hypothesized that the organic-rich deposit facilitated the onset of hypoxic conditions in the harbor (Brooks et al. 2006). A hypoxic zone that can approach $90 \mathrm{~km}^{2}$ (Camp, Dresser, and McKee, Inc. 1998) now regularly occurs during periods of high freshwater inflow such as after a tropical cyclone (Tomasko et al. 2006; Stevens et al. 2006). Hypoxia has been recorded periodically in the bottom waters of the harbor since the mid-1970s (Heyl 1998), but it is possible that the sediment influx around 1980 was the catalyst for its regular occurrence, which could have driven changes in the diatom assemblages.

The next assemblage shift occurred in approximately 1996-1997 and is characterized by increases in Chaetoceros resting spores and Rhizosolenia. Chaetoceros resting spores have previously been identified as anthropogenic impact indicators 
associated with eutrophication (Witak et al. 2011); these spores are also heavily silicified and preserve well in sediments (Spaulding and Edlund 2008), so their relative absence prior to the recent period is not likely an artefact of preservation. Rhizosolenia, by contrast, are very lightly silicified but do not appear in the record until approximately 1980 and then increase markedly in relative abundance following the 1996-1997 transition. Interestingly, this transition roughly coincides with the return to the warm phase of the AMO, and Zone 1 assemblages, which encompass the period since that time, were significantly correlated with the AMO in each year and the 3-year average, although there has not been a subsequent shift in the AMO. This may suggest that Zone 1 assemblages are associated with modern day warm phase AMO conditions, and could possibly provide an indicator of future transitions.

Evidence of past storm events

Lower dispersion characterized assemblages with low salinity and high TP inferences. As decreased dispersion was documented in samples from the watershed following a tropical storm (Chapter 3), it is possible that predictions of low salinity and/or high TP coupled with lower dispersion are proxies that can be used to evaluate past tropical storm occurrence. Assemblages with low salinity and high TP inferences were from approximately 2000, 2002, 2004, and 2005. In 2004 and 2005, major storms affected the Charlotte Harbor watershed; notably Hurricane Charley in 2004 was a category 4 hurricane that made landfall near the harbor and traveled up the Peace River, and 2005 was the most active hurricane season in recorded history, with Hurricanes Rita 
and Wilma directly affecting the watershed. The predictions for 2000 and 2002 do not correspond to major storm years for the area; however, the connection of Lake Okeechobee to the Caloosahatchee River created interaction between the estuary and much of South/Central Florida, confounding regional interpretations. Water releases to the estuary from Lake Okeechobee are managed in cooperation between the U.S. Army Corps of Engineers and the South Florida Water Management District, and while current information is readily available, records of the timing and volume of past releases are difficult to obtain. It is possible that 2000 and 2002 were high water-release years that would mimic the effects of increased flow following a severe storm.

Other samples that predicted low salinity roughly correspond with years that tropical cyclones passed within $200 \mathrm{~km}$ of the harbor, with one exception in the early 1970s. The other assemblage that predicted high TP did not correspond with any known storm event. Predictions of TN had no discernible pattern; in previous analyses, assemblage relationships with TP and TN proved to be highly region-specific following a tropical storm, with different patterns of change in different sub-basins across the watershed (Chapter 3). The relationship between assemblage and salinity, in contrast, was strong and consistent across the watershed and its sub-basins (Chapter 3), so diatominferred salinity is the best metric to evaluate past storm events using an assemblage weighted-averaging approach for the watershed. Together with lower dispersion among samples, diatom-inferred low salinity may provide a tool for estimating when storms may have occurred in the paleoecological record.

The episodic sedimentation discussed above may also be evidence of storm events; however, many of the pulses do not correspond to known storms, possibly 
including the sudden deposit around 1980. The cause of such dramatic pulses of sediment remains unclear, but they are most likely driven by a variety of interacting factors, from anthropogenically-derived effluence to severe storms to large-scale climate cycles. The Peace River is naturally enriched in P, and has historically been dredged and mined for phosphate (O’Donnell 1990), periodically affecting runoff and sedimentation (Martin and Kim 1977). As it was likely the physical source of the 1980 deposit, episodic dumping and other anthropogenic effects must be considered in concert with larger environmental drivers in the modern record.

\section{Conclusions and future directions}

This research demonstrates that there have been significant and directional changes in diatom assemblages over the period of known climatological records and anthropogenic effects in Charlotte Harbor. It is difficult to separate these drivers of change, but while anthropogenic effects appear to be a directional change that has progressed through time, during times of relative stability (within the zones designated in this study) it is clear that large-scale climate drivers are also related to assemblage shifts. At different times, it appears that different drivers were the most likely cause of major shifts in diatom assemblages. This sediment core provided a high-resolution temporal record of changes in the harbor, but fluctuations in the sedimentation rate made it difficult to identify a true time series that could be used to identify patterns through time related to climate shifts. Individual storm events in the record are also difficult to separate from likely anthropogenic impacts, but samples predicted to have low salinity by 
the diatom assemblages did correlate with some known storms. Lower dispersion in these samples builds on previous research (Chapter 3) and suggests that low diatominferred salinity in the paleoecological record, along with lower dispersion, may be an indication of enhanced storm activity in a given time period. In future research, it would be useful to test the method on other highly temporally-resolved sediment cores around the region (such as from Tampa Bay, discussed in Chapter 4) across the same time period to evaluate its applicability on a broader spatial scale and evaluate the importance of local effects.

\section{Acknowledgments}

This research was conducted in collaboration with the palaeoecology research group at Utrecht University. I would like to thank Drs. Friederike Wagner-Cremer and Timme Donders for providing materials and invaluable advice and assistance throughout the project. I would also like to thank Dr. Gregg Brooks at Eckerd College for providing the sediment core age model and helpful assistance with its interpretation. 
Table 11. Pearson's correlation coefficients for each hypothesized driver with the diatom assemblage ordination. ${ }^{*}$ designates statistical significance at $\mathrm{p}<0.05$.

\begin{tabular}{lcccc}
\hline Driver & All dates & $\begin{array}{c}\text { Zone } 1 \\
(\sim 1996 \text { to } 2009)\end{array}$ & $\begin{array}{c}\text { Zone } 2 \\
(\sim 1980 \text { to } 1996)\end{array}$ & $\begin{array}{c}\text { Zone 3 } \\
(\sim 1893 \text { to 1980 })\end{array}$ \\
\hline AMO & 0.218 & $0.635^{*}$ & 0.287 & $0.714^{*}$ \\
AMO 3-yr & $0.320^{*}$ & $0.549^{*}$ & $0.578^{*}$ & $0.606^{*}$ \\
ENSO & 0.212 & 0.365 & -0.113 & 0.204 \\
ENSO 3-yr & $0.300^{*}$ & $0.535^{*}$ & -0.346 & 0.244 \\
Population & $0.938^{*}$ & -0.163 & -0.225 & $-0.718^{*}$ \\
Year & $0.858^{*}$ & -0.223 & $-0.538^{*}$ & $-0.582^{*}$
\end{tabular}


Fig. 17. Map showing location of the sediment core taken from Charlotte Harbor.

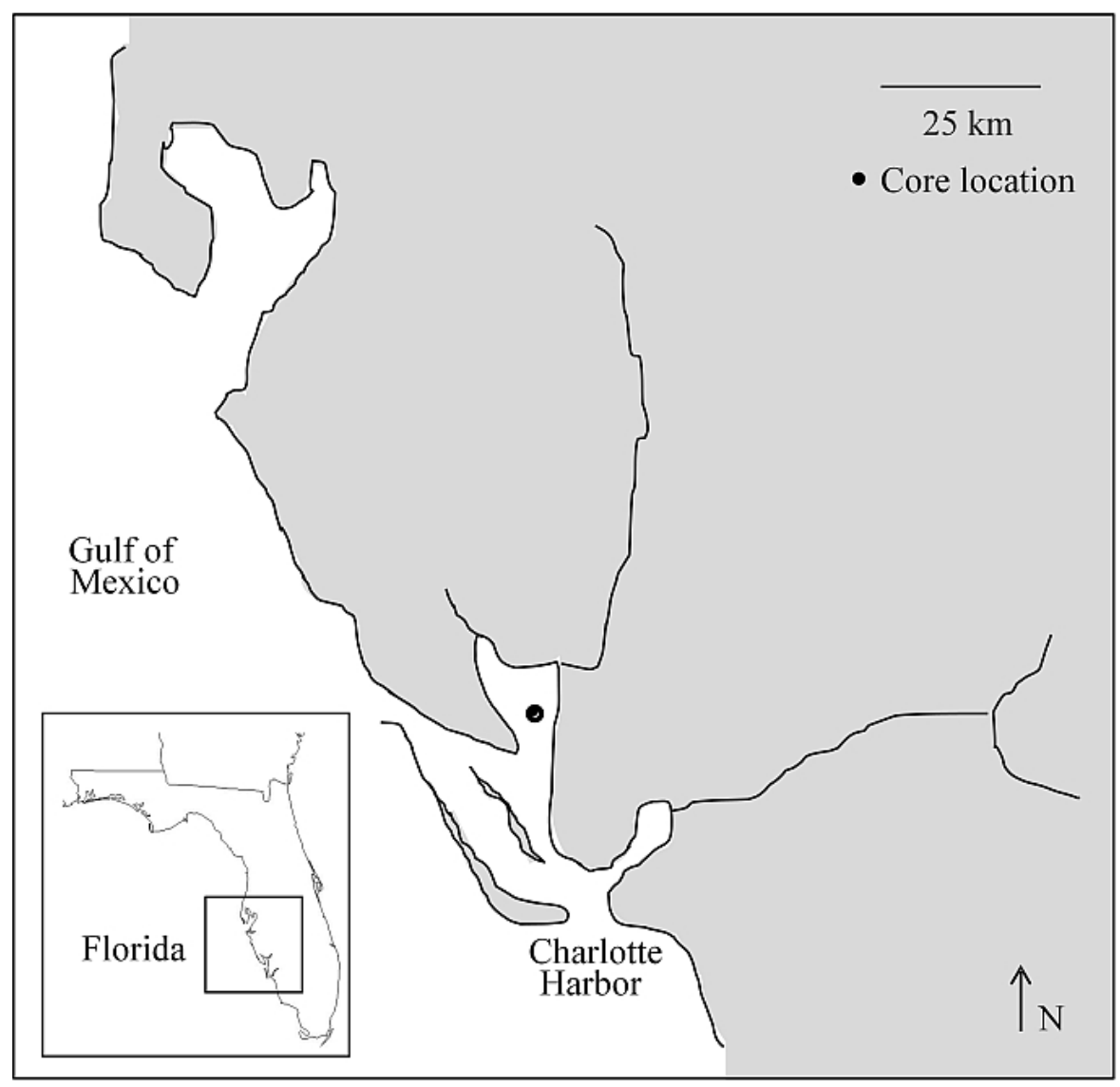


Fig. 18. Constrained cluster analysis dendrogram showing sample division into zones at first two branches (dotted lines).

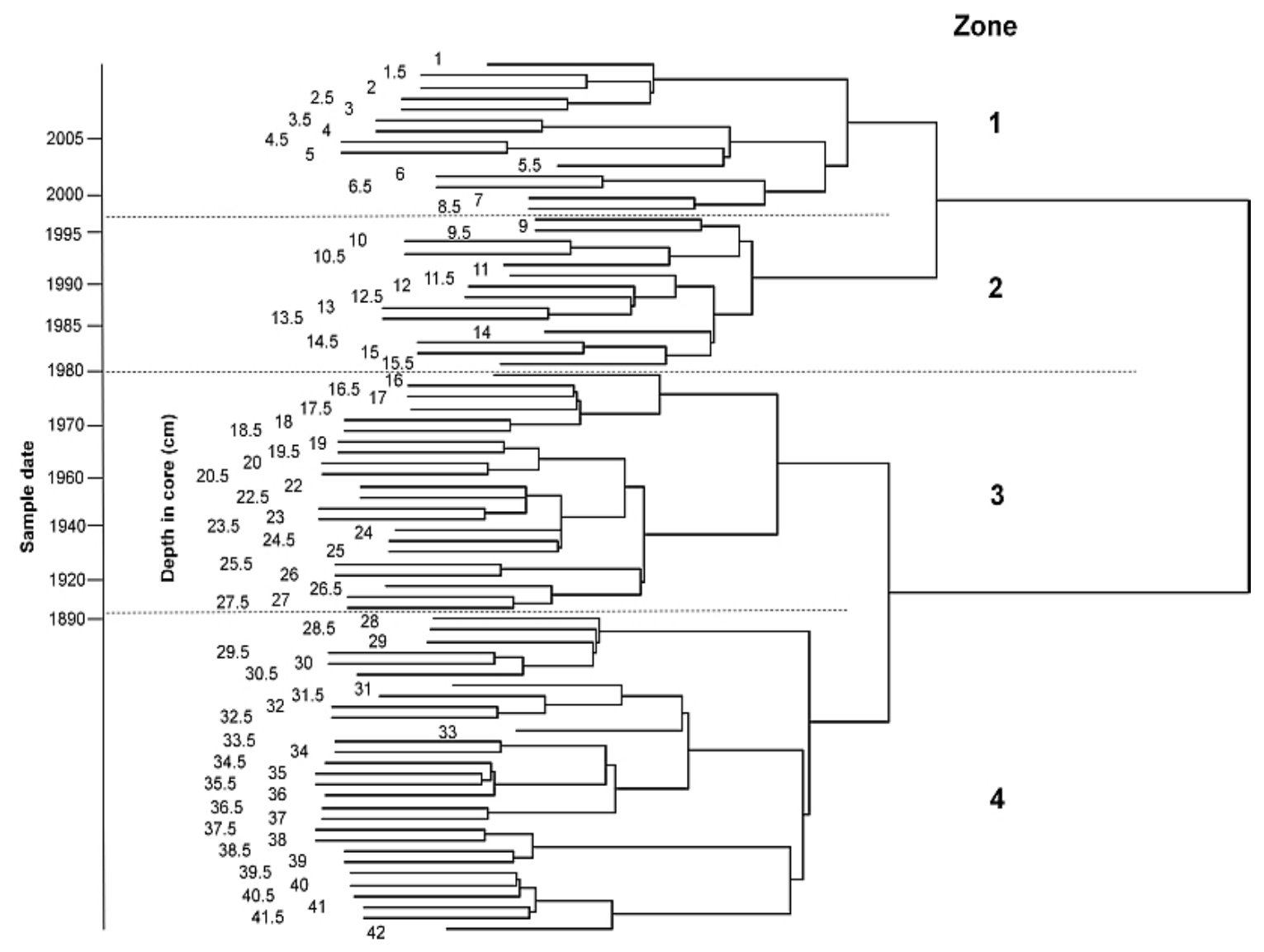


Fig. 19. Stratigraphy plots showing percent relative abundance of abundant diatom taxa with depth in core. Gray and white bands illustrate zones defined by constrained cluster analysis (number on right).

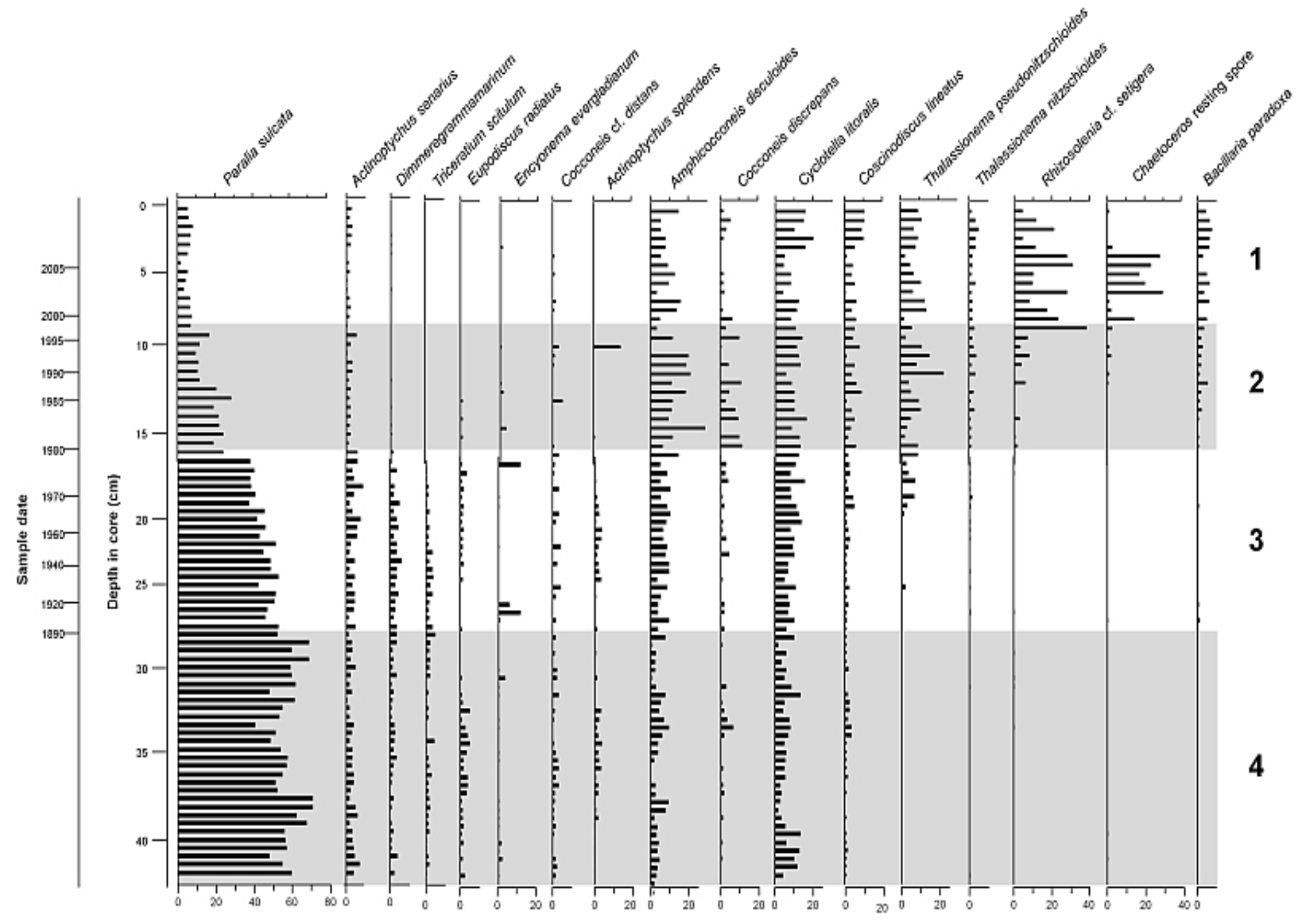


Fig. 20. Nonmetric multidimensional scaling ordination diagrams based on Bray-Curtis similarity of diatom assemblages in sediment core. Solid line represents the trajectory of time from the surface sample to the oldest; approximate dates are labeled along the trajectory. Dotted circles delineate zones defined by constrained cluster analysis.

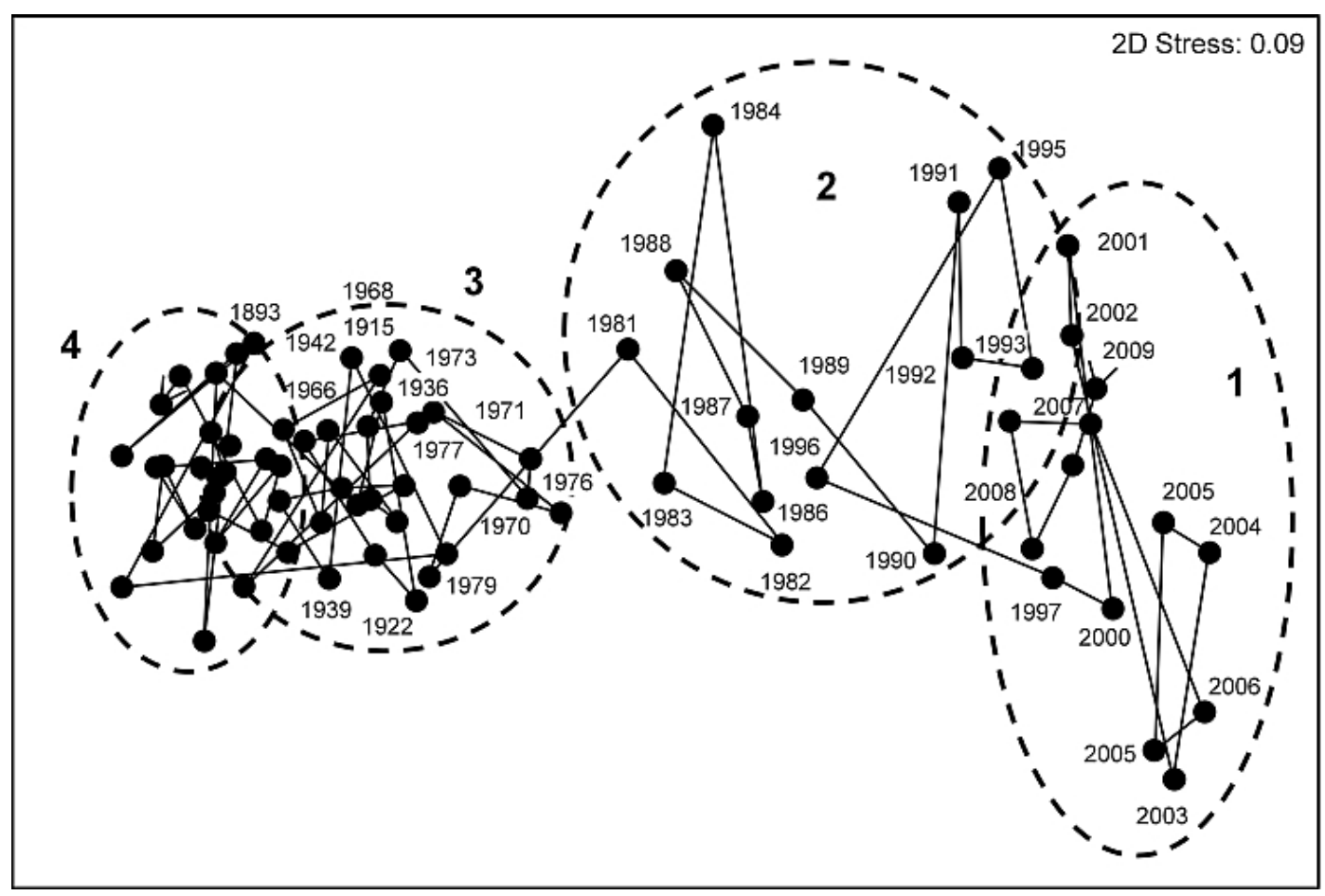


Fig. 21. Nonmetric multidimensional scaling ordination diagrams based on Bray-Curtis similarity of diatom assemblages from the period of known records in the sediment core and correlations with hypothesized drivers overlaid. Drivers include the AMO index and 3-year average, the ENSO index and 3-year average, the population of the surrounding watershed (Pop), and the year represented. All ordinations are rotated to align the year with the X-axis: a) all dated samples, from 1893 to 2009; b) Zone 1 representing 1996 to 2009; Zone 2 representing 1980 to 1996; and the later portion of Zone 3 that includes ENSO values representing $~ 1950$ to 1980.
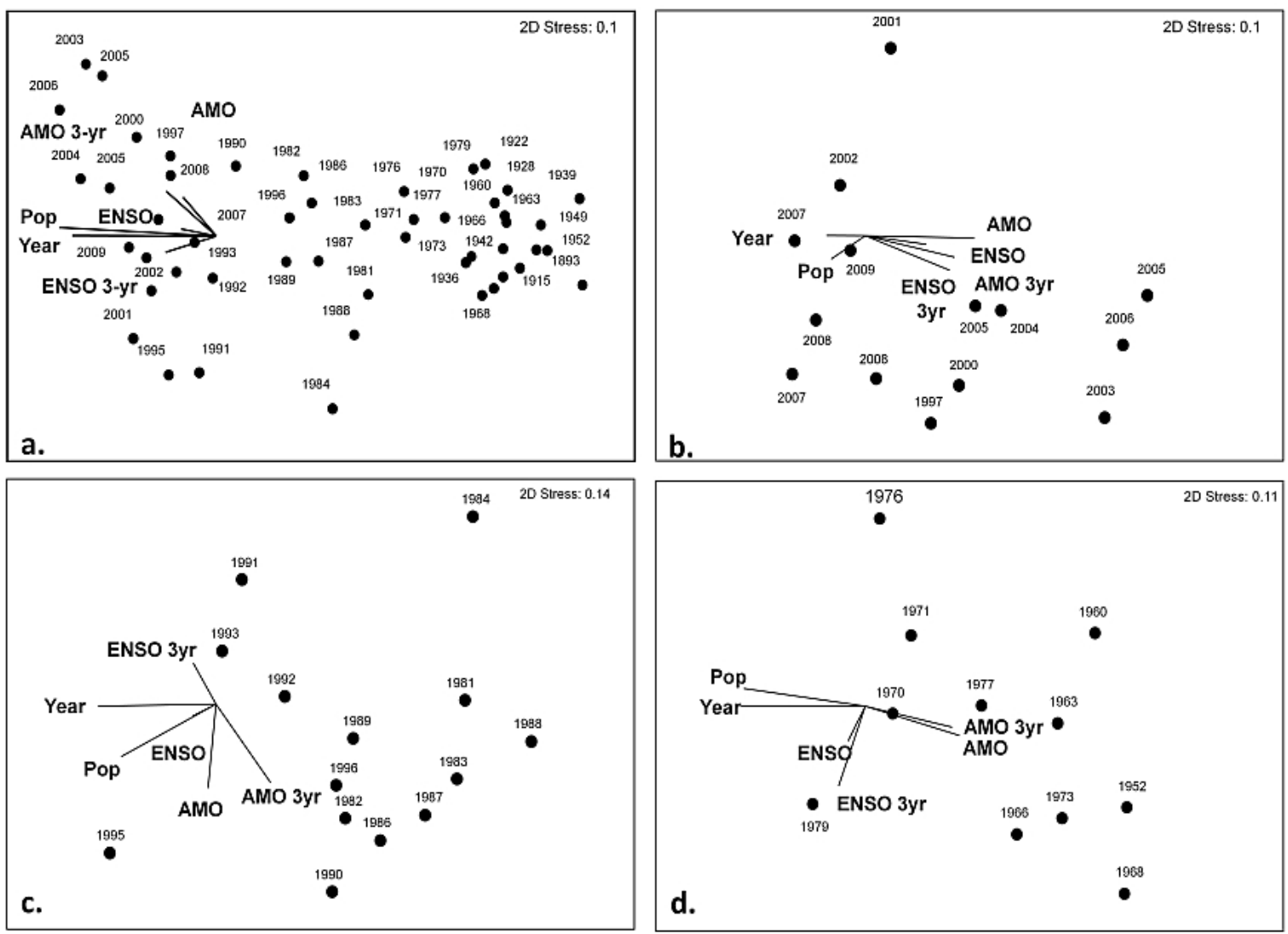
Fig. 22. Bar graphs of the IMD value (number above each bar) for each sample group: those with diatom-inferred estimates higher than $(\mathrm{H})$, within $(\mathrm{M})$, and lower than $(\mathrm{L})$ one standard deviation from the mean parameter estimate.

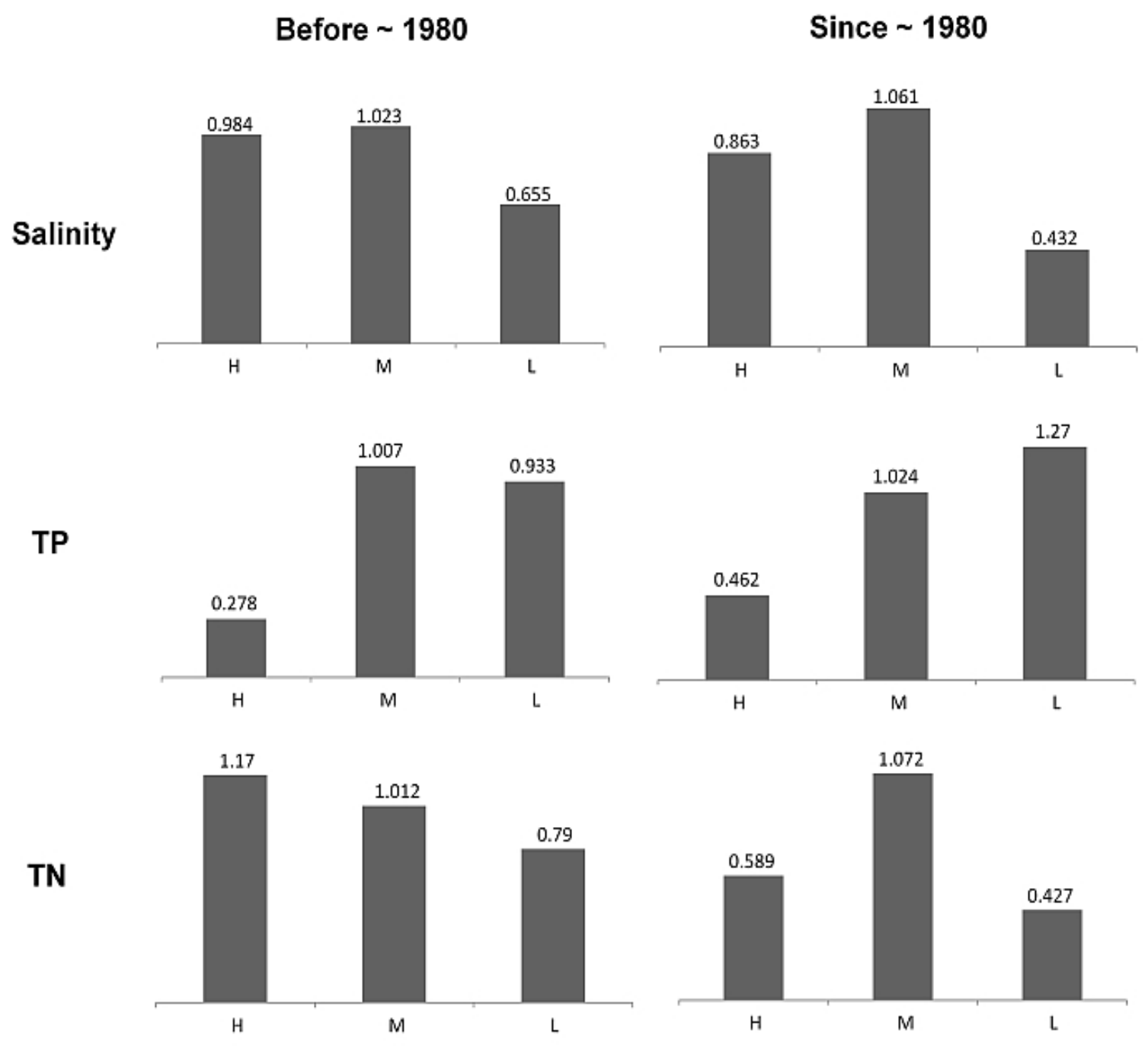




\section{References}

Battarbee, R.W. 1986. Diatom analysis. In B.E. Berglund (Editor), Handbook of Holocene palaeoecology and palaeohydrology. Caldwell: Blackburn, 527-570.

Binford, M.W. 1990. Calculation and uncertainty analysis of ${ }^{210} \mathrm{~Pb}$ dates for PIRLA project lake sediment cores. Journal of Paleolimnology 3: 253-267.

Birks, H.J.B. 1995. Quantitative paleoenvironmental reconstructions. In D.Maddy and J.S. Brew (Editors), Statistical Modelling of Quaternary Science Data, Technical Guide No. 5. Quaternary Research Association, Cambridge, pp. 161-236.

Borcard, D., F. Gillet, and P. Legendre. 2011. Cluster Analysis. In Borcard, D., F. Gillet, and P. Legendre, Numerical Ecology with R. New York: Springer, pp. 53-114.

Brooks, G.R., C.W. Holmes, and R.A. Larson. 2006. Recent Depositional History of Charlotte Harbor, Florida: Phase II -Anthropogenic Controls on Sediment Input and Hypoxia, Final Rept. Mote Marine Laboratory, Sarasota, FL.

Camp, Dresser, and McKee, Inc. 1998. The study of seasonal and spatial patterns of hypoxia in Upper Charlotte Harbor. Final Report to Surface Water Improvement and Management Section. Record Number QH 541.5 E8 S68. Tampa: Southwest Florida Water Management District.

Clarke, K.R., and W.M. Warwick. 2001. Change in marine communities: An approach to statistical analysis and interpretation. Plymouth: Primer-E Ltd.

Clarke, K.R., and R.N. Gorley. 2006. Primer v6: user manual/tutorial. Plymouth: Primer-E Ltd.

Cooper, S.R. 1999. Estuarine paleoenvironmental reconstructions using diatoms. In E.F Stoermer and J.P. Smol (Editors), The Diatoms: Applications for the Environmental and Earth Sciences, $1^{\text {st }}$ edition, pp. 352-373.

Cremer, H., F. Sangiorgi, F. Wagner-Cremer, V. McGee, A.F. Lotter, and H. Visscher. 2007. Diatoms (Bacillariophyceae) and Dinoflagellate Cysts (Dinophyceae) from Rookery Bay, Florida, U.S.A. Caribbean Journal of Science 43: 23-58.

Donders, T.H., F. Wagner, D.L. Dilcher, and H. Visscher. 2005. Mid- to late-Holocene El Niño - Southern Oscillation dynamics reflected in the subtropical terrestrial realm. Proceedings of the National Academy of Sciences of the USA 102: 10904-10908. 
Donnelly, J. P., S.S. Bryant, J. Butler, J. Dowling, L. Fan, N. Hausmann, P. Newby, B. Shuman, J. Stern, K. Westover, and T. Webb, III. 2001. 700 yr sedimentary record of intense hurricane landfalls in southern New England. Geological Society of America Bulletin 113: 714-727.

Enfield, D.B., A.M. Mestas-Nuñez, and P.J. Trimble. 2001. The Atlantic Multidecadal Oscillation and its Relation to Rainfall and River Flows in the Continental U.S. Geophysical Research Letters 28: 2077-2080.

FDEP. 2012. Charlotte Harbor Estuary. Florida Forever Annual Report. Tallahassee: Florida Department of Environmental Protection.

Flower, R.J. 1993. Diatom preservation: experiments and observations on dissolution and breakage in modern and fossil material. Hydrobiologia 269-270: 473-484.

Foged, N. 1984. Freshwater and littoral diatoms from Cuba. Bibliotheca Diatomologica 5: $1-243$.

Gray, S.T., L.J. Graumlich, J.L. Betancourt, and G.T. Pederson. 2004. A tree-ring based reconstruction of the Atlantic Multidecadal Oscillation since 1567 A.D. Geophysical Research Letters 31: L12205.

Hemphill-Haley, E. 1995. Diatom evidence for earthquake-induced subsidence and tsunami $300 \mathrm{yr}$ ago in southern coastal Washington. Geological Society of America Bulletin 107: 367-378.

Hendey, N.I. 1964. An introductory account of the smaller algae of British coastal waters, Part V. Bacillariophyceae. In Fisheries Investigations (Series IV). London: Great Britain Ministry of Agriculture.

Heslop, D. and A. Paul. 2011. Can oceanic paleothermometers reconstruct the Atlantic Multidecadal Oscillation? Climate of the Past 7: 151-159.

Heyl, M.G. 1998. Hypoxia in Upper Charlotte Harbor. In S. Treat (Editor), Proceedings of the Charlotte Harbor Public Conference and Technical Symposium; 1997 March 1516; Punta Gorda, Fla. Charlotte Harbor National Estuary Program Technical Report No. 98-02. West Plam Beach, FL: South Florida Water Management District.

Hustedt, F. 1930. Die Kieselalgen Deutschlands, Österreichs und der Schweiz, 1. Teil. In L. Rabenhorst's Kryptogamen-Flora, Band 7/1:1-920. Champaign: Koeltz Scientific Books (Reprint 1991).

Hustedt, F. 1955. Marine littoral diatoms of Beaufort, North Carolina. Duke University Marine Station Bulletin 6: 1-67. 
Juggins, S. 2012. rioja: Analysis of Quaternary Science Data, R package version (0.8-5). (http://cran.r-project.org/package=rioja).

Kruskal, J.B., and M. Wish. 1978. Multidimensional scaling. In J.L. Sullivan and R.G. Niemi (Editors), Quantitative applications in social sciences series 11, Sage University Series, vol. 92. Beverly Hills: Sage, pp. 1-91.

Lambert, W.J., P. Aharon, and A.B. Rodriquez. 2003. An Assessment of the Late Holocene Record of Severe Storm Impacts from Lake Shelby, Alabama. Gulf Coast Association of Geological Societies Transactions 53: 443-452.

Landsea, C. W., R. A. Pielke, Jr., A. M. Mestas-Nuñez, and J. A. Knaff. 1999. Atlantic Basin Hurricanes: Indices of Climatic Changes. Climatic Change 42: 89-129.

Lane, D.P., J.P. Donnelly, J.D. Woodruff,, and A.D. Hawkes. 2011. A decadallyresolved paleohurricane record archived in the late Holocene sediments of a Florida sinkhole. Marine Geology 287: 14-30.

Lane, G. Jr. 1990. Caloosahatchee River. In D. Marth and M. Marth (Editors), The Rivers of Florida. Sarasota: Pineapple Press, Inc., pp. 41-44.

Liu, K.-b., and M. L. Fearn. 1993. Lake-sediment record of late Holocene hurricane activities from coastal Alabama. Geology 21: 793-796.

Liu, K.-b., and M. L. Fearn. 2000. Reconstruction of prehistoric landfall frequencies of catastrophic hurricanes in northwestern Florida from lake sediment records. Quaternary Research 54: 238-245.

Mallin, M.A., H.W. Paerl, and J. Rudek. 1991. Seasonal phytoplankton composition, productivity and biomass in the Neuse River estuary, North Carolina. Estuarine, Coastal and Shelf Science 32: 609-623.

Martin, D.F., and Y.S. Kim. 1977. Long term Peace River characteristics as a measure of a phosphate slime spill impact. Water Research 11: 963-970.

McCune, B., and J.B. Grace, with a contribution from D.L. Urban. 2002. Analysis of ecological communities. Gleneden Beach: MjM Software Design.

Mestas-Nuñez, A.M., and D.B. Enfield. 2003. Investigation of Intra-seasonal to Multidecadal Variability in South Florida Rainfall. NOAA/OAR Technical Memorandum Prepared for the South Florida Water Management District Under contract C-10806. Atlantic Oceanographic and Meteorological Laboratory Miami, Florida. 
Moses, C.S., W.T. Anderson, C. Saunders, and F. Sklar. 2013. Regional climate gradients in precipitation and temperature in response to climate teleconnections in the Greater Everglades ecosystem of South Florida. Journal of Paleolimnology 49: 5-14.

Nigam, S., B. Guan, and A. Ruiz-Barradas. 2011. Key role of the Atlantic Multidecadal Oscillation in 20th century drought and wet periods over the Great Plains, Geophysical Research Letters 38: L16713.

O'Donnell, B. 1990. Peace River. In D. Marth and M. Marth (Editors), The Rivers of Florida. Sarasota: Pineapple Press, Inc., pp. 51-54.

Peragallo, H., and M. Peragallo. 1908. In Diatomees de France, ed. M.J. Tempere, 2. Grez-sur-Loing: Micrographe-Editeur.

Pielke Jr., R.A. and C.N. Landsea, 1999: La Niña, El Niño and Atlantic Hurricane Damages in the United States. Bulletin of the American Meteorological Society 80: 2027-2033.

Rodbell, D.T., G.O. Seltzer, D.M. Anderson, M.B. Abbott, D.B. Enfield, and J.H. Newman. 1999. An 15,000-Year Record of El Niño-Driven Alluviation in Southwestern Ecuador. Science 283: 516-520.

Spaulding, S., and M. Edlund. 2008. Chaetoceros. In Diatoms of the United States. Retrieved July 14, 2014, from http://westerndiatoms.colorado.edu/taxa/genus/Chaetoceros.

Stevens, P.W, D.A. Blewett, and J.P. Casey. 2006. Short-term effects of a low dissolved oxygen event on estuarine fish assemblages following the passage of hurricane Charley. Estuaries and Coasts 29: 997-1003.

Stevenson, R.J., Y. Pan, and H. Van Dam. 2010. Assessing environmental conditions in rivers and streams with diatoms. In E.F. Stoermer and J.P. Smol (Editors), The Diatoms: Applications for the Environmental and Earth Sciences, $2^{\text {nd }}$ edition. Cambridge: Cambridge University Press, pp. 57-85.

Tomasko, D.A., C. Anastasiou, and C. Kovach. 2006. Dissolved oxygen dynamics in Charlotte Harbor and its contributing watershed, in response to Hurricanes Charley, Frances, and Jeanne - Impacts and recovery. Estuaries and Coasts 29: 932-938.

Van Soelen, E.E., G.R. Brooks, R.A. Larson, J.S. Sinninghe Damste, and G.J. Reichart. 2012. Mid- to late-Holocene coastal environmental changes in southwest Florida, USA. The Holocene 22: 929-938. 
Witak, M., J. Dunder, and M. Lesniewska. 2011. Chaetoceros resting spores as indicators of Holocene paleoenvironmental changes in the Gulf of Gdansk, southern Baltic Sea. Oceanological \& Hydrobiological Studies 40: 21-29.

Witkowski, A., H. Lange-Bertalot, and D. Metzeltin. 2000. Diatom flora of marine coasts. I. Iconographia Diatomologica 7: 1-925.

Zhang, R. and T.L. Delworth. 2006. Impact of Atlantic multidecadal oscillations on India/Sahel rainfall and Atlantic hurricanes. Geophysical Research Letters 33: L17712. 


\section{SUMMARY AND CONCLUSIONS}

The Charlotte Harbor watershed, with its heterogeneous catchment basins, provided an excellent opportunity to investigate ecosystem response to disturbance on different scales. Diatom assemblages in the watershed have strong relationships with environmental gradients, and changes in their patterns of assembly reflect environmental changes in the watershed on multiple spatial and temporal scales. This research shows how diatom assemblages in the Charlotte Harbor watershed provide information about environmental changes from very large time-scales related to sea level rise throughout the Holocene to the smaller scale of a single tropical storm, and provides guidance regarding the spatial scale that is most appropriate for evaluating different scales of disturbance. Changes related to anthropogenic pressures are also made evident, and can help to inform management decisions that may help to mitigate future ecosystem disturbance.

In Chapter 2, I developed quantitative tools to evaluate environmental changes in the past using diatom assemblage composition. The strong relationships between diatom taxa and salinity, TP, and TN enable estimation of these parameters without directly measuring them, providing a method for paleoecological environmental reconstructions. Chapter 2 also demonstrates the importance of spatial scale when using such tools, as diatoms in the different sub-basins of the watershed relate differently to environmental variables, an issue that I explored further in Chapter 4. For example, TP is more strongly correlated with diatom assemblage composition in the Myakka River, where concentrations are relatively low, than in the Peace River, where assemblages may be regionally adapted to naturally high concentrations. Use of assemblages for 
environmental interpretation may be appropriate on various spatial scales, but it is important to consider when a sub-basin or regional approach might be best applicable for different research questions.

Estuarine ecosystems are highly dynamic on various temporal scales as well. In Chapter 3, I documented changes in diatom assemblage composition through the seasons and following a tropical storm that affected Charlotte Harbor in June 2012. Diatom assemblages were remarkably stable across the wet and dry seasons but showed reduced dispersion following the tropical storm, in spite of greater departure of environmental parameters from "normal" (wet/dry season) conditions. Response and recovery following the storm occurred on time scales that varied by site, but the pattern of assemblage convergence following the storm was consistent in all sub-basins. This research provided evidence that intense hydrological management may affect ecosystem resilience and response to disturbance, in that the greatest reduction in diatom assemblage dispersion occurred in the most pristine sub-basin in the watershed, the Myakka River basin, and the smallest reduction in dispersion occurred in the channelized and dammed Caloosahatchee River. It is important to understand how response regimes are affected by management so that we can make informed decisions that may help to mitigate negative impacts on the ecosystem.

Climatic controls have variable influence over relatively small spatial scales across Florida, requiring a high spatial resolution to interpret paleoecological patterns. In Chapter 4, I used the quantitative models developed in Chapter 2 to evaluate long-term hydrological changes during the Holocene in two southwest Florida estuaries, Charlotte Harbor, where the models were developed, and nearby Tampa Bay. Estimates of salinity 
and nutrient concentrations suggested that major changes in precipitation and runoff patterns occurred approximately 5.5 and 3 kyrs BP, which is consistent with other research from the region using additional paleoecological proxies. Patterns were similar in the two estuaries, but varied through time, suggesting that large-scale climate patterns across central and south Florida may have been dynamic through time. The variable timing and spatial patterning have important implications for model applicability on a regional scale, in that locally-derived models may be useful for broader spatial interpretation during some periods but that caution should be applied.

Large-scale climate cycles also influence the pace and pattern of tropical cyclone landfall in Florida. In Chapter 5, I evaluated evidence of major climate changes and past storm activity using the diatom assemblages from a highly temporally-resolved sediment core. Assemblages were significantly related to the three-year average index value of the Atlantic Multidecadal Oscillation (AMO), which is a large-scale cycle known to influence tropical cyclone activity and patterns. In the years since 1996, when the AMO has been in a warm phase, assemblages were also correlated with the three-year average index of the El Niño Southern Oscillation, another large-scale driver of tropical storm activity. I used the inference models developed in Chapter 2 and dispersion analysis to evaluate evidence of past storm activity, investigating the hypothesis that assemblages that suggest low salinity and high nutrient concentrations (conditions expected following a severe storm) would also reflect low dispersion, as was found following the 2012 storm discussed in Chapter 4. Assemblages that suggested low salinity and high TP also had the lowest dispersion and corresponded with some major storms in the known record. However, anthropogenic effects must be considered in concert with larger environmental 
drivers, as changes in the flow patterns and pace of sedimentation may cause environmental changes that mimic the effect of a severe storm.

This research provides a quantitative tool for evaluating past changes on the Florida coast, elucidates patterns of ecosystem resilience and recovery in a heterogeneous watershed, and provides evidence of major climate patterns over long time-scales as well as more recent climate cycle changes and storms. There have been significant and directional changes in diatom assemblages over the period of known climatological records and anthropogenic effects in Charlotte Harbor, as well as throughout the Holocene, that have occurred in response to different drivers. This analysis helps to clarify the role of those drivers and understand ecosystem responses on different spatial and temporal scales, and could prove particularly valuable as water management decisions are continually updated with the goals of improving ecosystem integrity and resilience. 
VITA

\section{EMILY RODEHEFFER NODINE}

Born, Schwerte, Germany

1992-1996

B.A., Humanities

New College of Florida

Sarasota, Florida

1999-2005

Education Specialist

Friends of the National Zoo

Washington, District of Columbia

2003-2005

M.S., Environmental Sciences and Policy

Johns Hopkins University

Baltimore, Maryland

2005-2009

Ecologist

Kevin Erwin Consulting Ecologist, Inc.

Fort Myers, Florida

2009-2014

Doctoral Candidate

Florida International University

Miami, Florida

\section{PUBLICATIONS AND PRESENTATIONS}

Nodine, E.R. and E.E. Gaiser. 2014. Distribution of diatoms along environmental gradients in the Charlotte Harbor, Florida (USA), estuary and its watershed: implications for bioassessment of salinity and nutrient concentrations. Estuaries and Coasts 37: 864-879.

Nodine, E. 2011. Eupodiscus radiatus. In Diatoms of the United States. http://westerndiatoms.colorado.edu/taxa/species/eupodiscus_radiatus.

Read, E.K., V. Patil, S.K. Oliver, A.L. Hetherington, J.A. Brentrup, J.A. Zwart, K.M. Winters, J.R. Corman, E.R. Nodine, R.I. Woolway, H.A. Dugan, A. Jaimes, A.B. Samtoso, G.S. Hong, L.A. Winslow, P.C. Hanson, and K.C. Weathers. The importance of lake-specific characteristics for water quality across the continental US (accepted by Ecological Applications, 2014). 
Nodine, E.R. Understanding climate through diatom community dynamics in Charlotte Harbor, Florida: a summary of my dissertation research. Oral presentation: Cary Institute Science Seminar/Global Lake Ecological Observatory Network Fellowship Workshop. 2014 January 23; Millbrook, NY.

Nodine, E.R., H. Cremer, E.E. Gaiser, and F. Wagner-Cremer. Mid- to late-Holocene environmental changes inferred from diatom assemblages in two southwest Florida estuaries. Oral presentation: South Florida Paleoecology Mini-Symposium. 2013 October 25; Miami, Florida.

Nodine, E.R. Proceedings and progress for the GLEON fellows from the Science of Team Science conference. Oral presentation: Global Lake Ecological Observatory Network Fellowship Workshop. 2013 August 19-23; Boulder Junction, Wisconsin.

Nodine, E.R. Non-metric multidimensional scaling with individually selected labels using R. Oral presentation: Global Lake Ecological Observatory Network Fellowship Workshop. 2013 January 14-18; Sunapee, New Hampshire.

Nodine, E.R. and E.E. Gaiser. Seasonal patterns in diatom assemblages and water quality across a coastal watershed: the changing effects of freshwater flow through seasons and following a tropical storm. Poster presentation: Global Lake Ecological Observatory Network $15^{\text {th }}$ All-Hands Meeting. 2013 November 4-8; Bahia Blanca, Argentina.

Corman, J., E. Nodine, V. Patil, R. Woolway, J. Zwart, H. Dugan, A. Jaimes, A. Santoso, L. Winslow, J. Brentrup, A. Hetherington, P. Hanson, G. Hong, S. Oliver, E. Read, K. Winters, and $\mathrm{K}$. Weathers. Comparison of gas flux in lakes and consequences for metabolism and $\mathrm{CO}_{2}$ emissions. Poster presentation: Global Lake Ecological Observatory Network $15^{\text {th }}$ All-Hands Meeting. 2013 November 4-8; Bahia Blanca, Argentina.

Nodine, E.R. and E.E. Gaiser. Diatom community assemblage changes following Tropical Storm Debby in a southwest Florida watershed: applications to understanding long-term tropical cyclone dynamics. Poster presentation: North American Diatom Symposium. 2013 August 13-17; Bar Harbor, Maine.

Nodine, E. and K. Winters; J. Brentrup, J. Corman, H. Dugan, P.C. Hanson, A. Hetherington, G. Hong, A. Jaimes, S. Oliver, V. Patil, E. Read, A. Santoso, K.C. Weathers, L. Winslow, R. Woolway, and J. Zwart. The Global Lake Ecological Observatory Network Graduate Student Fellowship Program: developing new strategies for globally-distributed collaboration. Poster presentation: Science of Team Science Conference. 2013 June 24-27; Evanston, Illinois. 